UNIVERSIDADE DE SÃO PAULO

FACULDADE DE ODONTOLOGIA DE BAURU

HAYANA RAMOS LIMA

Análise do envolvimento de células T reguladoras na hanseníase 



\section{Análise do envolvimento de células T reguladoras na hanseníase}

Tese apresentada à Faculdade de Odontologia de Bauru, Universidade de São Paulo, como pré-requisito para a obtenção do título de Doutor em Ciências Odontológicas Aplicadas, área de Estomatologia e Biologia Oral.

Orientadora: $\operatorname{Prof}^{a}{ }^{2}{ }^{a}$ Ana Paula Campanelli

Versão Corrigida 


\begin{tabular}{|l|}
\hline Lima, Hayana Ramos \\
$\begin{array}{c}\text { Análise do envolvimento de células T reguladoras na } \\
\text { hanseníase/ Hayana Ramos Lima. - Bauru, 2012. }\end{array}$ \\
117 p.; il.; $30 \mathrm{~cm}$ \\
Tese (Doutorado) - Faculdade de Odontologia de \\
Bauru. Universidade de São Paulo. \\
Orientadora: Prof ${ }^{a}$ Dr $^{a}$ Ana Paula Campanelli
\end{tabular}

Nota: a versão original desta tese encontra-se disponível no Serviço de Biblioteca da Faculdade de Odontologia de Bauru - FOB/USP

Autorizo, exclusivamente para fins acadêmicos e científicos, a reprodução parcial desta tese, por processos fotocopiadores e/ou meios eletrônicos.

Assinatura do autor:

Data:

Comitê de Ética em Pesquisa da FOB-USP:

Projeto de pesquisa aprovado em 29 de outubro de 2009

Número do protocolo: 148/2009 
Trabalho realizado no Laboratório de Microbiologia e Imunologia do Departamento de Ciências Biológicas da Faculdade de Odontologia de Bauru, Universidade de São Paulo.

Apoio: FAPESP (Processos 2009/10247-8 e 2010/18142-8). 

Dedico esta tese à minha família, por todo amor e incentivo que não cabem em palavras. 



\section{AGRADEGIMENTOS}

Minha sincera gratidão à Universidade de São Paulo e à Faculdade de Odontologia de Bauru, pela excelência no ensino e por me terem permitido fazer parte desta destacada instituição. Aos funcionários, alunos e professores que se empenham em fazê-la a melhor Universidade de nosso país.

Ao Instituto Lauro de Souza Lima pela colaboração sem a qual esta pesquisa não poderia ter sido realizada. Minha gratidão aos funcionários, técnicos, residentes em Dermatologia e demais estudantes pelo compromisso em trabalhar com excelência. Minha especial gratidão aos pacientes, participantes ou não desta pesquisa, pelas inestimáveis lições de vida compartilhadas.

À Fundação de Amparo à Pesquisa do Estado de São Paulo, FAPESP, pelo essencial suporte financeiro durante a execução desta pesquisa, através da concessão de minha bolsa de doutorado e de auxílio à pesquisa e, igualmente, à Fundação Paulista contra a Hanseníase pelo suporte financeiro.

À minha orientadora, $\operatorname{Prof}^{\mathrm{a}} \operatorname{Dr}^{\mathrm{a}}$ Ana Paula Campanelli, pela confiança, pelas oportunidades oferecidas, suporte e criteriosa orientação ao longo de meu mestrado e doutorado. Obrigada por seu cuidado, exemplo e por fazer parte desta etapa tão especial de minha vida.

Minha sincera gratidão à Dra. Maria Renata Salles por ter aberto as portas do Instituto Lauro de Souza Lima, pela amizade e constantes gentileza e solicitude. Às pesquisadoras Elaine Camarinha e Fabiana Corvolo pela dedicada colaboração e prestatividade. À Vânia Brito, Ida Foschiani, Ana Carla Pereira e Esther Salles pela cordialidade. Ao Dr. Jaison Antônio Barreto pela colaboração durante a seleção dos pacientes e coleta de amostras.

Aos Professores Gustavo Pompermaier Garlet, Sérgio Torres, Carlos Ferreira dos Santos, Denise Tostes de Oliveira, Lucimara Teixeira, Jesus Andreo, Gerson de Assis, Rumio Taga e Antônio Rodrigues pela constante gentileza e cordialidade.

Ao Dr. Bashir Gazi, pela colaboração e pelo entusiasmo com que sempre me auxiliou nesta pesquisa. 

Aos funcionários e colegas da disciplina de Microbiologia e Imunologia: André da Silva, Dalva Oliveira, Lívia Melo, Edilene Zapater, Carine Ervolino, Cláudia Pinheiro, Thaís Gasparoto, Tatiana Malaspina, Rodrigo Nalio, Eduardo Aleixo, Eduardo Belai, Valéria Gelani, Juliana Pires, Lucas Bermejo e Ronan Jacques. Sou grata por todos os momentos produtivos, pela agradável convivência diária e também pela disposição em servir e em compartilhar conhecimento.

Aos alunos de iniciação científica Marina Vicente, Jacqueline Aquino, Rayssa Fonseca, Aneli Abe, Thalita Dalboni, Luiza Freitas.

Aos técnicos do Departamento de Ciências Biológicas Ovídio dos Santos, Thiago Dionísio, Daniela Ceolin, Patrícia Germino e Tânia Cestari por serem sempre solicitos. A Márcia Graeff e Telma pela competência e excelência, além de serem exemplo de perseverança e determinação.

Ao Laboratório de Análises clínicas do Hospital de Anomalias crânio-faciais pelo suporte durante as coletas de sangue. A Ana Lúcia Perone Costa Cardoso, Sílvia Cristina Arantes e Narciso Almeida Vieira pela constante solicitude, gentileza e cordialidade.

Aos colegas de pós-graduação Carlos Repeke, Élcia Silveira, Marcela Claudino, Luciana Rezende, Gabriela Genaro, Andrea Espindola, Juliana Moraes, Luciana Mendonça, Polliana Scaffa, Nuria Branco, Daniel Brozoski, Max Dorea, Luana Mendonça, Luiz Neto, Marcela Calabria e Cristiane Baldini sempre espirituosos e gentis.

A Carla Sipert, pela amizade leve, senso de praticidade e pelos bons momentos compartilhados.

A Flávia Nahsan e Luciana Franciscone pela amizade sincera, companheirismo e conselhos que serão lembrados por toda a vida. Minha gratidão profunda por dividirem comigo suas famílias, amigos, conquistas e também as vicissitudes. A amizade de vocês é um tesouro e certamente faz com que eu seja uma pessoa melhor.

À família Marangon pela generosidade, amizade e cuidado que com que sou tratada por todos vocês. Obrigada por me receberem em sua casa com tamanha alegria.

À família Fávaro Franciscone pelas incontáveis vezes em que fui calorosamente recebida em sua casa. Pela amizade e carinho imutáveis que ajudaram a aliviar a saudade da família distante.

A Neuza Vieira por sua hospitalidade, pela convivência pacífica e por permitir que, por tanto tempo, sua casa fosse minha. Minha gratidão se estende a Débora Amgarten, Camila Quaglio, Simone Faustino, Isabela Caetano e Michele Cassis, amigas com quem dividi esta casa e com quem mantenho laços de amizade que a distância, o tempo e as circunstâncias da vida não afastam. Agradeço também a Marinês Vieira pelos bons dias em que vivemos e pelo companheirismo. 

Às família Cassis e Benjamin pelo cuidado, amizade, atenção e carinho que tenho em vocês. A Michelle Cassis Benjamin, minha amiga-irmã, minha gratidão pelos anos em que vivemos juntas, pela amizade e admiração mútua. Sou profundamente grata por você e Neto Benjamin fazerem parte de minha vida.

À Comunidade Batista Vida Nova, em Bauru. Às famílias Smallman, Blazer, Spoelhof, Andrade, Oliveira, Alvares, Ciola, Figueiredo, Vanini, Murback, Fukuura, Sanches e Zwicker, pela forma acolhedora com que fui recebida na vida de vocês.

A Valerie Smallman pela amizade verdadeira e desinteressada, por ser incansável em servir, ouvir e aconselhar com afeto e carinho. Obrigada por fazer parte de minha vida.

A Camila Porto, Fernanda Ribeiro, Izadora Balinha e Tatiana Novais pelos profundos laços de amizade e admiração que cultivamos.

A Manuel Junior, Elza Conceição e Bárbara Agate pela amizade e pelo coração acolhedor. Obrigada pelas inúmeras vezes em que pude desfrutar não apenas da hospitalidade de vocês, mas da amizade e carinho.

A minha família, pelo amor, incentivo e apoio que esvaziam o sentido destas palavras. A Yara e Itamara por serem não apenas minhas irmãs, mas principalmente amigas e companheiras. Eu as admiro e amo profundamente. Obrigada pelo constante incentivo que torna minhas escolhas leves. A meu cunhado Robério, obrigada por ser um irmão cuidadoso, amoroso e presente. A meus tios, avós e primos pelas orações, incentivo e apoio.

A minha mãe, uma mulher que empenhou seus melhores esforços para que, dentro de suas possibilidades, minhas irmãs e eu tivéssemos o melhor desta vida. Obrigada por sua fé, carinho e amor imutáveis. Agradeço a Deus a benção de ser sua filha.

Ao meu pai, obrigada por ser exemplo de dedicação, perseverança, generosidade e por sempre prover amor, afeto e alegria. Obrigada por acreditar e incentivar meus sonhos e por vibrar a cada conquista de minha vida. Agradeço por compartilhar seus valores, sabedoria e princípios.

A Deus, Senhor de meu coração, minha eterna gratidão por sua misericórdia e amor infinitos. Por me sustentar quando os problemas sufocaram a esperança, por me ensinar em meio a minhas limitações e erros e por me cercar de pessoas tão especiais e amáveis que enchem a vida de sentido e alegria. 

"Navegar é preciso. Viver não é preciso."

(Fernando Pessoa) 

Resumo 



\section{RESUMO}

A hanseníase é uma doença crônica causada por Mycobacterium leprae e apresenta diversas formas clínicas. O entendimento da interação parasita-hospedeiro na hanseníase evidenciou que ocorre a persistência assintomática do patógeno, caracterizando um estado de latência. Os fatores mais importantes relacionados com a permanência do patógeno são: a patogenicidade do agente infeccioso e o perfil da resposta imune, no qual os eventos de migração celular, produção de citocinas, as células efetoras e reguladoras são extremamente relevantes. As células $\mathrm{T}$ reguladoras (Treg) desempenham papel central na regulação da resposta imune em infecções crônicas o que favorece a persistência do patógeno. A importância de células $\mathrm{T}$ reguladores na hanseníase ainda é pouco conhecida. Neste trabalho investigou-se a presença de células T reguladoras em lesões e sangue periférico de indivíduos com hanseníase. Inicialmente avaliou-se a proliferação e a produção de citocinas por células mononucleares do sangue periférico (PBMC) de pacientes com hanseníase. Os resultados evidenciaram que não há diferenças quanto à proliferação de células $\mathrm{T}$ e produção de IFN- $\gamma \mathrm{e}$ TNF- $\alpha$ por células desses pacientes, mas a produção de IL-4 e IL-5 foi detectada apenas entre os pacientes com hanseníase virchoviana. Em relação à presença de células $\mathrm{T}$ reguladoras, os resultados evidenciaram aumento no número de linfócitos $\mathrm{T} \mathrm{CD} 4{ }^{+} \mathrm{CD} 25^{+} \mathrm{FoxP} 3^{+}$no sangue periférico de pacientes com hanseníase virchoviana. As células $\mathrm{T}$ reguladoras dos pacientes com hanseníase apresentaram elevada expressão de moléculas co-inibitórias PD-1, CTLA-4, GITR e ICOS. De modo relevante, as células $\mathrm{T} C D 4^{+} \mathrm{CD} 25^{+}$isolados de pacientes com hanseníase virchoviana apresentaram maior atividade supressora quando comparado às células isoladas de pacientes com hanseníase tuberculóide. As células $\mathrm{T} \mathrm{CD}^{+} \mathrm{CD} 25^{+}$de pacientes com hanseníase virchoviana inibiram a proliferação de PBMC alogênico e a produção de IFN- $\gamma$ e TNF- $\alpha$. Os resultados demonstraram também que nas amostras de lesão de pele de pacientes com hanseníase virchoviana há acúmulo de células $\mathrm{CD} 25^{+}$produtoras de IL-10 e TGF- $\beta$, enquanto que estas células não foram detectadas nas lesões de pacientes com hanseníase tuberculóide. Dessa forma, os resultados descritos indicam que pacientes com hanseníase virchoviana apresentam aumento no número de células T reguladoras circulantes e no infiltrado inflamatório, e estas células apresentaram maior atividade supressora. O acúmulo de células $\mathrm{T}$ reguladoras no sítio da infecção pode ser correlacionado com o controle da resposta imune e conseqüente persistência de $M$. leprae.

Palavras-chave: hanseníase, células $\mathrm{T}$ reguladoras, citocinas anti-inflamatórias, supressão imune. 

Abstract 



\begin{abstract}
Leprosy is caused by Mycobacterium leprae and its clinical features depend on the host immune background. The understanding of parasite-host interactions in leprosy have highlighted asymptomatic persistence of the pathogen, which indicates that this infection becomes latent. The most important factors related to the permanence of pathogens are: the pathogenicity of the infectious agents; the profile of the immune response developed by the host whose events of cellular migration, cytokines production, and the effector and regulatory cells are extremely relevant. The regulatory $\mathrm{T}$ cells (Treg) seem to play a central role in the regulation of the immune response in chronic infections, which favors the persistence of the pathogen. Herein, we analyzed the relation between tuberculoid and lepromatous leprosy with the presence and function of $\mathrm{T}$ regulatory cells from peripheral blood mononuclear cells (PBMC) and skin lesions from these patients. First, the proliferation and cytokine production of PBMC isolated from leprosy patients were analyzed. We did not observe any difference in the proliferation ability or IFN- $\gamma$ and TNF- $\alpha$ release; however, the production of IL- 4 and IL5 was detected only in patients with lepromatous leprosy. Furthermore, $\mathrm{T} \mathrm{CD} 4^{+} \mathrm{CD} 25^{+} \mathrm{FoxP} 3^{+}$ cells were detected in the PBMC of patients with leprosy and these cells from lepromatous patients showed high expression of co-inhibitory molecules such as PD-1, GITR, CTLA-4 and ICOS. $\mathrm{T}$ CD $4^{+} \mathrm{CD} 25^{+}$cells isolated from patients with lepromatous leprosy were significantly more suppressive than the cells obtained from tuberculoid patients. In addition, T $\mathrm{CD} 4^{+} \mathrm{CD} 25^{+}$cells isolated from patients with lepromatous leprosy inhibited allogeneic PBMC proliferation and their production of IFN- $\gamma$ and TNF- $\alpha$. The results also demonstrated that IL10 and TGF- $\beta$ were co-expressed with $\mathrm{CD} 25^{+}$cells at the inflammatory infiltrate of skin lesions from lepromatous patients, but similar results were not detected among tuberculoid patients. Thus, these results indicate that lepromatous leprosy patients have an enhanced presence of Treg cells with a suppressive ability in the blood and in the inflammatory infiltrate. The accumulation of Treg cells at the infection sites might be associated to the control of immune response and consequently to Mycobacterium leprae presistence.
\end{abstract}

Key-words: leprosy, T regulatory cells, immune suppression, anti-inflammatory cytokines 



\section{LISTA DE ABREVIATURAS E SÍMBOLOS}

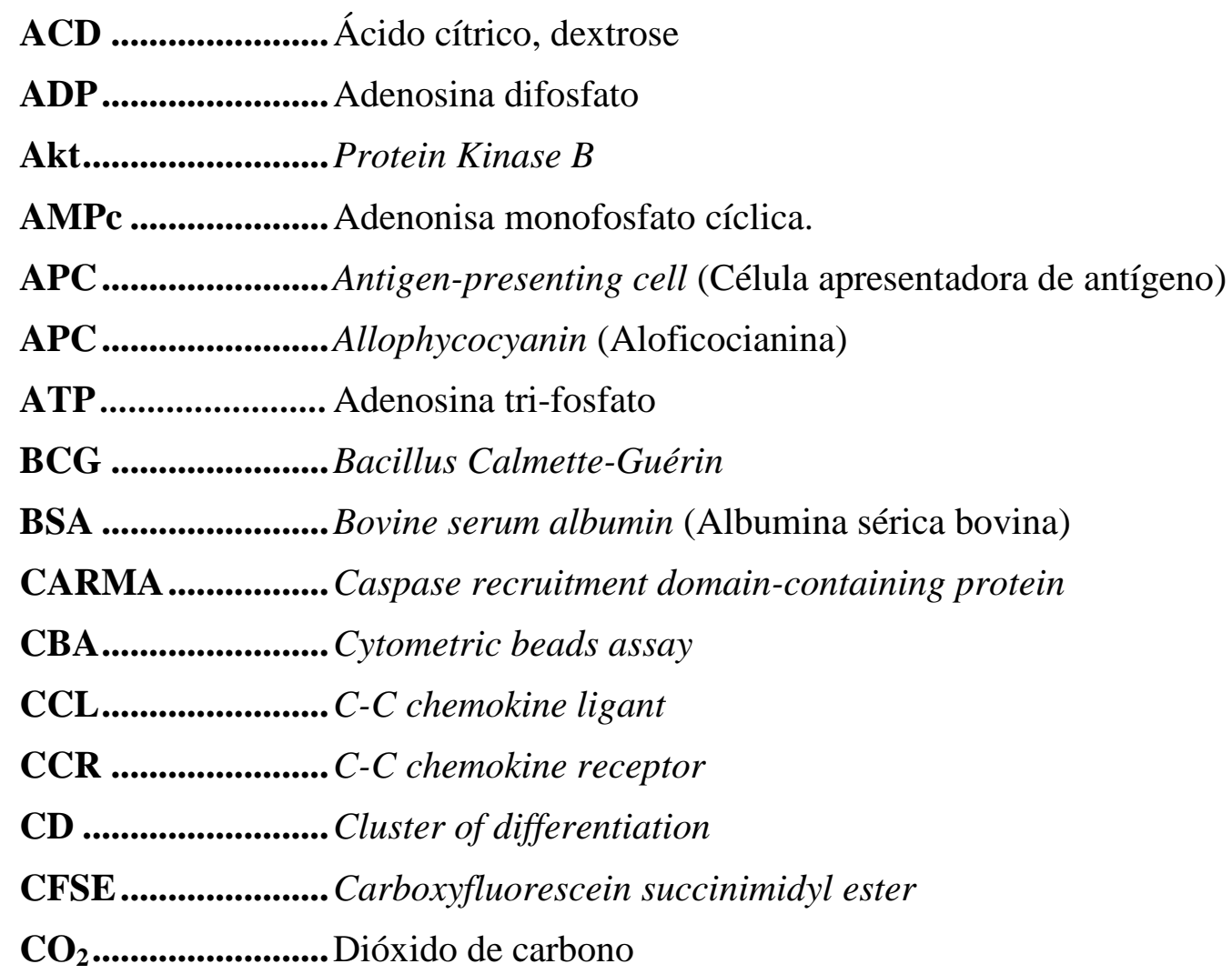

CREB ...................... cAMP response element-binding protein

CTLA-4................... Cytotoxic T-Lymphocyte Antigen 4

CXCR..................... C-X-C chemokine receptor

DAPI ......................4 4',6-diamidino-2-phenylindole

DC-SIGN ................ Dendritic Cell-Specific Intercellular adhesion molecule-3-Grabbing Non-integrin

DO ......................... Densidade óptica

DR .......................... Locus de HLA

DQ .........................Locus de HLA

Ebi3 ........................ Epstein-Barr virus induced gene 3

EDTA ....................... Ethylenediaminetetraacetic acid (Ácido etileno-dimano-tetra- acético)

ELISA ...................... Enzyme-linked immunosorbent assay (Ensaio imuno-enzimático)

Eos.......................... zinc-finger transcription factor of Ikaros family

EPM ........................Erro padrão médio

ERK ........................ Extracellular-signal-regulated kinases

EUA.......................... Estados Unidos da América 

FITC. Fluorescein isothiocyanate (Isotiocianato de fluoresceína)

FL ............................ Fluorescent light (Canal de fluorescência)

FoxP3 ....................... Forkhead box P3

FSC............................Forward scatter (Parâmetro de análise celular por tamanho)

g ........................... gravidade

g........................... grama

GATA.......................Trans-acting T-cell-specific transcription factor

GITR ....................... Glucocorticoid-induced TNFR-related protein

HEPES ....................4-(2-hydroxyethyl)-1-piperazineethanesulfonic acid

HLA ....................... Human leukocyte antigen

HSP ....................... Heat shock protein (Proteína do choque séptico)

H\&E ........................ Hematoxilina e Eosina

ICOS ....................... Inducible T-cell costimulator

IDO......................... Indoleamine 2,3-dioxigenase

IFN ......................... Interferon

Ig.............................. Imunoglobulina

IL ............................. Interleucina

INOS ...................... induced nitric oxide synthases (óxido nítrico sintase induzida)

iTreg......................... Linfócitos T reguladores induzidos

LAG-3 ..................... Lymphocyte-activation gene 3

LAM....................... Lipoarabinomanana

LAT ......................... Linker for activation of T cells (Adaptador para ativação de células T)

MB........................ Multibacilar

mg.......................... miligramas

MHC ........................ Major histocompability complex

MHT....................... Hanseníase tuberculóide

MHV ....................... Hanseníase virchoviana

min ........................... minutos

MIP .......................... Macrophage Inflammatory Proteins

mL ............................ mililitro

mM ......................... milimolar

mTOR .................... Mammalian target of rapamycin

N ..............................normal (medidade de normalidade)

NADH ..................... Nicotinamide adenine dinucleotide 

NFAT Nuclear factor of activated T-cells

NF- $\mathrm{KB}$ Nuclear factor kappa-light-chain-enhancer of activated B cells

nm. nanômetros

NO Óxido nítrico

NOD Nucleotide Oligomerization Domain receptors

nTreg. Linfócitos $\mathrm{T}$ reguladores naturais

PARKIN Protein encoded by the PARK2

PB Paucibacilar

PBMC Peripheral blood mononuclear cells (Células mononucleares de sangue periférico)

PBS Phosphate buffered saline (Solução salina tamponada em fosfato)

PD-1 Programmed cell death protein 1

PD-L1 Programmed cell death 1 ligand 1

PE phycoerythrin

PE-Cy7 Phycoerythrin-cyanine dye 7

pg. picograma

PGL-1 phenolic glycolipid 1

pH. potencial hidrogeniônico

PHA........................ Phytohaemagglutinin (Fitohematoglutinina)

ROR $\boldsymbol{\gamma} \mathbf{T}$.................... RAR-related orphan receptor gamma

RPMI-1640 ............. Meio de cultura celular

PQT ..........................Poliquimioterapia

SFB ........................ Soro fetal bovino

SNP......................... Single-nucleotide polymorphism

SMAD .................... Sma and Mad related protein

SSC ........................... Side scatter (Parâmetro de análise celular por granulosidade)

STAT ...................... Signal Transducer and Activator of Transcription

TAK ...................... Transforming growth factor- $\beta$ (TGF- $\beta$ )-activated kinase 1

TAP .........................Antigen peptide transporter

TARC..................... Thymus and Activation Regulated Chemokine

T-bet T-box transcription factor TBX21

TGF Transforming growth factor

Th Linfócito T auxiliar (helper)

TLR Toll like receptor 

TNF ......................... Tumor Necrosis Factor

TRAF .....................TNF receptor-associated factor

Tr1......................... Linfócitos T reguladores 1

Treg .........................Linfócitos T reguladores

TCR.......................T cell receptor (Receptor de células T)

ZAP70 .....................Zeta-chain-associated protein kinase 70

Hg............................. microgramas

$\boldsymbol{\mu} \mathbf{L}$............................ microlitros

$\boldsymbol{\mu M}$..........................micromolar 



\section{SUMÁRIO}

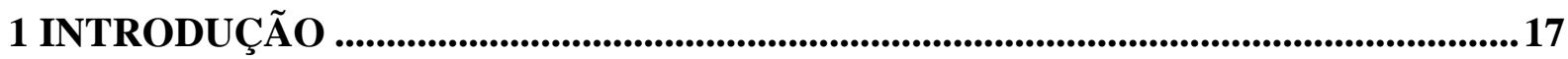

2 PROPOSIÇÃO ..............................................................................................................31

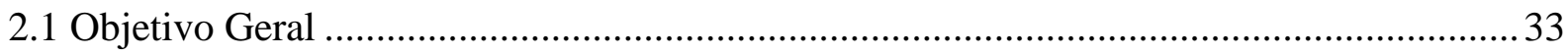

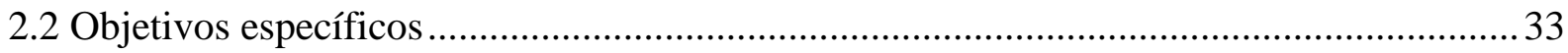

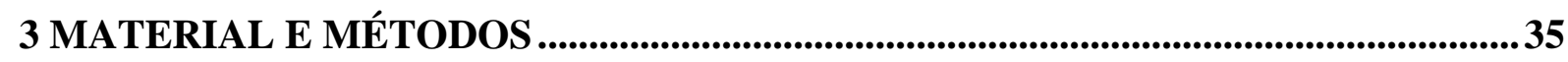

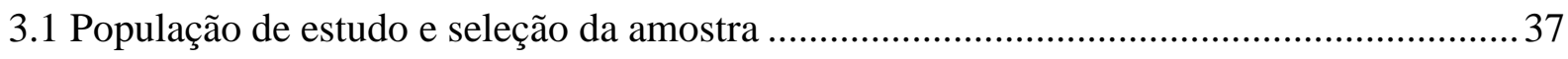

3.2 Coleta das amostras das lesões de pele............................................................................ 39

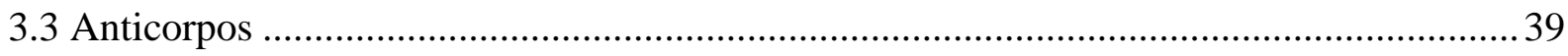

3.4 Análise do infiltrado celular por imunofluorescência .......................................................... 40

3.5 Obtenção de células mononucleares do sangue................................................................ 41

3.6 Citometria de fluxo para a análise de expressão de moléculas de

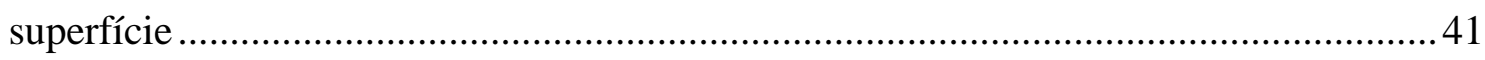

3.7 Separação das subpopulações de células T obtidas do PBMC .............................................42

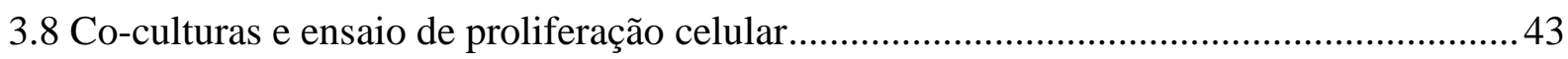

3.9 Avaliação do padrão de citocinas no sobrenadante das co-culturas por

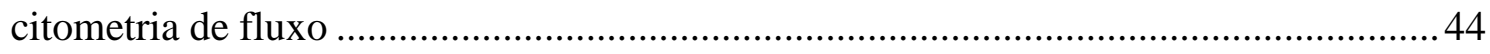

3.10 Ensaio imunoenzimático (ELISA) para dosagem de TGF- $\beta 1$............................................. 45

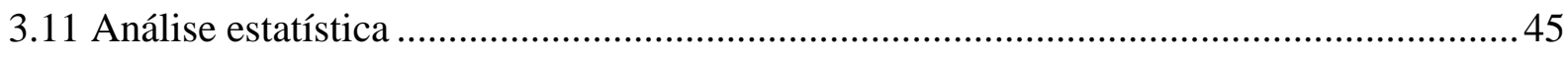

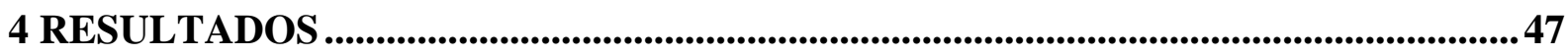

4.1 Análise histopatológica das amostras de pele de pacientes com

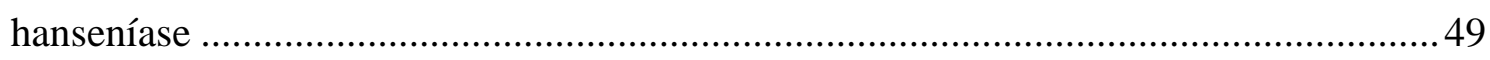

4.2 Caracterização das populações de leucócitos presentes no sangue de

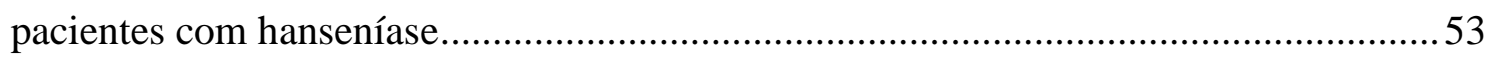

4.3 Análise da proliferação e produção de citocinas por células mononucleares do sangue periférico de pacientes com hanseníase 

4.4 Caracterização da população de linfócito $\mathrm{T} \mathrm{CD} 4^{+} \mathrm{CD} 25^{+}$presente no sangue de pacientes com hanseníase

4.5 Análise da atividade supressora de células $\mathrm{T} \mathrm{CD} 4{ }^{+} \mathrm{CD} 25^{+}$isoladas de pacientes com hanseníase...... 65

4.6 Detecção de células T reguladoras em lesão de paciente com hanseníase. 75

5 DISCUSSÃO 79

6 CONCLUSÃO 



\section{Introdução}





\section{INTRODUÇÃO}

A hanseníase é ainda um problema de saúde pública no Brasil (ALBERTS et al., 2011; WHO, 2012). A incidência da hanseníase é mundial e o Brasil apresenta o maior número de casos das Américas (WHO, 2012). Embora a doença seja endêmica em regiões da África, Ásia e Oceania, regiões cujos índices de desenvolvimento são baixos (HOTEZ; AKSOY, 2011), há um crescente número de novos casos na Europa e América do norte devido, especialmente, às ondas migratórias (MONOT et al., 2005; WALKER; LOCKWOOD, 2006; WHITE, 2011; WOROBEC, 2009). No Brasil, as regiões Norte e Centro-Oeste são hiperendêmicas e o registro de novos casos, ainda que decrescente, mantém-se elevado em todas as regiões (MINISTÉRIO DA SAÚDE, 2002; RODRIGUES; LOCKWOOD, 2011).

A hanseníase é uma doença tratável, mas o seu controle é um desafio à saúde pública (LOCKWOOD, 2005). Embora a prevalência da doença esteja reduzindo, principalmente pela administração dos antibióticos e pela vacinação com BCG (SCOLLARD et al., 2006), a hanseníase ainda será um problema de saúde por muito tempo, devido ao elevado número de casos negligenciados (RODRIGUES; LOCKWOOD, 2011). Ademais, o tratamento das seqüelas causadas pela doença demanda recursos humanos e materiais que, geralmente, são de difícil execução (WALKER; LOCKWOOD, 2006; WOROBEC, 2009). A dificuldade de diagnóstico inicial, tratamento insuficiente, recidivas e reinfecção são fatores relacionados à manutenção da cadeia de transmissão da doença (LOCKWOOD, 2005; RODRIGUES; LOCKWOOD, 2011).

A hanseníase é uma doença infecciosa, de evolução crônica que acomete predominantemente os nervos periféricos e, secundariamente, pele e mucosas (SCOLLARD et al., 2006; WALKER; LOCKWOOD, 2006). Seu agente etiológico é Mycobacterium leprae (M. leprae), um bacilo álcool-ácido resistente, que possui tropismo por fibras nervosas periféricas levando a diversas incapacidades (HETT; RUBIN, 2008; SCOLLARD et al., 2006). M. leprae é um bacilo intracelular obrigatório que infecta, preferencialmente, macrófagos e células de Schwann (RAMBUKKANA, 2001).

A transmissão de $M$. leprae ocorre pelas vias aéreas superiores, principalmente por contato prolongado e repetido com pacientes bacilíferos (RODRIGUES; LOCKWOOD, 
2011; SUZUKI et al., 2012; WALKER; LOCKWOOD, 2006). A maioria dos indivíduos infectados por $M$. leprae não desenvolve a doença, o que evidencia a dependência de fatores genéticos e imunológicos como determinantes de susceptibilidade e resistência (ALTER et al., 2011; PINHEIRO et al., 2011; SCOLLARD et al., 2006). A primeira manifestação clínica observada nos pacientes é a dormência, a qual pode ocorrer anos antes do aparecimento de outros sinais clínicos. Esse sinal neurológico se deve ao tropismo de M. leprae às fibras nervosas periféricas. Curiosamente, algumas formas da doença são assintomáticas, mesmo em pacientes crônicos (SCOLLARD et al., 2006). No sistema nervoso periférico, as células de Schwann expressam laminina-2, molécula que se liga a antígenos de $M$. leprae, o que permite a infecção dessas células (RAMBUKKANA, 2001). M. leprae também pode infectar macrófagos, os quais reconhecem o bacilo através de receptores do tipo Toll e de lecitina, como DC-SIGN, facilitando a fagocitose deste microrganismo (BARREIRO et al., 2006; KRUTZIK et al., 2003; SCOLLARD et al., 2006). No interior da célula, o bacilo mantém-se viável por interferir na fusão do fagossomo ao lisossomo, através do aumento da viscosidade das membranas dessas organelas ou por evadir-se do fagolisossomo mantendo-se no citosol (TANIGAWA et al., 2009; VAN DER WEL et al., 2007). Além disto, o bacilo também infecta células musculares e do endotélio vascular (FITNESS; TOSH; HILL, 2002; GELUK; OTTENHOFF, 2006; WALKER, S.L.; LOCKWOOD, 2006). O intervalo entre a infecção e as manifestações clínicas varia entre 2 a 12 anos (RODRIGUES; LOCKWOOD, 2011) e pode acometer todas as faixas etárias, embora seja rara entre crianças (WOROBEC, 2009).

Outras formas de infecção por $M$. leprae, principalmente ambientais, têm sido cogitadas, como inalação de solo contaminado, picadas de mosquitos e também a transmissão por tatus, animais que são reservatório natural do bacilo (LAVANIA et al., 2008; RODRIGUES; LOCKWOOD, 2011; TURANKAR et al., 2012). Contudo, estas formas de transmissão são controversas uma vez que não há estudos controlados que comprovem esses dados (SCOLLARD et al., 2006).

M. leprae é uma bactéria de crescimento lento e realiza divisão binária em um intervalo de 12 a 14 dias (COLE et al., 2001), além disto, mesmo não sendo capaz de formar esporos, o bacilo mantém-se em um estado metabólico estável por semanas (COLE et al., 2001; SCOLLARD et al., 2006). M. leprae também compartilha com outras micobactérias características como parede celular formada por lipídios na forma de ácido micólico e lipoarabinomanana (LAM) (HETT; RUBIN, 2008). Apresenta também glicolipídios, com 
destaque para o glicolípidio fenólico (PGL-1), antígeno de $M$. leprae essencial para a interação com a laminina-2 presente nas células de Schwann (RAMBUKKANA, 2001; SCOLLARD et al., 2006). A ausência de genes para o metabolismo de lipídeos e proteínas, comuns a outras espécies de micobactérias, pode explicar a razão pela qual $M$. leprae é uma bactéria intracelular obrigatória. Além disto, M. leprae não possui proteínas relacionadas ao transporte de elétrons, importantes para a síntese de ATP a partir da oxidação de NADH (SCOLLARD et al., 2006), mas apresenta outras vias metabólicas funcionais relacionadas à síntese de purinas, piramidinas, ácidos nucléicos_e vitaminas (COLE et al., 2001).

A análise do genoma de M. leprae, quando comparado a Mycobacterium tuberculosis, revela redução de seu conteúdo genético e elevado número de pseudogenes (COLE et al., 2001; MONOT et al., 2005). Diversos genes, comuns ao gênero das micobatérias, cuja função primordial está relacionada ao metabolismo e transporte de substâncias, estão ausentes em Mycobacterium leprae. O genoma de diferentes cepas de M. leprae é bastante conservado quando comparado a outras bactérias como, por exemplo, Mycobacterium tuberculosis $e$ Helicobacter pilori, uma vez que apresenta baixa frequência de polimorfismos de nucleotídeos únicos (SNPs) (MONOT et al., 2005). Recentemente, uma nova espécie de micobactéria, Mycobacterium lepromatosis, foi identificada e relacionada com casos de hanseníase lepromatosa disseminada e grave em indivíduos do México e Caribe (HAN et al., 2009).

Como mencionado anteriormente, a maioria da população é resistente à infecção por M. leprae e a exposição ao bacilo, nestes indivíduos, leva à sua eliminação (GELUK; OTTENHOFF, 2006). Para aqueles susceptíveis à infecção, a doença se manifesta de modo heterogêneo, o que sugere que os fatores genéticos e imunológicos determinam o padrão de resposta imune do indivíduo contra o bacilo e o curso da doença (GELUK; OTTENHOFF, 2006; MISCH et al., 2010; PRADO MONTES DE OCA, 2011). A classificação da hanseníase com base nos critérios clínicos e histopatológicos foi proposta por Ridley e Jopling e é amplamente aceita até o presente (RIDLEY; JOPLING, 1966). De acordo com esta classificação, a hanseníase apresenta cinco diferentes formas de manifestações clínicas, além da forma indeterminada. A hanseníase tuberculóide caracteriza a forma clínica de contenção da multiplicação bacilar, os indivíduos são, geralmente, resistentes à doença ou podem evoluir para a cura espontânea. As lesões cutâneas são em pequeno número, hipopigmentadas, bem delimitadas e com poucos bacilos. (WOROBEC, 2009). 
Contrariamente, a forma mais grave da doença, a hanseníase lepromatosa ou virchoviana, caracteriza-se por elevado número de lesões cutâneas placóides, maculares ou nodulares (hansenomas), mal delimitadas e que apresentam infiltrado inflamatório difuso e intenso com a presença de macrófagos, linfócitos e muitos bacilos. A maioria dos pacientes, entretanto, apresenta as formas intermediárias entre os pólos de maior resistência e susceptibilidade da doença, que variam de acordo com as manifestações clínicas e histológicas entre dimorfotuberculóide, dimorfo-dimorfo e diformo-lepromatoso (SCOLLARD et al., 2006). As lesões cutâneas que apresentam infiltrado inflamatório perineural sem a presença de sinais clínicos característicos das demais formas da doença categorizadas por Ridley e Jopling são classificadas como indeterminadas e, provavelmente, referem-se a lesões em seus estágios iniciais.

Na forma virchoviana, ao ser avaliada a resposta imune a $M$. leprae, observa-se a presença de intenso infiltrado nas lesões, além de elevada produção de citocinas como IL-4, IL-10 e TGF- $\beta$, as quais induzem o desenvolvimento de resposta imune predominantemente humoral (MODLIN, 1994; SIELING; MODLIN, 1994). Contudo, a elevada produção de anticorpos, principalmente anti-PGL-I, não é capaz de promover a ativação de mecanismos efetores que levem à eliminação dos bacilos, os quais persistem viáveis no interior dos macrófagos. Contrariamente, nos pacientes com a forma tuberculóide observa-se a presença de um infiltrado inflamatório contendo linfócitos $\mathrm{T} \mathrm{CD}^{+}$produtores de TNF- $\alpha$ e IFN- $\gamma$, citocinas que participam da ativação de macrófagos. Uma vez ativados, estes fagócitos controlam a evolução da doença através da eliminação dos bacilos de $M$. leprae e da apresentação de seus antígenos a linfócitos infiltrados nas lesões (MISCH et al., 2010). A maioria dos pacientes apresenta as formas clínicas intermediárias da hanseníase, cuja resposta imune é instável, tornando-os propensos ao desenvolvimento de reações semelhantes às observadas durante a síndrome de reconstituição do sistema imune (Tipo I) ou às de hipersensibilidade mediada por imunocomplexos (eritema nodoso hansênico) (SCOLLARD et al., 2006).

A resposta imune do hospedeiro é, portanto, crucial para o curso e desenvolvimento da hanseníase. Há evidências que sugerem uma relevante influência genética sobre a função de células da imunidade inata e adaptativa, cujo controle altera a resistência e susceptibilidade à infecção por M. leprae (ALTER et al., 2008; SCOLLARD et al., 2006; WOROBEC, 2009). Estudos de polimorfismos e de associação genética em populações brasileira, indiana e 
vietnamita indicam que mutações em genes responsáveis pela expressão de moléculas de receptores de reconhecimento padrão TLR2, TLR4 e NOD2, bem como de proteínas envolvidas na degradação protéica via proteassomo (PARKIN e TAP1), além de mediadores inflamatórios como TNF- $\alpha$ e INOS estão associados à maior susceptibilidade à hanseníase (ALTER et al., 2008; FITNESS; TOSH; HILL, 2002; SCOLLARD et al., 2006; WALKER; LOCKWOOD, 2006). A caracterização do HLA de indivíduos com hanseníase também demonstra haver uma relação entre a presença de alguns alelos nos loci DQ e DR com as formas graves da doença (ALTER et al., 2008; FITNESS; TOSH; HILL, 2002).

Os primeiros eventos relacionados à resposta imune contra $M$. leprae são desenvolvidos no tecido epitelial, que é composto por diferentes células da imunidade capazes de sintetizar diversos mediadores inflamatórios (KUPPER; FUHLBRIGGE, 2004; NESTLE et al., 2009). As células dendríticas são uma das primeiras células a reconhecerem M. leprae, principalmente através de receptores de reconhecimento padrão, como receptores de lectina tipo $\mathrm{C}$ (que reconhece padrões de carboidratos como liporabinomanana da parede celular das bactérias), receptores do tipo Toll (especialmente TLR2 e TLR4, que reconhecem lipoproteínas) e NOD2 (que reconhece peptideoglicanas da parede celular), os quais modulam a produção de citocinas e a expressão de moléculas de MHC de classe II e co-estimulatórias (GRINGHUIS et al., 2007; JO, 2008; KRUTZIK et al., 2003; WALKER, S.L.; LOCKWOOD, 2006). As células dendríticas quando ativadas produzem citocinas como IL$1 \beta$, IL-12 e TNF- $\alpha$ que são importantes para a modulação da resposta imune adaptativa em Th1 e Th2 (SHORTMAN; NAIK, 2007). Contudo, indivíduos com a forma lepromatosa da hanseníase apresentam um número reduzido de células de Langerhans, um tipo de célula dendrítica que iniciam a resposta imune na derme, quando comparado a indivíduos com a forma tuberculóide ou saudáveis (MIRANDA et al., 2007; SIELING et al., 1999). Além disto, M. leprae, diferentemente de outras micobactérias, interfere na maturação das células dendríticas (MAKINO et al., 2006; MURRAY et al., 2007; TABOURET et al., 2010), alterando a produção de citocinas pró-inflamatórias, reduzindo a atividade de $\mathrm{NF}-\kappa \mathrm{B}$ e a expressão de moléculas co-estimulatórias, como CD80, CD83, CD86 e CD40 (LEE, D.J. et al., 2007; MURRAY et al., 2007; TABOURET et al., 2010; WALKER, S.L.; LOCKWOOD, 2006).

Além das células dendríticas, os macrófagos presentes na derme desempenham importante papel na patogênese da hanseníase uma vez que participam da eliminação do 
bacilo e na apresentação de antígenos a linfócitos T CD4 ${ }^{+}$e CD8 ${ }^{+}$(MODLIN, 2010; OCHOA et al., 2008) e também contribuem para a formação do granuloma, estrutura importante para a contenção da disseminação do bacilo (RAMAKRISHNAN, 2012). A produção de espécies reativas de nitrogênio e oxigênio por macrófagos é estimulada, principalmente, pela sinalização via IFN- $\gamma$ e promove a eliminação do bacilo (MONTOYA et al., 2009) e este mecanismo efetor encontra-se preservado nos indivíduos com a forma tuberculóide da hanseníase. Os macrófagos de pacientes com a forma lepromatosa, no entanto, apresentam alterações em seu metabolismo e redução em sua capacidade de eliminar M. leprae, o que permite que a doença persista (KRUTZIK et al., 2003; MATTOS et al., 2010; OCHOA et al., 2008). A grande concentração de bacilos viáveis no citoplasma de macrófagos modula a ativação destas células, aumentando a produção de citocinas anti-inflamatórias, como IL-10, e reduzindo a expressão de moléculas co-estimulatórias (MONTOYA et al., 2009; SINSIMER et al., 2010; TABOURET et al., 2010).

A apresentação de antígenos de $M$. leprae a linfócitos $\mathrm{T}$ reduz a sinalização via TCR/CD28 bem como a fosforilação de ZAP70 e ERK1/2 (CHATTREE; KHANNA; RAO, 2007; DAGUR et al., 2010; KUMAR et al., 2011b; SRIDEVI et al., 2004). A expressão de moléculas de ativação, como CD25 e CD69, também é modulada pelos antígenos do bacilo, limitando a proliferação e a produção de IL-2 por células T (DAGUR et al., 2010). Os linfócitos de indivíduos com a forma lepromatosa da doença não proliferam em níveis semelhantes aos de indivíduos saudáveis ou com a forma tuberculóide, mesmo quando estimulados com IL-2 (BLOOM; MODLIN; SALGAME, 1992; KAPLAN et al., 1985; MUTIS et al., 1993; REA, 1983). As razões para este declínio na resposta contra M. leprae incluem a ausência de clones de linfócitos $\mathrm{T}$ capazes de reconhecer os antígenos do bacilo, a ativação de fatores supressores ou a presença de células com atividade supressora (BACH; LAUNOIS, 1988; KAPLAN et al., 1985). Em pacientes com hanseníase é também possível observar a presença de moléculas co-inibitórias, como CTLA-4, bem como de citocinas antiinflamatórias como IL-10 e TGF- $\beta$ (KANG et al., 2004; SRIDEVI et al., 2004). Além disto, recentemente, foi identificada uma população de células com fenótipo regulador no infiltrado inflamatório de pacientes com hanseníase (MASSONE et al., 2010), as quais poderiam estar relacionadas com o controle da resposta imune nestes indivíduos.

As células T reguladoras são cruciais na modulação negativa dos mecanismos efetores do sistema imune, principalmente no controle de doença autoimune em órgãos periféricos. 
Em algumas doenças infecciosas estes mecanismos imunoregulatórios podem ser induzidos a participar do controle de uma intensa reposta imune eventualmente gerada durante a infecção, e assim limitar o dano tecidual excessivo que porventura tenha sido causado (BELKAID, 2007). Contudo, alguns microrganismos evadem-se da eliminação promovida pela resposta imune através da modulação de mecanismos de regulação da resposta imune (BELKAID, 2007; VIGNALI; COLLISON; WORKMAN, 2008) e em algumas doenças infecciosas crônicas, como a leishmaniose, malária, hepatite e filariose, a presença de células $\mathrm{T}$ reguladoras está associada à persistência da infecção (BERRETTA et al., 2011; CAMPANELLI et al., 2006; MOORMAN et al., 2012; TAYLOR et al., 2009).

Os linfócitos T reguladores (Tregs) são uma população de células heterogênea cuja função primordial é manter a tolerância periférica através da modulação da resposta imune contra antígenos próprios e pelo controle de doenças autoimunes, além de limitar uma resposta imune exacerbada contra patógenos ou alérgenos, podendo também vir a facilitar que alguns tumores escapem à vigilância imunológica (FEUERER et al., 2009; VIGNALI; COLLISON; WORKMAN, 2008; WING; SAKAGUCHI, 2010). As Tregs apresentam atividade supressora sobre diversos tipos celulares, como linfócitos efetores ou de memória, macrófagos, células dendríticas, neutrófilos e mastócitos (AZUMA et al., 2003; SHEVACH, 2009; TANG; BLUESTONE, 2008).

As células reguladoras são na maioria linfócitos $\mathrm{T} \mathrm{CD}^{+}$e podem ser classificadas como células $\mathrm{T}$ reguladores naturais (nTregs), induzidas (iTregs) e ainda Tregs produtoras de IL-10 (Th3) ou TGF- $\beta$ (Tr1) (JONULEIT; SCHMITT, 2003). Especula-se que os diferentes tipos de iTregs relacionem-se a estágios funcionais distintos desta população de células modulados pelo microambiente inflamatório, e não necessariamente a linhagens de células distintas (JONULEIT; SCHMITT, 2003). Embora todos os tipos de células reguladoras apresentem atividade supressora, a importância hierárquica de cada um destes linfócitos não é conhecida e a diferença primordial entre eles refere-se não apenas aos tecidos onde ocorre a diferenciação destas células, mas também a seus fenótipos e aos mecanismos utilizados para promover a supressão da resposta imune (CUROTTO DE LAFAILLE; LAFAILLE, 2009; HARIBHAI et al., 2011).

As Tregs induzidas diferenciam-se a partir de linfóticos $\mathrm{T} \mathrm{CD}^{+}$nä̈ve após a exposição a sinais derivados de células tolerogênicas, drogas imunossupressoras, microbiota residente e pelo reconhecimento de antígenos expressos por células apresentadoras de 
antígenos na periferia na ausência de co-estímulos e citocinas pró-inflamatórias (BELKAID, 2007). iTregs desenvolvem-se em órgãos linfóides secundários, no tecido epitelial, no estroma tumoral, em tecidos cronicamente inflamados e enxertos (BILATE; LAFAILLE, 2012; CUROTTO DE LAFAILLE; LAFAILLE, 2009). Para a diferenciação de linfócitos T naïve em iTregs é necessário a sinalização via TCR, TGF- $\beta$, IL-10 e sinais co-inibitórios por CTLA-4 e PD-1 (BILATE; LAFAILLE, 2012; FRANCISCO et al., 2009; LIANG et al., 2005) os quais participam da expressão de FoxP3 pela ativação de STAT3 e NFAT (JOSEFOWICZ; RUDENSKY, 2009).

As nTregs são o subtipo de células $\mathrm{T}$ reguladoras que ocorrem naturalmente e desenvolvem-se na medula do timo, durante os eventos de seleção negativa a partir da diferenciação de clones de linfócitos $\mathrm{T} \mathrm{CD}^{+}$auto-reativos (CARPENTER; BOSSELUT, 2010; FEUERER et al., 2009; SHEVACH, 2002; VON BOEHMER; MELCHERS, 2010). Estes eventos requerem uma forte interação entre TCR e MHC das células epiteliais tímicas, sob co-estimulação da molécula de CD28 e sinalização via IL-2, IL-15 e TGF- $\beta$ (FEUERER et al., 2009; SHEVACH, 2009; VON BOEHMER; MELCHERS, 2010) o que, provavelmente, confere às nTregs maior resistência à deleção clonal (FEUERER et al., 2009). Dados recentes apontam que a sinalização intracelular via STAT5, CARMA 1 e TAK1 está envolvida com a diferenciação de células T reguladoras naturais (GUCKEL et al., 2011; LEE et al., 2010). O fenótipo das nTregs, em microambiente inflamatório ou não, é mais estável que o das iTregs (RUBTSOV et al., 2010) as quais estão mais sujeitas a mudanças epigenéticas, induzidas por citocinas pró-inflamatórias, como IL-1, IL-6 e IL-12, ou pelo contato com as células dendríticas, podendo vir a apresentar uma plasticidade em seu fenótipo e deixar de exercer suas funções supressoras (CAMPBELL; KOCH, 2011; MIYAO et al., 2012).

A ativação de Tregs é dependente da sinalização via TCR (FEUERER et al., 2009; SHEVACH, 2002; WALKER et al., 2003), através do reconhecimento de antígenos próprios ou de microrganismos apresentados por células dendríticas (BELKAID, 2007; YAMAZAKI et al., 2006) e uma vez que tenha sido ativada, a supressão das células alvo é antígeno independente (TANG; BLUESTONE, 2008). A baixa concentração de antígenos e a forte sinalização via TCR também estão associadas ao aumento do número de iTregs (GOTTSCHALK; CORSE; ALLISON, 2010). Esta ativação das Tregs também induz sua proliferação e manutenção do número desta população de células (BELKAID, 2007) e as 
células dendríticas parecem exercer importante papel indução da diferenciação de iTregs a partir de linfócitos T CD4 ${ }^{+}$FoxP3- (BILATE; LAFAILLE, 2012; FRANCISCO et al., 2009; GROUX; FOURNIER; COTTREZ, 2004; HARADA et al., 2010; YAMAZAKI et al., 2006).

As Tregs naturais e induzidas expressam diversos marcadores de superfície, como CD25, CD44, CD45RO, CD69, GITR, CD103, CD62L, CD73, CD39 além de moléculas coinibitórias, como ICOS, CTLA-4 e PD-1, galectinas, receptor de folato 4 e receptores de citocinas (BELKAID, 2007; FEUERER et al., 2009; YAMAGUCHI et al., 2007). Após sua diferenciação no timo, as nTregs são $\mathrm{CD} 25^{\mathrm{hi}} \mathrm{CD} 62 \mathrm{~L}^{+} \mathrm{CCR} 7^{+} \mathrm{e}$, ao migrarem dos órgãos linfóides secundários para a periferia, adquirem um fenótipo com marcadores comuns aos linfócitos de memória e ativados (CAMPBELL; KOCH, 2011).

A molécula de CD25 (cadeia alfa do receptor de IL-2) foi o marcador inicialmente empregado para caracterizar a célula T reguladora e a sinalização via este receptor de IL-2 é essencial para a geração de células $\mathrm{T}$ reguladoras no timo e na periferia (CAMPBELL; KOCH, 2011; FONTENOT et al., 2005; FONTENOT; RUDENSKY, 2004). A expressão desta molécula é regulada positivamente quando o linfócito é ativado, o que permite um aumento no consumo da IL-2 (TANG; BLUESTONE, 2008). Este consumo de IL-2 reduz a concentração desta citocina no microambiente inflamatório e, dessa forma, limita a proliferação de outros tipos de linfócitos (TANG; BLUESTONE, 2008). Dessa forma, a supressão promovida pelas Tregs pode também decorrer pela privação de IL-2 para a célula efetora.

Além disto, as células efetoras são reguladas negativamente pelo aumento na concentração de adenosina monofosfato cíclica (AMPc) no microambiente inflamatório (DEAGLIO et al., 2007; DWYER et al., 2007; GRADER-BECK et al., 2003). O AMP cíclico é produto da clivagem de ATP e ADP, sob a ação das ecotoenzimas CD39 e CD73 e o reconhecimento desta molécula pelas células efetoras reduz o seu metabolismo (HASKO et al., 2008). As células $\mathrm{T}$ reguladoras, além de expressarem estas ecotoenzimas quando ativadas, são também capazes de transferir AMPc após contato com as células $\mathrm{T}$ efetoras através de canais celulares chamados calnexinas (DEAGLIO et al., 2007; SHEVACH, 2009; VIGNALI; COLLISON; WORKMAN, 2008) .

O controle genético de diversas das funções das células T reguladoras é realizado pelo fator de transcrição FoxP3 (VIGNALI; COLLISON; WORKMAN, 2008). Análises do 
genoma de indivíduos acometidos por doença auto-imune severa (IPEX) bem como em camundongos da linhagem "scurfin", que espontaneamente apresentam doenças autoimunes, determinaram uma relação entre mutações no gene FoxP3 e a freqüência destas doenças (BRUNKOW et al., 2001; WILDIN et al., 2001). Posteriormente, a expressão de FoxP3 foi demonstrada em linfócitos $\mathrm{T} C D 4^{+} \mathrm{CD} 25^{+}$e a transfecção do gene de FoxP3 para células efetoras induziu em tais células uma atividade supressora (HORI; NOMURA; SAKAGUCHI, 2003).

A expressão de FoxP3 é induzida em linfócitos pela sinalização via TCR e TGF- $\beta$ (RELLAND et al., 2009). A região promotora deste fator de transcrição possui sítios de ligação para moléculas de SMAD3, STAT 5 e CREB, bem como para NFAT (LAL; BROMBERG, 2009; MARSON et al., 2007). FoxP3 controla a expressão de outros fatores de transcrição nuclear como T-bet, GATA-3 e ROR- $\gamma \mathrm{T}$ e, dessa forma, controla a plasticidade dos linfócitos TCD4 ${ }^{+}$(CAMPBELL; KOCH, 2011; LU; RUDENSKY, 2009; MARSON et al., 2007). Em algumas populações de iTreg, FoxP3 pode estar associado a outros fatores de transcrição, como Eos (PAN et al., 2009), Helios e Icaros os quais reforçam à manutenção do fenótipo supressor nestas células (HARIBHAI et al., 2011).

Tregs expressam receptores de quimiocinas, como CCR4, CCR5, CCR8 e CXCR4, que lhes permitem migrar para tecidos inflamados, em resposta a um gradiente de quimiocinas como CCL1, CCL5, MIP-1, TARC (CAMPBELL; KOCH, 2011) A molécula de CD103, integrina que se liga a E-caderina, permite que estas células possam ser retidas nos tecidos periféricos, durante a inflamação (BELKAID, 2007; FEUERER et al., 2009; TANG; BLUESTONE, 2008).

As células $\mathrm{T}$ reguladoras naturais requerem o contato com a célula alvo para exercerem sua função supressora. A expressão de moléculas de granzimas A e B e perfurina induzem a apoptose da célula-alvo por mecanismos semelhantes aos das células $\mathrm{T}$ citotóxicas (SHEVACH, 2009; VIGNALI; COLLISON; WORKMAN, 2008). Entretanto, não há evidencias de que células dendríticas e linfócitos $\mathrm{B}$ sejam alvo de citólise por células $\mathrm{T}$ reguladoras (SHEVACH, 2009). A célula T reguladora pode também levar a um estado de anergia da célula-alvo, pela parada do ciclo celular, através da sinalização via galectinas 1 e 9 , glicoproteinas solúveis ou aderidas à membrana, que se ligam a CD45, CD43 e CD7 (SHEVACH, 2009; TANG; BLUESTONE, 2008). 
Outro mecanismo relevante da Treg no controle da resposta imune ocorre através da redução da maturação da célula dendrítica com consequiente prejuízo na ativação de células $\mathrm{T}$ efetoras (BELKAID, 2007; SHEVACH, 2009). A molécula de LAG-3, homóloga a CD4, expressa pelas Tregs, é capaz de promover a endocitose das moléculas de MHC de Classe II quando em contato com células dendríticas (SHEVACH, 2009; VIGNALI; COLLISON; WORKMAN, 2008). Semelhantemente, a ligação entre CTLA-4 expresso pela Treg e CD80/CD86, das células dendríticas, também reduz a expressão dessas moléculas coestimulatórias (ODERUP et al., 2006; QURESHI, O.S. et al., 2011; SHEVACH, 2009). A sinalização via CTLA-4/CD80-CD86 também está associada a aumento na expressão de IDO (indolamina 2,3-deoxigenase), enzima cuja atividade aumenta a produção de um metabólito citotóxico, a quinurenina, a partir de triptofano (BELKAID, 2007; MELLOR; MUNN, 2004; TANG; BLUESTONE, 2008; VIGNALI; COLLISON; WORKMAN, 2008). IDO também regula a expressão do fator de transcrição Foxo3, que controla o metabolismo da célula dendrítica e reduz a síntese de citocinas pró-inflamatórias, como a IL-6 (HARADA et al., 2010; SHEVACH, 2009).

As células dendríticas são também importantes na manutenção da população de células $\mathrm{T}$ reguladoras e a ausência destas células apresentadoras de antígeno determina a redução no número deste tipo de linfócitos (DARRASSE-JEZE et al., 2009; MORELLI; THOMSON, 2007). As células dendríticas intestinais $\mathrm{CD}_{103}{ }^{+}$desempenham importante papel na indução de células reguladoras, principalmente através da sinalização via ácido retinóico e vitamina D (CAMPBELL; KOCH, 2011). Além disto, a sinalização via PD-L1/PD-L2 pelas células dendríticas, potencializada pela presença de TGF- $\beta$, também é capaz de induzir um fenótipo regulador em linfócitos nä̈ve, além de reduzir a mensagem via Akt-mTOR, irrelevante para a diferenciação de Tregs (FRANCISCO; SAGE; SHARPE, 2010; FRANCISCO et al., 2009). A sinalização via IDO/CTLA-4 também parece estar envolvida com a diferenciação de células $\mathrm{T}$ reguladoras nos tecidos periféricos (PUCCETTI; GROHMANN, 2007).

As Tregs produzem citocinas anti-inflamatórias, como IL-10, TGF- $\beta$ e IL-35. TGF- $\beta$ é uma citocina de ação pleotrópica sobre diversas células da imunidade inata e adaptativa e sua sinalização interfere na plasticidade dos subtipos de linfócitos e indução de iTregs, principalmente nas mucosas (BELKAID, 2007; TANG; BLUESTONE, 2008; VIGNALI; COLLISON; WORKMAN, 2008). Em modelo de colite experimental, a transferência de 
células TCD45RB ${ }^{\text {low }}$ (Treg) reverte a inflamação e o bloqueio de TGF- $\beta$ levou a um aumento da população de linfócitos efetores e manutenção do quadro inflamatório (TAKAHASHI et al., 1998). A expressão de LAT (TGF- $\beta$ em sua forma latente) nas células T reguladoras aumenta a capacidade de supressão pelo contato com as células-alvo (SHEVACH, 2009; VIGNALI; COLLISON; WORKMAN, 2008). LAT está envolvido nos mecanismos de tolerância infecciosa, em que o "pool" de células reguladoras é aumentado a partir de linfócitos T CD4 ${ }^{+}$FoxP3- (SHEVACH, 2009; TANG; BLUESTONE, 2008).

IL-10 é uma citocina com atividade anti-inflamatória. A síntese desta citocina pode ser realizada por diversas células, como as dendríticas, macrófagos, linfócitos B e "natural killers” (BELKAID, 2007). A produção de IL-10 por Tregs atua no controle de doença inflamatória intestinal e é também detectada em diversos tipos de câncer (VIGNALI; COLLISON; WORKMAN, 2008). Diversos patógenos, como Bordetella pertussis, L. major, S. Mansonni, T. gondii induzem a produção de IL-10 pelas células dendríticas e, dessa forma, induzem a conversão de células T CD4 ${ }^{+}$em iTregs (BELKAID, 2007).

Recentemente, uma citocina heterodimérica da família das IL-12 foi descoberta, a IL35, cuja síntese é realizada por células T reguladoras. IL-35 é formada pelas subunidades p35 (comum à IL-27) e Ebi3 (produto do gene induzido por Epstein-Barr), e a expressão desta última proteína é regulada por FoxP3 (SHEVACH, 2009). Células T reguladoras de animais “knockouts" para Ebi3 apresentaram redução em sua capacidade supressora em modelos de doença intestinal inflamatória (COLLISON; MURPHY; JOLLY, 2008). A importância hierárquica de cada um dos mecanismos de supressão das Tregs ainda não é conhecida, e provavelmente apenas alguns deles sejam cruciais para as funções regulatórias desta célula. Possivelmente, o microambiente de atuação dessas células e seus alvos determinam quais serão as formas de supressão a serem ativadas. (VIGNALI; COLLISON; WORKMAN, 2008).

$\mathrm{Na}$ hanseníase, os pacientes com a forma mais grave da doença apresentam marcante produção das citocinas anti-inflamatórias IL-10 e TGF- $\beta$. Recentemente foi descrito um acúmulo de células reguladoras em lesões de pacientes com a forma virchoviana da doença e a presença de linfócitos T CD4 ${ }^{+} \mathrm{FoxP} 3^{+}$(MASSONE et al., 2010), no entanto, o papel destas células no desenvolvimento e progressão da doença não são compreendidos mas a sua presença pode ser um dos fatores relacionados à persistência do bacilo. 
Proposição 



\section{PROPOSIÇÃO}

\subsection{Objetivo Geral:}

Avaliar a presença e função de células T reguladoras em lesões e sangue periférico de indivíduos com hanseníase tuberculóide e virchoviana.

\subsection{Objetivos específicos:}

1. Caracterizar o fenótipo das células $\mathrm{T}$ reguladoras presentes no sangue periférico de pacientes com hanseníase.

2. Isolar células $\mathrm{T}$ reguladores $\mathrm{CD} 4^{+} \mathrm{CD} 25^{+}$do sangue periférico e avaliá-las quanto à atividade supressora.

3. Investigar a presença de citocinas IL-10 e TGF- $\beta$ no infiltrado inflamatório das amostras de lesão de pele. 

Material e Métodos 



\section{MATERIAL E MÉTODOS}

\subsection{População de estudo e seleção da amostra}

A população de estudo foi constituída por pacientes diagnosticados com hanseníase tuberculóide $(\mathrm{n}=10)$ ou hanseníase virchoviana $(\mathrm{n}=10)$. Estes indivíduos foram selecionados no Ambulatório de Dermatologia do Instituto Lauro de Souza Lima. Todos os voluntários que concordaram em participar deste estudo assinaram o termo de consentimento livre e esclarecido após a leitura da carta de informação ao paciente.

Os indivíduos foram submetidos à anamnese e exame clínico, e quando necessário, foram realizados os exames histopatológicos das lesões cutâneas e exames complementares de baciloscopia, dosagem de anticorpos anti-PGL-1 e teste de Mitsuda. Foram excluídos os pacientes que apresentaram episódios reacionais por um período menor que três meses antes da coleta das amostras. Os indivíduos foram categorizados, segundo a classificação de Ridley e Jopling (RIDLEY; JOPLING, 1966), em dois grupos experimentais que compreendem os pacientes com hanseníase tuberculóide ou dimorfa tuberculóide (MHT) e hanseníase virchoviana ou dimorfa virchoviana (MHV) de acordo com as características clínicas e histopatológicas (Tabela 1).

A análise dos pacientes com hanseníase revelou um maior comprometimento de pacientes do sexo masculino (50\% para a forma tuberculóide e $80 \%$ para a forma virchoviana), conforme descrito na Tabela 1. A idade mínima apresentada na época do diagnóstico e coleta dos espécimes foi de 29 anos nos pacientes com hanseníase tuberculóide e a máxima de 65 anos. A idade mínima entre os pacientes com hanseníase virchoviana foi de 30 anos e a máxima de 73 anos. Nas amostras estudadas, a baciloscopia foi positiva em $60 \%$ dos pacientes com MHV e 10\% dos pacientes com MHT.

Em relação ao tratamento, $60 \%$ dos pacientes com MHT e 30\% dos pacientes MHV nunca haviam sido submetidos à poliquimioterapia (PQT). Os pacientes com a forma tuberculóide foram tratados preferencialmente com esquema paucibacilar (PB) ou ainda não haviam iniciado tratamento poliquimioterápico, enquanto a maioria daqueles com a forma virchoviana foram tratados com esquema multibacilar (MB). 
As amostras de lesão e sangue foram obtidos após consentimento, de acordo com protocolo aprovado pelo Comitê de Ética da Faculdade de Odontologia de Bauru e Comissão Científica do Instituto Lauro de Souza Lima, e encaminhadas para o Laboratório de Imunologia e Microbiologia da FOB-USP. Um fragmento da biópsia foi retirado e dividido em duas partes: uma para a confirmação do diagnóstico clínico por análise histopatológica e para os ensaios de imunofluorescência.

O sangue de 10 indivíduos saudáveis (média de idade de 33,7 \pm 8,4) foi coletado como controle dos ensaios de fenotipagem e proliferação. Além disto, amostras de pele foram obtidas de seis indivíduos saudáveis (que foram submetidos à cirurgias plásticas; média de idade de 52,48 $\pm 6,27$ ) para serem utilizadas como controle dos experimentos de imunofluorescência.

Tabela 1 - Seleção de pacientes diagnosticados com Hanseníase

\begin{tabular}{llcc}
\hline \multicolumn{1}{c}{ Características dos Pacientes } & MHT & MHV \\
Idade & Média & $(\mathrm{n}=10)$ & $(\mathrm{n}=10)$ \\
& Mínima & 53,5 & 52,3 \\
& Máxima & 29 & 30 \\
Gênero & Masculino & 65 & 73 \\
\hline \multirow{2}{*}{ Baciloscopia } & Feminino & $5(50 \%)$ & $8(80 \%)$ \\
& Positiva & $5(50 \%)$ & $2(20 \%)$ \\
\hline PGL-1 & Negativa & $1(10 \%)$ & $6(60 \%)$ \\
& Não realizado & $9(90 \%)$ & $3(30 \%)$ \\
& Reagente & - & $1(10 \%)$ \\
\hline \multirow{2}{*}{ Teste de Mitsuda } & Não reagente & $2(20 \%)$ & $6(60 \%)$ \\
& Não realizado & $6(60 \%)$ & $2(20 \%)$ \\
& $>5$ mm & $2(20 \%)$ & $2(20 \%)$ \\
\hline \multirow{2}{*}{ Esquema terapêutico } & $<5$ mm & $10(100 \%)$ & - \\
& Negativa & - & $7(70 \%)$ \\
\hline & Não realizado & - & $2(20 \%)$ \\
& PQT/PB & - & $1(10 \%)$ \\
\hline
\end{tabular}

(*) valor <3+; (\#) valor maior que >4+; (c) valores de absorbância maiores que 0,15 


\subsection{Coleta das amostras das lesões de pele}

Os pacientes foram submetidos ao exame clínico, e as biópsias, incisionais ou punchs, foram praticadas quando necessário, obedecendo aos princípios clássicos de rotina. Do fragmento colhido, uma pequena parte foi destinada à pesquisa e, a maior parte, ao diagnóstico histopatológico para que o paciente fosse imediatamente submetido ao plano de tratamento necessário. As peças coletadas foram armazenadas em meio de cultura e, em seguida, encaminhadas para o laboratório de Microbiologia e Imunologia da FOB-USP. No laboratório, este material foi criopreservado para a realização das reações de imunofluorescência.

\subsection{Anticorpos}

Foram utilizados anticorpos monoclonais purificados ou conjugados à ficoeritrina (PE), isotiocianato de fluoresceína (FITC), ficoeritrina/cianina 7 (PE-Cy7) ou aloficocianina (APC) para os ensaios de fenotipagem por citometria de fluxo e imunofluorescência (Tabela 2). Os anticorpos purificados foram conjugados a anticorpos secundários conjugados aos fluorocromos Alexa Flúor 488 ou Alexa Flúor 596 (Invitrogen, EUA). 
Tabela 2 - Anticorpos utilizados nos ensaios de Fenotipagem e Imunofluorescência

\begin{tabular}{|c|c|c|c|}
\hline Molécula-alvo & Fluorocromo & Clone & Fabricante \\
\hline CD3 & FITC & UCHT1 & \\
\hline CD4 & FITC/ APC/ Purificado & RPA-T4 & \\
\hline CD8 & $\mathrm{PE}$ & RPA-T8 & \\
\hline CD14 & FITC & M5E2 & \\
\hline CD19 & $\mathrm{PE}$ & HIB19 & \\
\hline $\mathrm{CD} 25$ & PE-Cy7/Purificado & M-A251 & \\
\hline $\mathrm{CD} 28$ & $\mathrm{PE}$ & CD28.2 & \\
\hline CD45RO & $\mathrm{PE}$ & UCHL1 & \\
\hline CD62L & $\mathrm{PE}$ & DREG-56 & \\
\hline CD69 & $\mathrm{PE}$ & FN-50 & \\
\hline CD103 & $\mathrm{PE}$ & Ber-ACT8 & BD Bioscience \\
\hline CCR4 & $\mathrm{PE}$ & $1 \mathrm{G} 1$ & \\
\hline CCR5 & $\mathrm{PE}$ & 2D7 & \\
\hline CTLA-4 & $\mathrm{PE}$ & $\mathrm{BNI} 3$ & \\
\hline ICOS & PE & DX29 & \\
\hline IL-10 & PE/Purificado & JES3 - 19F1 & \\
\hline PD-1 & $\mathrm{PE}$ & MIH4 & \\
\hline PD-L1 & PE & MIHI & \\
\hline PD-L2 & $\mathrm{PE}$ & MIH18 & \\
\hline CD1a & $\mathrm{PE}$ & HI149 & \\
\hline FoxP3 & Alexa Fluor 488/Purificado & BD 236A/E7 & \\
\hline TGF- $\beta 1$ & Purificado & TW4-9E7 & \\
\hline FoxP3 & $\mathrm{APC} / \mathrm{PE}$ & PCH101 & eBioscience \\
\hline GITR & $\mathrm{PE}$ & 110416 & R\&D Systems \\
\hline
\end{tabular}

\subsection{Análise do infiltrado celular por imunofluorescência}

Os tecidos coletados foram embebidos em tissue-tek, congelados e armazenados em nitrogênio líquido até o momento do uso. Foram feitos cortes de $5 \mu \mathrm{m}$ os quais foram préfixados por 1 minuto em acetona e armazenados a $-20^{\circ} \mathrm{C}$ até o momento em que foram realizadas as reações de imunofluorêscencia. Para tanto, os cortes foram fixados por 10 minutos em acetona a $-20^{\circ} \mathrm{C}$, lavados por 10 vezes em PBS por 3 minutos (cada lavagem) e, posteriormente, os sítios inespecíficos bloqueados com RPMI 1640 suplementado com 20\% 
de soro de coelho e $5 \%$ de albumina sérica bovina, por 1 hora à temperatura ambiente. Em seguida, adicionou-se o anticorpo primário: anti-IL-10, anti-TGF- $\beta 1$, anti-CD4, anti-CD25 e anti-FoxP3, os quais haviam sido diluídos em PBS saponina $(0,001 \%)$ na concentração de 1:100 e um volume de $50 \mu \mathrm{L}$ foi dispensado sobre cada corte histológico. A reação foi incubada por 18 horas a $4^{\circ} \mathrm{C}$ e, após este procedimento, os cortes foram lavados dez vezes em PBS. Em seguida, foram adicionados os anticorpos secundários conjugados aos fluorocromos (FITC, PE, Alexa-Flúor 488 ou Alexa-Flúor 596) diluídos 1:500 em PBS. Após a incubação de $2 \mathrm{~h}$, os cortes foram novamente lavados, por dez vezes em PBS e as lâminas montadas com meio de montagem contendo DAPI (VectaSchield, Vector Laboratories, EUA) e armazenadas a $-20^{\circ} \mathrm{C}$ até que as imagens fossem adquiridas em microscópio Confocal TCSSPE (Leica Microsystems, Alemanha).

\subsection{Obtenção de células mononucleares do sangue}

O sangue periférico de indivíduos saudáveis e portadores de hanseníase foi obtido por punção venosa e $20 \mathrm{~mL}$ coletados em tubos à vácuo estéreis contendo ACD (BD Bioscience, EUA). Após a coleta, o sangue foi diluído em igual volume de meio RPMI 1640 e esta mistura dispensada sobre gradiente Ficoll-Paque (GE, Alemanha) e centrifugada a 460g por 30 minutos, em temperatura ambiente. A interface composta por células mononucleares do sangue periférico (PBMC) foi coletada e lavada duas vezes em meio RPMI 1640. Após este procedimento, o precipitado foi suspenso em $1 \mathrm{~mL}$ de meio RPMI 1640 contendo $10 \%$ de soro fetal bovino (SFB) e os leucócitos contados com o auxílio da câmara de Neubauer. A viabilidade foi determinada pela exclusão de coloração com azul de Trypan a $2 \%$.

\subsection{Citometria de fluxo para a análise de expressão de moléculas de superfície}

A análise da expressão de marcadores de superfície no intuito de caracterizar a população de células $\mathrm{T}, \mathrm{B}$, monócitos/macrófagos, células dendríticas, bem como a caracterização fenotípica das subpopulações de células $\mathrm{T} \mathrm{CD}^{+} \mathrm{CD} 25^{+}$e $\mathrm{CD} 4^{+} \mathrm{CD} 25^{-}$, foi realizada em células mononucleares do sangue periférico. As células ( $1 \times 10^{6}$ células por tubo) foram lavadas e incubadas com RPMI 1640 suplementado com 20\% de soro de coelho e 5\% de albumina sérica bovina para bloqueio de ligações inespecíficas por 60 minutos a $4^{\circ} \mathrm{C}$. Em 
seguida, os anticorpos específicos $(1,5 \mu \mathrm{g})$ foram incubados por 1 hora a $4^{\circ} \mathrm{C}$. Adicionalmente, anticorpos não relacionados, de mesmo isotipo, conjugados a FITC, PE, PECy7 ou APC (todos obtidos da BD Pharmingen, San Diego, CA) foram utilizados. Após incubação com os anticorpos, as amostras foram lavadas duas vezes com PBS acrescido de BSA $1 \%$, sendo centrifugadas a $250 g$ por 10 minutos.

Para a detecção de FoxP3, os leucócitos isolados foram ressuspensos em 100 $\mu 1$ de PBS e, primeiramente, marcados com anticorpos anti-moléculas de superfície, CD25 e CD4, conjugados a PE, PE-Cy7 e FITC, respectivamente, de acordo com o protocolo descrito acima. Após a incubação com os anticorpos, as células foram lavadas sucessivamente e permeabilizadas por 20 minutos em uma solução de permeabilização/fixação (Cytofix/Cytoperm, BD Bioscience, EUA) de acordo com as instruções do fabricante. As células permeabilizadas foram lavadas com uma solução "Perm/Wash" (BD Bioscience, EUA) e, então incubadas com anticorpo específico anti-hFoxP3 conjugado a APC na diluição 5:100 por 30 minutos à temperatura ambiente, sendo posteriormente lavadas com a solução de "Perm/Wash" e, em seguida, analisadas por citometria de fluxo.

As amostras foram adquiridas em FACS Callibur ${ }^{\mathrm{TM}}$ (BD Immunocytometry Systems, Franklin Lakes, NJ) utilizando-se os canais de fluorescência 1 (FL1) para CD4, 2 (FL2) para as moléculas de interesse, 3 (FL3) para CD25 e 4 (FL4) para FoxP3. As análises foram realizadas usando o programa CELLQuest ${ }^{\mathrm{TM}}$ (BD Immunocytometry Systems, Franklin Lakes, NJ) os quais permitem analisar todas as células adquiridas (20.000 por amostra) ou apenas determinadas populações, individualizadas por janelas (ou "gates") selecionadas de acordo com os parâmetros de tamanho (FSC) e granularidade ou fluorescência (FL).

\subsection{Separação das subpopulações de células T obtidas do PBMC}

Após o isolamento das células mononucleares do sangue periférico de pacientes com hanseníase e indivíduos saudáveis, as células foram lavadas em PBS gelado acrescido de $0,5 \%$ de BSA e $3 \mathrm{mM}$ de EDTA e as subpopulações de células T $\mathrm{CD}^{+} \mathrm{CD} 25^{+}$e $\mathrm{T}$ $\mathrm{CD} 4^{+} \mathrm{CD} 25^{-}$separadas utilizando um kit comercial proveniente da Miltenyi Biotec (Auburn, CA). Resumidamente, as células foram primeiramente marcadas com um "cocktail" de anticorpos monoclonais biotinilados contra tais moléculas humanas: CD8, CD14, CD16, CD19, CD36, CD56, CD123, TCR $\gamma \delta$ e Glycoforina A (expresso em hemácias humanas) e, 
subsequentemente a suspensão celular foi incubada com "micro-beads" cobertas com biotina. Após 15 minutos de incubação, as células foram lavadas, $300 \mathrm{~g}$ por 10 minutos a $4-8^{\circ} \mathrm{C}$ e a população $\mathrm{CD}^{-}$foi separada magneticamente por $\mathrm{MACS}^{\circledR}$-“sorting” através da seleção negativa em colunas adequadas ao número de células.

Em uma segunda etapa, as células $\mathrm{T}_{\mathrm{CD}}{ }^{+}$previamente selecionadas foram diretamente marcadas com "micro-beads" cobertas com anticorpos anti-CD25 e então obtida as subpopulações de interesse. As células $\mathrm{T} \mathrm{CD} 4^{+} \mathrm{CD} 25^{+}$foram selecionadas positivamente através da separação com colunas MACS ${ }^{\circledR}$ adequadas ao número de células.

\subsection{Co-culturas e ensaio de proliferação celular}

Culturas de células $\mathrm{T} \mathrm{CD} 4^{+} \mathrm{CD} 25^{+}$e $\mathrm{T} \mathrm{CD} 4^{+} \mathrm{CD} 25^{-}$isoladas de $\mathrm{PBMC}$ de pacientes na presença de PBMC alogênico foram realizadas no intuito de verificar a propriedade reguladora/supressora de tais células sobre a proliferação não específica de células $T$ convencionais. Para tal, PBMC alogênico foi incubado com $5 \mu \mathrm{M}$ de CFSE (diacetato/succinimidil éster de carboxifluoresceína, Invitrogen Life Tecnology, EUA) em meio RPMI 1640 por 5 minutos a $37^{\circ} \mathrm{C}$ e, em seguida, lavados $\left(250 \mathrm{~g}\right.$ a $4^{\circ} \mathrm{C}$ por 10 minutos). As culturas foram efetuadas em placa de fundo em U de 96 poços, numa concentração de $1 \times 10^{6}$ por $\mathrm{mL}\left(1 \times 10^{5}\right.$ células/poço) de PBMC alogeneico em RPMI 1640 suplementado com SFB 10\%, $100 \mathrm{U} / \mathrm{mL}$ de penicilina (Invitrogen Life Tecnology, EUA), $100 \mu \mathrm{g} / \mathrm{mL}$ de estreptomicina (Invitrogen Life Tecnology, EUA), 2 mM de L-glutamina (Invitrogen Life Tecnology, EUA), 10 mM de HEPES (Invitrogen Life Tecnology, EUA), 0.1 mM de aminoácido não essenciais (Invitrogen Life Tecnology, EUA), $1 \mathrm{mM}$ de piruvato de sódio (Invitrogen Life Tecnology, EUA) e 5mM de 2-Mercaptoetanol (Sigma Aldrich, EUA). As células foram estimuladas com PHA $(1 \mu \mathrm{g} / \mathrm{mL})$ na presença ou não de células T $\mathrm{CD} 4^{+} \mathrm{CD} 25^{+}$

e $\mathrm{T} \mathrm{CD}^{+} \mathrm{CD} 25^{-}$em número previamente padronizado de $1 \times 10^{5} / \mathrm{ml}$ ( $1 \times 10^{4}$ células/poço), resultando em uma proporção 1:10. Após um período de 142h em incubadora umidificada a $37^{\circ} \mathrm{C}$, contendo $5 \% \mathrm{CO}_{2}$, as células foram coletadas, lavadas duas vezes com PBS e ressuspensas em $300 \mu \mathrm{L}$ de RPMI 1640. Em seguida, as células foram imediatamente adquiridas em FACS Callibur ${ }^{\mathrm{TM}}$ (BD Immunocytometry Systems, Franklin Lakes, NJ) utilizando o canal de fluorescência 1 (FL1) para CFSE. As análises foram feitas usando programas Cell Quest (Becton and Dickson) e Win Midi (Joseph Trotter) os quais permitem 
analisar todas as células adquiridas (100.000/amostra), ou apenas determinadas populações, individualizadas por janelas ("gates") estabelecidas com base em parâmetros de tamanho (FSC), granulosidade (SSC) ou fluorescência (FL). Adicionalmente, a percentagem de inibição foi calculada e determinado o índice de estimulação através da razão entre as percentagens de proliferação, na presença ou não de células T $\mathrm{CD} 4^{+} \mathrm{CD} 25^{+}$ou T $\mathrm{CD} 4^{+} \mathrm{CD} 25^{-}$, pela proliferação basal (CAVASSANI et al., 2006).

\subsection{Avaliação do padrão de citocinas no sobrenadante das co-culturas por citometria de} fluxo

A produção de citocinas presentes no sobrenadante das co-culturas de células $\mathrm{T}$ $\mathrm{CD} 4^{+} \mathrm{CD} 25^{+}$isoladas de pacientes e PBMC alogênico foi avaliada utilizando-se o kit CBA para citocinas humanas Th1/Th2 (BD ${ }^{\mathrm{TM}}$ Cytometric Bead Array) de acordo com as instruções indicadas pelo fabricante. O princípio desta técnica baseia-se em uma mistura de esferas de poliestileno, de intensidades de fluorescência distintas, recobertas com anticorpos específicos para citocinas humanas detectadas no canal FL3. A utilização de uma mistura de esferas permite a avaliação simultânea de diversas citocinas de interesse no mesmo ensaio, empregando pequenos volumes de amostra.

O aparelho foi ajustado utilizando o BD FACSComp Software e o BD Calibrate Beads. Esse ajuste permite definir os parâmetros de tamanho e granulosidade adequados para o posicionamento das esferas de captura em gráficos de tamanho versus granulosidade. Após a seleção das esferas, procedeu-se o ajuste da intensidade de fluorescência para permitir a segregação das esferas policromáticas, apresentando diferentes intensidades de fluorescência em histogramas unidimensionais. Para cada tubo foram adquiridos 1800 eventos dentro da região selecionada R1 (300 eventos por citocina testada). Após a aquisição das amostras, a concentração de cada citocina presente nas amostras foi determinada através de um programa exclusivo (FCAP Array Software, Soft Flow Hungary). 


\subsection{Ensaio imunoenzimático (ELISA) para dosagem de TGF- $\beta 1$}

A presença da citocina TGF- $\beta 1$ foi determinada no sobrenadante das culturas por ELISA (Opteia, BD Bioscience, EUA). Para tanto, placas de 96 poços foram recobertas e incubadas durante $18 \mathrm{~h}$ em temperatura ambiente, com anticorpos anti-TGF- $\beta 1$ diluídos em Coating Buffer. Após o tempo de incubação, as placas foram lavadas com PBS, contendo Tween 20 0,05\% e bloqueadas durante $2 \mathrm{~h}$, em temperatura ambiente, com Assay diluent (BD Bioscience, EUA). As placas foram lavadas com PBS Tween e incubadas com quantidades conhecidas de TGF- $\beta 1$ recombinante durante $18 \mathrm{~h} \mathrm{a} 4^{\circ} \mathrm{C}$ e as amostras. Após este período, as placas foram novamente lavadas e incubadas com anticorpo biotinilado anti-TGF- $\beta 1$ e estreptavidina diluídas em Assay diluent por $2 \mathrm{~h}$ em temperatura ambiente. As placas foram lavadas novamente e o substrato peróxido de hidrogênio e tetrametilbenzidina na proporção de 1:1 (BD Bioscience, EUA) foi adicionado conforme as instruções do fabricante. Após 30 min, a solução de paralisação da reação (ácido sulfúrico $4 \mathrm{~N}$ ) foi adicionada e a leitura foi realizada em espectrofotômetro ajustado para o comprimento de onda de 450nm (Bio-Rad, EUA).

\subsection{Análise estatística}

Os resultados foram expressos como média \pm erro padrão médio (EPM) dos resultados obtidos para cada grupo. A análise estatística foi realizada aplicando-se o teste adequado a cada ensaio, como indicado na legendas das figuras (INSTAT software, Prisma GraphPad 5, EUA). Todos os valores foram considerados significativos quando $p<0,05$. 

Resultados 



\section{RESULTADOS}

\subsection{Análise histopatológica das amostras de pele de pacientes com hanseníase}

Amostras de lesão de pele de pacientes diagnosticados clinicamente com hanseníase tuberculóide (MHT) ou virchoviana (MHV) foram processadas e coradas com hematoxilina e eosina (H\&E) para a confirmação do diagnóstico e análise do processo inflamatório.

Nas amostras de pacientes com hanseníase tuberculóide observou-se, de modo geral, a formação de granuloma, constituído por agregado de células fagocitárias mononucleares com evidente diferenciação epitelióide, participação de células gigantes multinucleadas tipo Langhans no centro da lesão e com a presença de linfócitos que confere um halo denso contornando este granuloma. Nas amostras de pacientes com hanseníase virchoviana, observou-se um extenso infiltrado celular composto de macrófagos com abundante presença de bacilos no citoplasma e predominante presença de macrófagos próximos aos nervos e vasos. Além disto, a coloração de Faraco, para a detecção de Mycobacterium leprae, revelou abundante presença deste bacilo nas lesões dos pacientes virchovianos e fraca marcação nas lesões de pacientes tuberculóides (Figura 1). 

$\mathrm{H} \& \mathrm{E}$
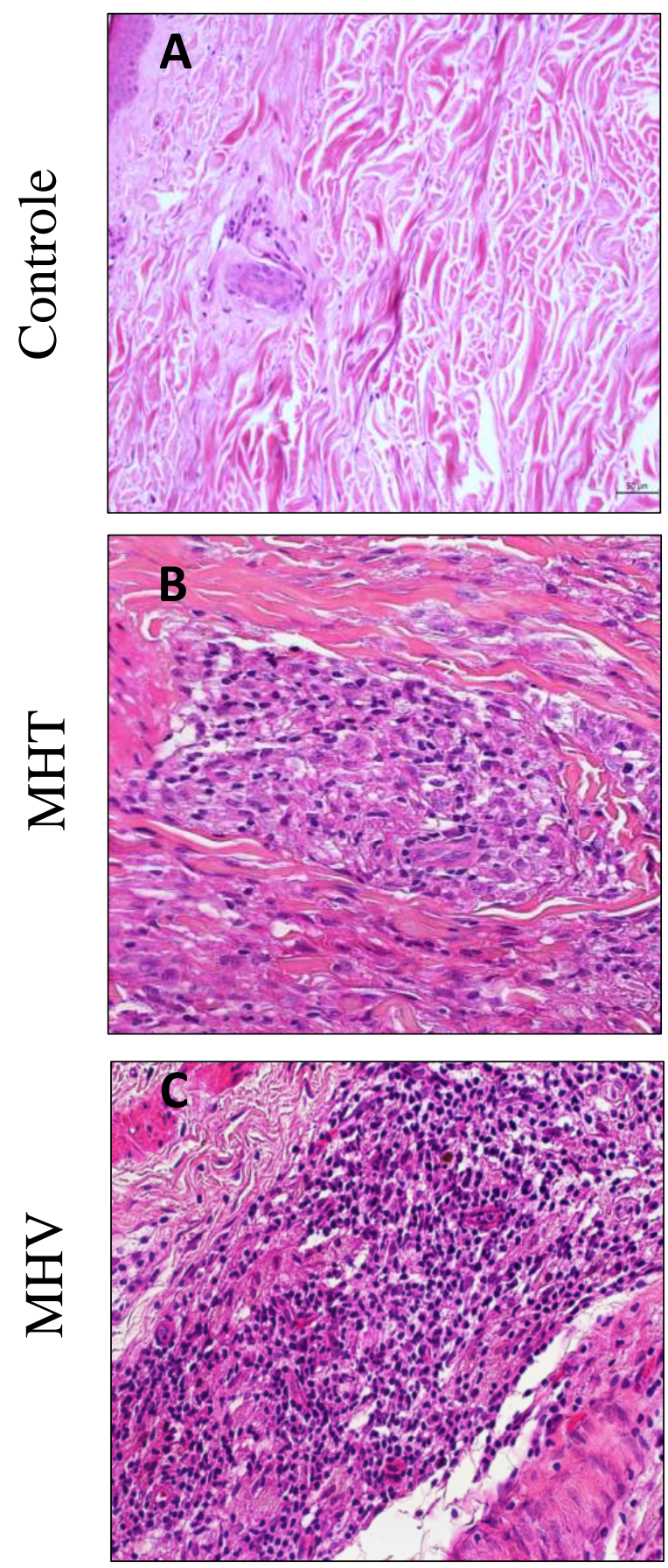

Faraco-Fite
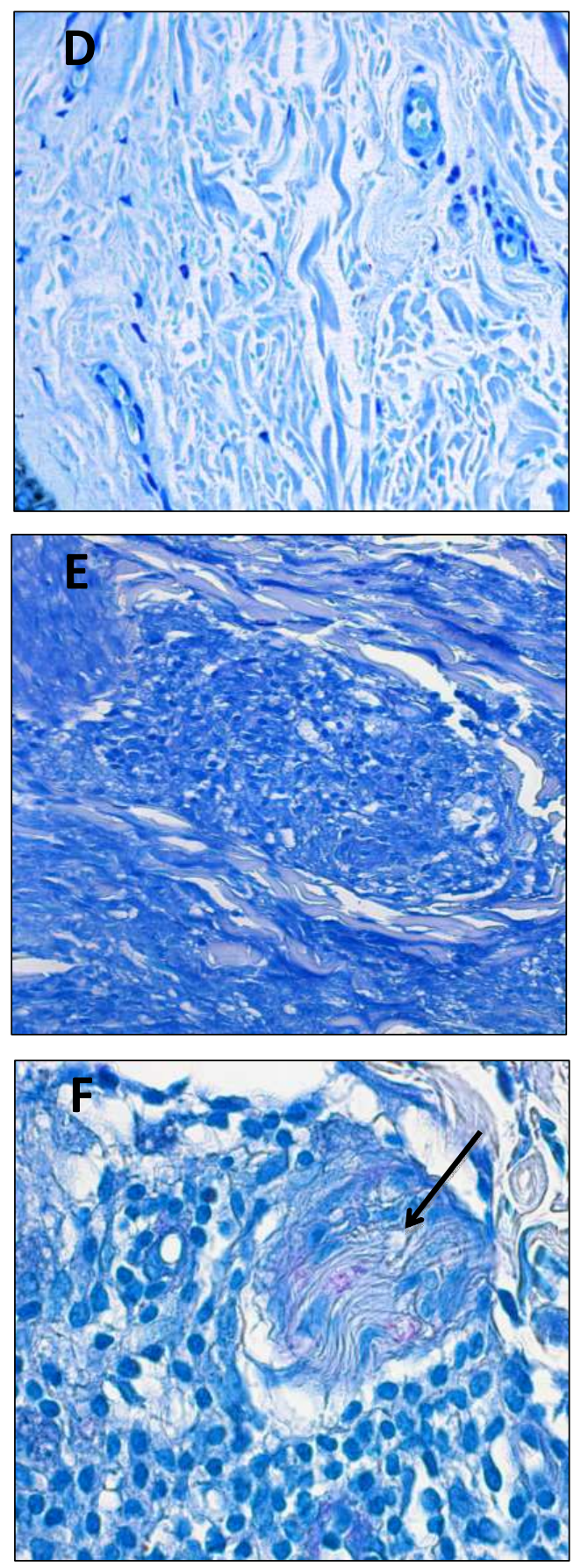

Figura 1: Fotomicografias das lesões de hanseníase e detecção de Mycobacterium leprae. Lesões de pele de pacientes diagnosticados clinicamente com hanseníase tuberculóide (MHT) ou virchoviana (MHV) foram processadas e coradas com hematoxilina e eosina (H\&E, 40x). A arquitetura tecidual foi observada e o infiltrado inflamatório foi analisado. Cortes sequenciais das lesões foram coradas com Faraco para detecção de Mycobacterium leprae (40x). Notar a presença de bactérias (seta). Fotomicrografias A-E aumento de 40x; F aumento de $100 x$. 



\subsection{Caracterização das populações de leucócitos presentes no sangue de pacientes com hanseníase}

A caracterização fenotípica das diferentes populações de leucócitos presentes no sangue periférico dos pacientes portadores de hanseníase e indivíduos controles foi realizada por citometria de fluxo. Os resultados demonstraram que não há diferenças significantes entre a percentagem de linfócitos $\mathrm{T} \mathrm{CD}^{+} \mathrm{CD}^{+}, \mathrm{T} \mathrm{CD}^{+} \mathrm{CD}^{+}$ou monócitos/macrófagos $\left(\mathrm{CD} 14^{+}\right)$ no sangue periférico de pacientes com hanseníase (virchoviana e tuberculóide) e indivíduos controle (Figura 2B).

Em relação à presença de células $\mathrm{T} \mathrm{CD}^{+} \mathrm{CD} 25^{+}$, os resultados revelaram que pacientes com hanseníase tuberculóide $(12,71 \pm 2,48 \%)$ apresentaram menor percentagem dessas células que os pacientes com hanseníase virchoviana $(21,54 \pm 3,11 \%)$ e indivíduos controle $(16,17 \pm 2,64 \%)$ (Figura $2 \mathrm{~B})$.

Além disto, a expressão de FoxP3 entre a população de células $\mathrm{T}$ CD $4{ }^{+} \mathrm{CD} 25^{+}$dos pacientes e indivíduos saudáveis foi determinada e mostrou-se mais frequente entre os pacientes com hanseníase virchoviana $(13,17 \pm 1,02 \%)$ do que naqueles com hanseníase tuberculóide $(5,51 \pm 1,02 \%)$ ou entre indivíduos saudáveis $(7,39 \pm 0,98 \%)$. Os resultados mostraram que não existe diferença na composição celular isolada do sangue periférico de pacientes e indivíduos controle, mas há maior número de células $\mathrm{FoxP}^{+}$isoladas das amostras de pacientes com hanseníase virchoviana (Figura 2B). 


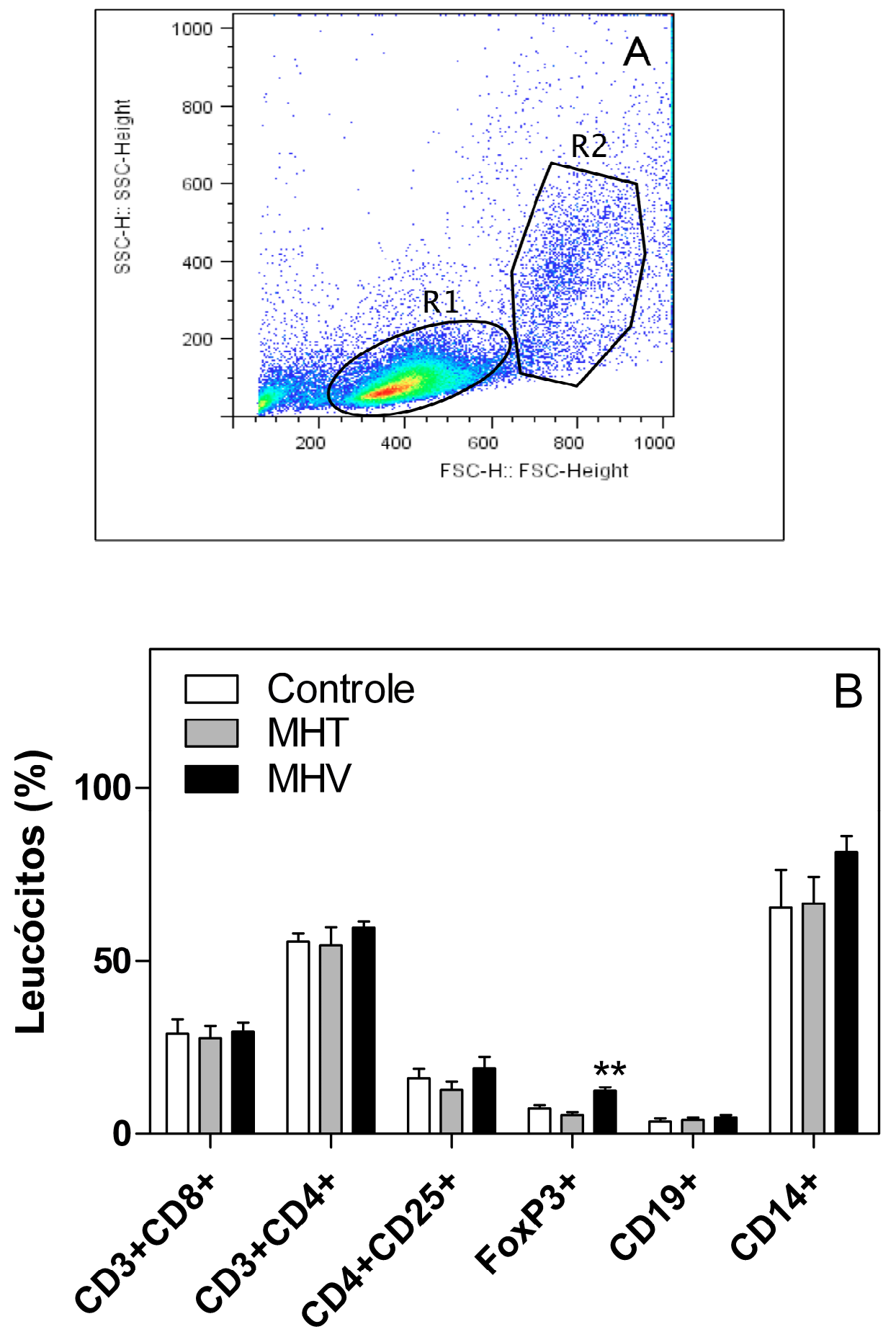

Figura 2. Fenotipagem de leucócitos. As células mononucleares do sangue periférico foram isoladas de indivíduos controle ou com hanseníase tuberculóide e virchoviana e fenotipadas por citometria de fluxo. (A) Dot-Plot representativo das características de tamanho e complexidade células das populações analisadas (R1 - Linfócitos e R2 - Monócitos. (B) Cada coluna representa a percentagem de células presentes na gate de linfócitos (R1) que expressam CD3, CD4, CD8, CD25, CD19 e FoxP3 e na gate de monócitos (R2) que expressam CD14. As barras representam a média \pm erro padrão médio. ${ }^{*}{ }^{*} p<0,01$ pelo teste ANOVA one-way e pós-teste de Tukey em relação ao grupo controle. 



\subsection{Análise da proliferação e produção de citocinas por células mononucleares do sangue periférico de pacientes com hanseníase.}

Dados na literatura demonstraram que PBMCs de indivíduos com hanseníase virchoviana apresentam baixa resposta proliferativa frente à estimulação policlonal ou por antígenos de M. leprae (DAGUR et al., 2010; KUMAR et al., 2011a; PALERMO et al., 2012). Para avaliar o perfil da resposta proliferativa, PBMCs de indivíduos saudáveis e pacientes com hanseníase foram estimuladas por $142 \mathrm{~h}$ com fitohematoglutinina (PHA), e determinado o índice de proliferação. Os resultados demonstraram não haver diferenças entre a proliferação basal de células de pacientes com hanseníase e indivíduos controle (Figura 3A). A estimulação com PHA, um mitógeno policlonal, induziu intensa reposta proliferativa de células T, tanto de indivíduos controle como de pacientes com hanseníase (Figura 3A). Esses resultados diferem dos resultados apresentados previamente, que mostraram que a estimulação com PHA induz uma baixa resposta proliferativa de PBMCs de pacientes com hanseníase virchoviana (PALERMO et al., 2012). Tal fato poderia ser explicado devido às diferentes metodologias empregadas.

A produção diferencial de citocinas por linfócitos é um dos possíveis determinantes da hanseníase (MODLIN, 1994). Para avaliar o perfil de produção de citocinas por PBMCs de indivíduos saudáveis e dos pacientes, as células foram cultivadas por $142 \mathrm{~h}$ na presença de PHA e a produção de citocinas avaliada por CBA (IL-4, IL-5, IL-10, IFN- $\gamma$ e TNF- $\alpha$ ) e ELISA (TGF- $\beta$ ). Na ausência de estimulação, não se detectou a produção de IL-4 e IL-5 por células de indivíduos controle e pacientes (Figura 3). No entanto, níveis elevados de IFN- $\gamma$, TNF- $\alpha$ e IL-10 foram detectados nas culturas de PBMC de pacientes com hanseníase tuberculóide. A produção basal de TGF- $\beta$ foi semelhante entre os grupos (Figura 3G). A estimulação com PHA induziu a produção de IL-4, IL-5, IL-10, IFN- $\gamma$ e TNF- $\alpha$ por PBMC de pacientes com hanseníase virchoviana. De modo divergente, a estimulação com PHA induziu leve aumento na produção de IL-5 e IL-10 por PBMC de pacientes com hanseníase tuberculóide, mas a produção das outras citocinas foi similar à produção basal (Figura 3). A produção de IL-5 e IL-4, citocinas relevantes na polarização da resposta imune humoral, foi detectada predominantemente nas culturas de PBMC de pacientes com hanseníase virchoviana (Figura 3D e E). 


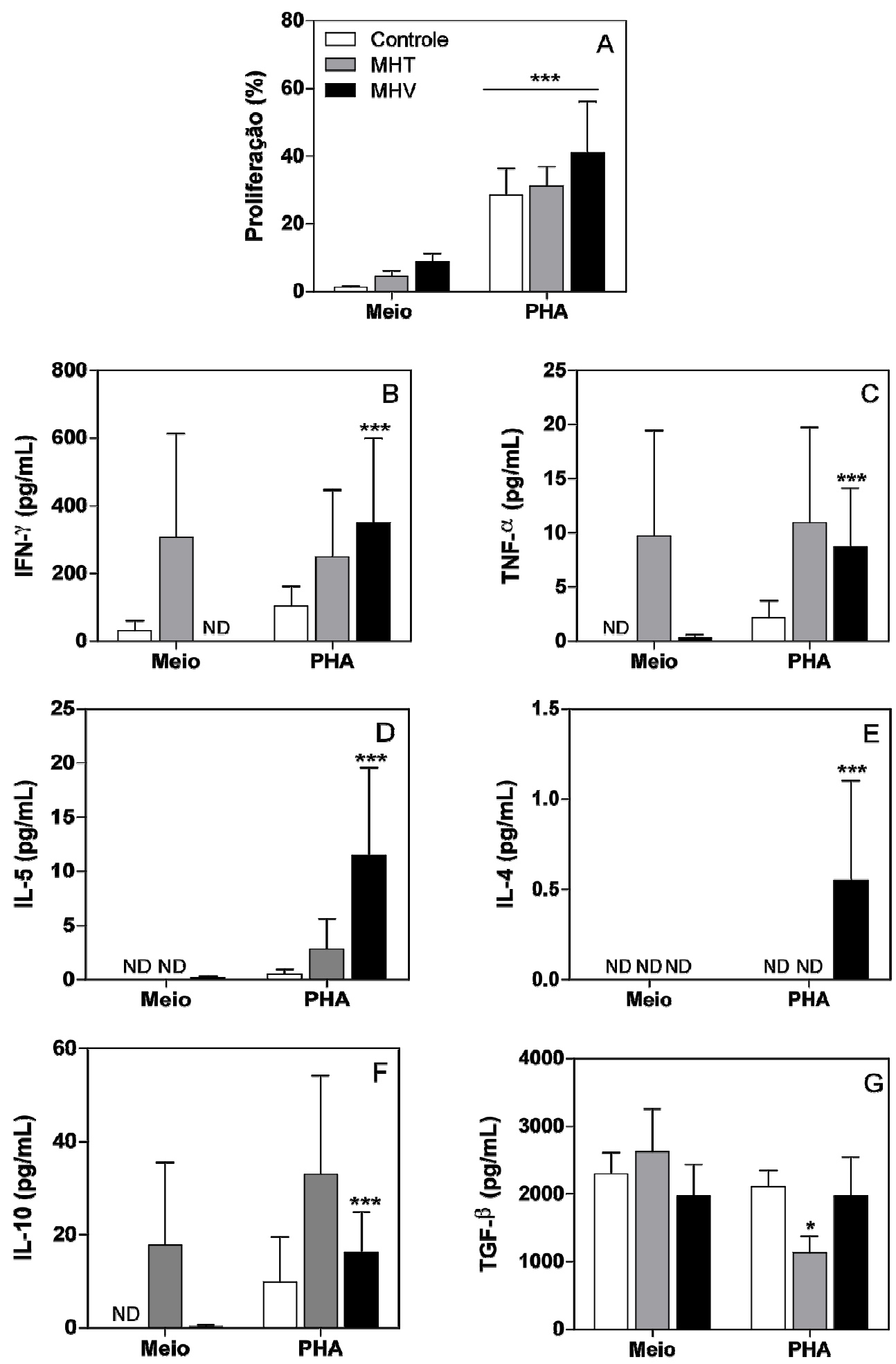

Figura 3. Proliferação e produção de citocinas por células mononucleares do sangue periférico de paciente com hanseníase. (A) As barras representam a média \pm erro padrão da percentagem de proliferação de PBMC de pacientes e indivíduos controle. A produção de $(\mathbf{B})$ IFN- $\gamma$, (C) TNF- $\alpha$, (D) IL-5, (E) IL-4, (F) IL-10, e (G) TGF- $\beta 1$ foi mensurada no sobrenadante das culturas por CBA e ELISA e a concentração de cada citocinas representada por $\mathrm{pg} / \mathrm{mL} .{ }^{*} \mathrm{p}<0,05 ; * * * \mathrm{p}<0,001$ pelo teste-t não pareado. ND (Não detectado). 


\subsection{Caracterização da população de linfócito $\mathrm{T} \mathrm{CD4}^{+} \mathrm{CD} 5^{+}$presente no sangue de pacientes com hanseníase}

Uma vez que células expressando a molécula de CD25 podem não pertencer à população de células Treg, torna-se necessário a caracterização destas células. Para tal, células isoladas do sangue periférico foram divididas em duas populações: uma que expressa a molécula de FoxP3 e outra que não expressa. As duas populações foram analisadas quanto à presença de diferentes marcadores de superfície e intracelulares (CD28, CD45RO, CD62L, CD69, CD103, CCR4, CCR5, CTLA-4, ICOS, GITR, PD-1 e IL-10) por citometria de fluxo.

Os resultados revelaram que os pacientes com hanseníase e indivíduos controle apresentaram percentagens semelhantes de linfócitos $\mathrm{T} \mathrm{CD} 4^{+} \mathrm{CD} 25^{+} \mathrm{FoxP} 3^{+}$expressando os marcadores de ativação CD28, CD45RO, CD69, as moléculas de adesão CD62L, CD103 e o receptor de quimiocina CCR5 (Figura 4A). As células Treg de pacientes com hanseníase apresentaram aumento na expressão de CCR4, contudo, somente em células de pacientes com a forma virchoviana notou-se discreto aumento na expressão de CTLA-4, GITR e PD-1 (Figura 4A). Os pacientes com hanseníase tuberculóide apresentaram redução na expressão de IL-10 por linfócitos $\mathrm{T} C D 4^{+} \mathrm{CD} 25^{+} \mathrm{FoxP} 3^{+}$quando comparado às células de pacientes com a forma virchoviana e controle (Figura 4A). Nenhuma diferença estatisticamente significante foi observado entre os grupos.

As células $\mathrm{T} \mathrm{CD}^{+} \mathrm{CD} 25^{+} \mathrm{FoxP} 3^{-}$de indivíduos controle e com hanseníase apresentaram percentagens semelhantes de expressão de CD28, CD45RO, CD62L, CD69, CD103 e CCR4 (Figura 4B). As células dos pacientes com a forma virchoviana apresentaram discreta redução na expressão de CCR5 quando comparado aos pacientes com a forma tuberculóide e controle. A expressão de IL-10 e ICOS foi semelhantes entre os paciente com hanseníase (Figura 4B). O aumento na expressão de CTLA-4, GITR e PD-1 foi detectado apenas entre as células de pacientes com a forma virchoviana, quando comparado aos pacientes com hanseníase tuberculóide e indivíduos do grupo controle (Figura 4B). 


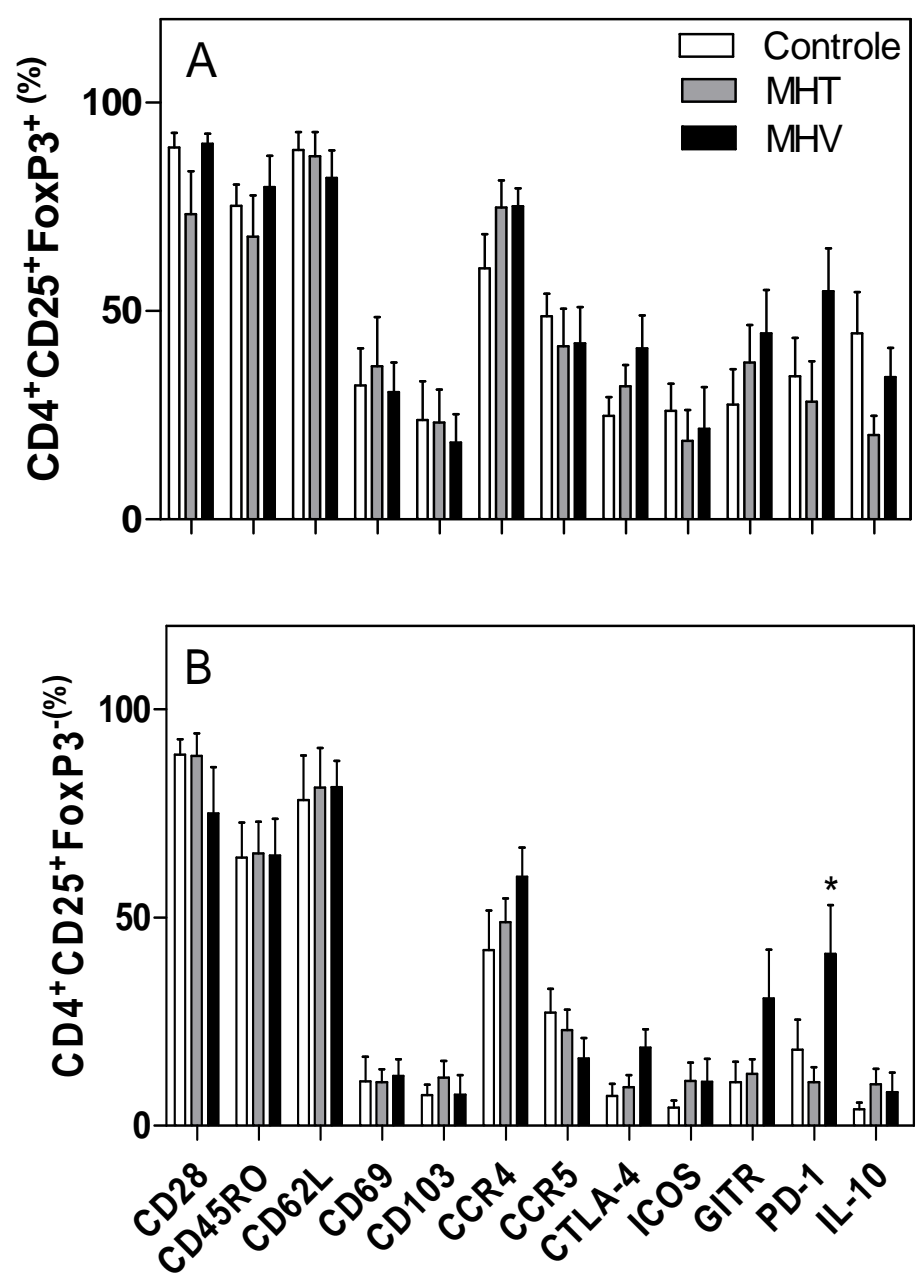

Figura 4. Caracterização de linfócitos $\mathrm{T} \mathrm{CD4}^{+} \mathrm{CD}^{2} 5^{+}$de pacientes com hanseníase. Cada coluna representa a percentagem de células $\mathrm{T} \mathrm{CD} 4^{+} \mathrm{CD} 25^{+} \mathrm{FoxP}^{+}$(A) e $\mathrm{T} \mathrm{CD} 4^{+} \mathrm{CD} 25^{+} \mathrm{FoxP} 3^{-}$ (B) que co-expressam CD28, CD45RO, CD62L, CD69, CD103, CCR4, CCR5, CTLA-4, ICOS, GITR, PD-1 e IL-10. Os resultados representam a média \pm erro padrão da percentagem de expressão de cada molécula. **p $<0,05$ pelo teste ANOVA one-way e pós-teste de Tukey em relação ao grupo MHT. 



\subsection{Análise da atividade supressora de células $\mathrm{T} \mathrm{CD}^{+} \mathrm{CD}^{2} 5^{+}$isoladas de pacientes com hanseníase}

Para avaliar se as células T $\mathrm{CD} 4{ }^{+} \mathrm{CD} 25^{+}$apresentavam atividade supressora, realizouse ensaio de inibição de proliferação de PBMC alogênico. Para isso, os linfócitos T $\mathrm{CD} 4^{+} \mathrm{CD} 25^{+}$e $\mathrm{T} \mathrm{CD} 4^{+} \mathrm{CD} 25^{-}$isolados do sangue periférico de indivíduos saudáveis e de pacientes foram cultivadas com PBMC alogênico (1:10), previamente marcado com CFSE, e o índice de proliferação mensurado por citometria de fluxo.

Os resultados demostraram que as células $\mathrm{T} \mathrm{CD}^{+} \mathrm{CD} 25^{+}$isoladas de pacientes e indivíduos controle apresentaram significativa atividade supressora, por inibir a proliferação de PBMC alogênico (Figura 5). As células $\mathrm{T} \mathrm{CD} 4{ }^{+} \mathrm{CD} 25^{+}$isoladas do sangue periférico de paciente com hanseníase virchoviana apresentaram maior atividade supressora que as células isoladas de pacientes com hanseníase tuberculóide (Figura 5A).

A co-cultura de PBMC alogênico com as células T CD4 ${ }^{+} \mathrm{CD} 25^{-}$isoladas do sangue de pacientes e indivíduos controle levou a aumento da proliferação celular. $O$ índice de estimulação das células $\mathrm{T} \mathrm{CD} 4^{+} \mathrm{CD} 25^{-}$isoladas de pacientes com hanseníase virchoviana foi menor que o índice de estimulação mediado por células de pacientes com hanseníase tuberculóide e indivíduos saudáveis (Figura 5).

Em seguida, avaliou-se a produção de IFN- $\gamma$, TNF- $\alpha$, IL-5, IL-4, IL-10 e TGF- $\beta 1$ no sobrenadante das co-culturas de PBMC alogênico com células T CD4 $4^{+} \mathrm{CD} 25^{+}$e $\mathrm{CD} 4^{+} \mathrm{CD} 25^{-}$ (1:10) de indivíduos controle e pacientes com hanseníase (Figuras 6 e 7). PBMC alogênico produziu níveis basais de IFN- $\gamma$, TNF- $\alpha$, IL-5, IL-4, IL-10 e TGF- $\beta 1$ quando cultivado apenas com meio (Figura 7). A estimulação com PHA induziu de modo significante a produção de IFN- $\gamma$, TNF- $\alpha$ e IL-10. A co-cultura do PBMC alogênico com células T CD4 ${ }^{+} \mathrm{CD} 25^{+}$isoladas de pacientes com hanseníase virchoviana inibiu a produção de TNF- $\alpha$ e IFN- $\gamma$, citocinas relevantes na polarização da resposta Th1 (Figuras 7A e B). De modo diferente, as células T $\mathrm{CD} 4^{+} \mathrm{CD} 25^{+}$dos indivíduos controle e pacientes com hanseníase tuberculóide não inibiram significativamente a produção dessas citocinas. 


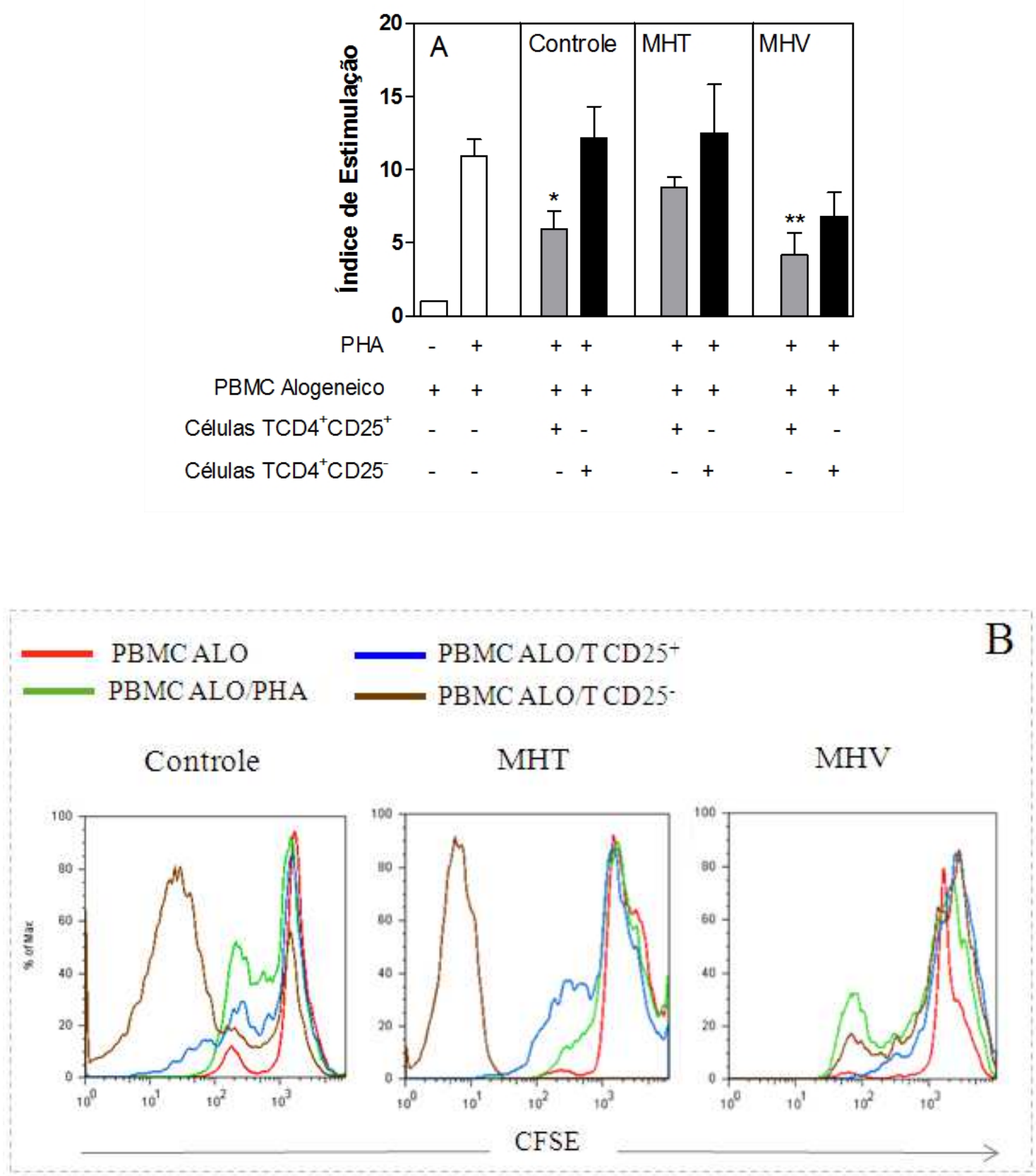

Figura 5. Análise da atividade supressora de linfócitos $\mathrm{T} \mathrm{CD}^{+} \mathrm{CD25}{ }^{+}$isolados do sangue periférico de paciente com hanseníase. Linfócitos $\mathrm{T} C D 4^{+} \mathrm{CD} 25^{+}$e $\mathrm{T} \mathrm{CD} 4^{+} \mathrm{CD} 25^{-}$isolados do sangue periférico de indivíduos controle e de paciente com hanseníase tuberculóide e virchoviana foram cultivados na presença de fitohematoglutinina (PHA) e PBMC de doador alogênico (1:10) previamente marcado com CFSE. (A) O índice de estimulação da proliferação de PBMC alogênico foi representado pela média \pm erro padrão. (B) Histogramas representativos da proliferação de células de pacientes com hanseníase e indivíduos controle. ${ }^{*} \mathrm{p}<0,05 ; * *^{*}<0,01$ pelo teste ANOVA e pós-teste de Tukey 



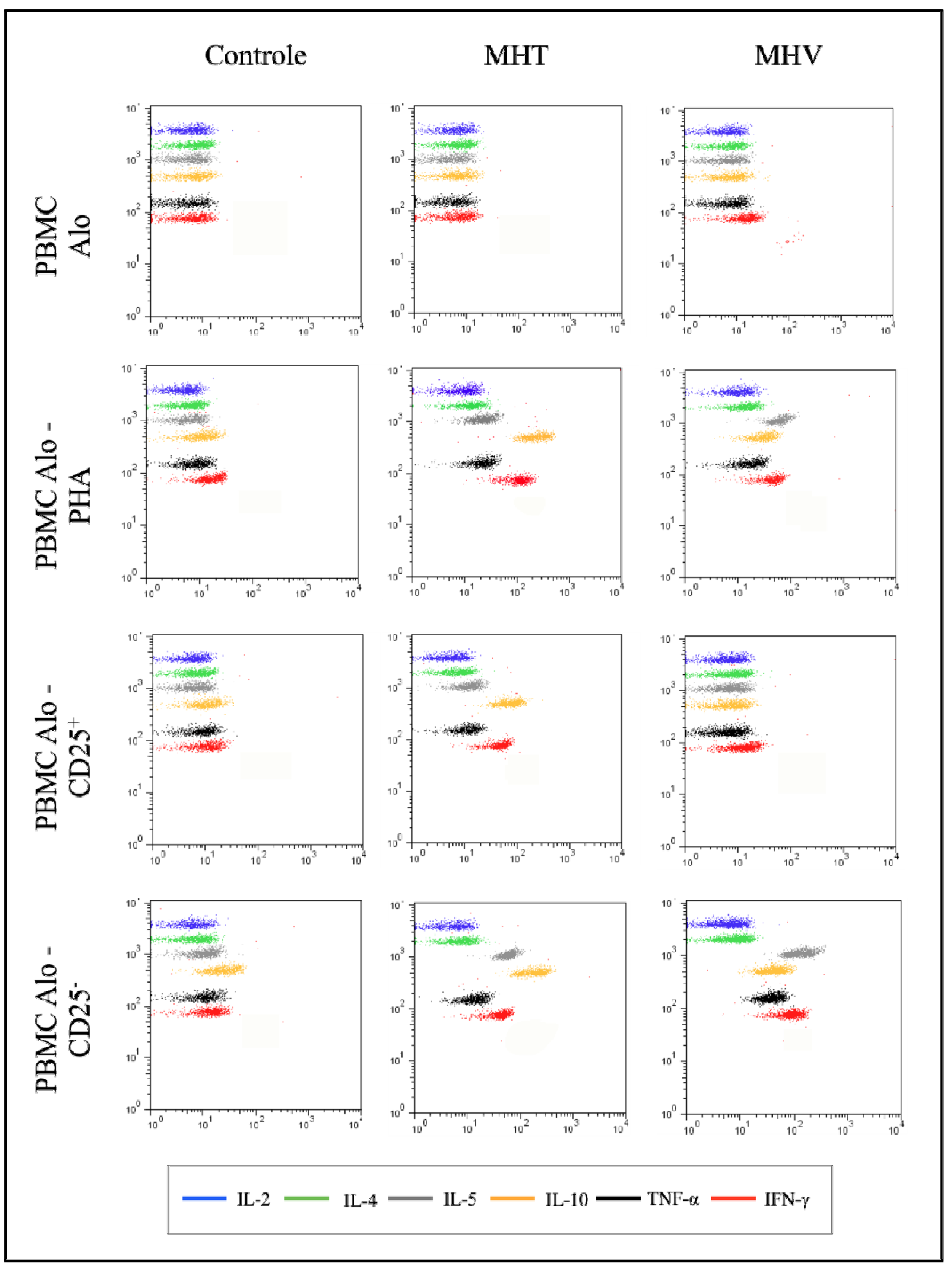

Figura 6. Produção de citocinas em co-cultura de PBMC alogênico e células $T$ $\mathrm{CD4}^{+} \mathrm{CD25}^{+}$. Dot plots representativos das amostras do ensaio de CBA para pacientes com hanseníase virchoviana (MHV) e tuberculoide (MHT) e controle. 

A co-cultura de PBMC alogênico com células $\mathrm{T} \mathrm{CD} 4^{+} \mathrm{CD} 25^{-}$isoladas de pacientes com hanseníase e indivíduos controle não inibiu a produção de TNF- $\alpha$ e IFN- $\gamma$ (Figuras 7A e B), observando-se um leve aumento na produção destas citocinas após a co-cultura. A produção de IL-5 e IL-4, citocinas envolvidas com a reposta do tipo Th2, não foi influenciada pela co-cultura com células $\mathrm{T} \mathrm{CD} 4{ }^{+} \mathrm{CD} 25^{+}$isoladas de pacientes com hanseníase e indivíduos controle (Figura 7C e D). De modo relevante, a co-cultura com células T CD4 ${ }^{+} \mathrm{CD} 25^{-}$isoladas de pacientes com hanseníase virchoviana induziu aumento significativo na produção de IL-5, e não alterou os níveis de IL-4.

A produção de IL-10 foi negativamente modulada nas co-culturas em que estavam presentes as células $\mathrm{T} \mathrm{CD} 4^{+} \mathrm{CD} 25^{+}$isoladas de pacientes com hanseníase (Figura 7E). As células $\mathrm{T} \mathrm{CD}^{+} \mathrm{CD} 25^{+}$de indivíduos controle não inibiram a produção de IL-10 por PBMC alogênico (Figura 7E). Contrariamente, a produção de TGF- $\beta 1$ não foi influenciada pelas células T CD $4^{+} \mathrm{CD} 25^{+}$e $\mathrm{T} \mathrm{CD} 4^{+} \mathrm{CD} 25^{-}$e manteve-se semelhante entre pacientes virchovianos e tuberculóides (Figura 7F). 


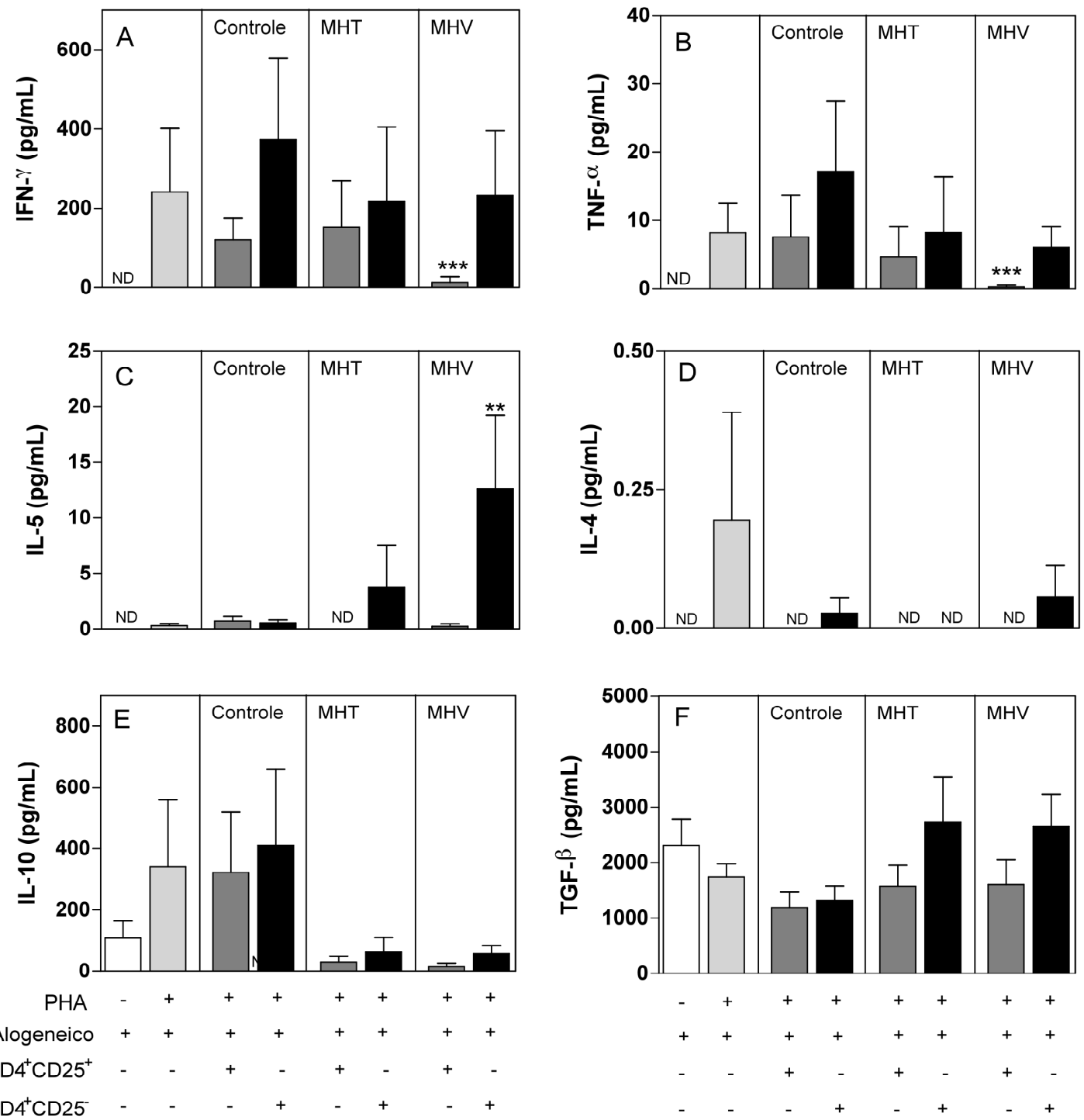

Figura 7. Análise da produção de citocinas em co-cultura de PBMC alogênico e células T $\mathrm{CD4}^{+} \mathrm{CD}^{+} 5^{+}$isoladas do sangue periférico de paciente com hanseníase. A produção das citocinas (A) IFN- $\gamma$, (B) TNF- $\alpha$, (C) IL-5, (D) IL-4, (E) IL-10 e (F) TGF- $\beta 1$ foi determinada no sobrenadante das co-culturas de PBMC alogênico e linfócitos $\mathrm{T} \mathrm{CD}^{+} \mathrm{CD} 25^{+}$e $\mathrm{T}$ $\mathrm{CD} 4^{+} \mathrm{CD} 25^{-}$. Os valores são representados em $\mathrm{pg} / \mathrm{mL} \pm$ erro padrão. ${ }^{* *} \mathrm{p}<0,01 ; * * * \mathrm{p}<0,001$ pelo teste ANOVA e pós-teste de Tukey. ND (não detectado). 



\subsection{Detecção de células $T$ reguladoras em lesão de paciente com hanseníase}

Com o intuito de avaliar a presença de células $\mathrm{T}$ reguladoras nas lesões de pacientes com hanseníase, avaliamos através de imunomarcação e análise por microscopia confocal a presença de células positivas para TGF- $\beta 1$, IL-10 e FoxP3 nas amostras de pele de pacientes com hanseníase. Nas amostras de pele de indivíduos controle, não foi detectada a presença de infiltrado inflamatório no tecido conjuntivo, nem marcação para CD25, IL-10, TGF- $\beta 1$ e FoxP3 (Figura 8). Os resultados revelaram a presença de células $\mathrm{T} \mathrm{CD}_{2} 5^{+}$que coexpressavam IL-10 e TGF- $\beta 1$ nas lesões de pacientes com hanseníase virchoviana, além da expressão de FoxP3, marcador específico para células T reguladoras. No entanto, nas lesões de pacientes com hanseníase tuberculóides detectou-se células $\mathrm{T} \mathrm{CD}^{+} 5^{+}$que expressavam FoxP3, mas que apresentavam mínima expressão de IL-10 e TGF- $\beta 1$ (Figura 8). Os dados apontam para maior acúmulo de células $\mathrm{FoxP}^{+}$nas amostras de lesão de pacientes com hanseníase virchoviana. 


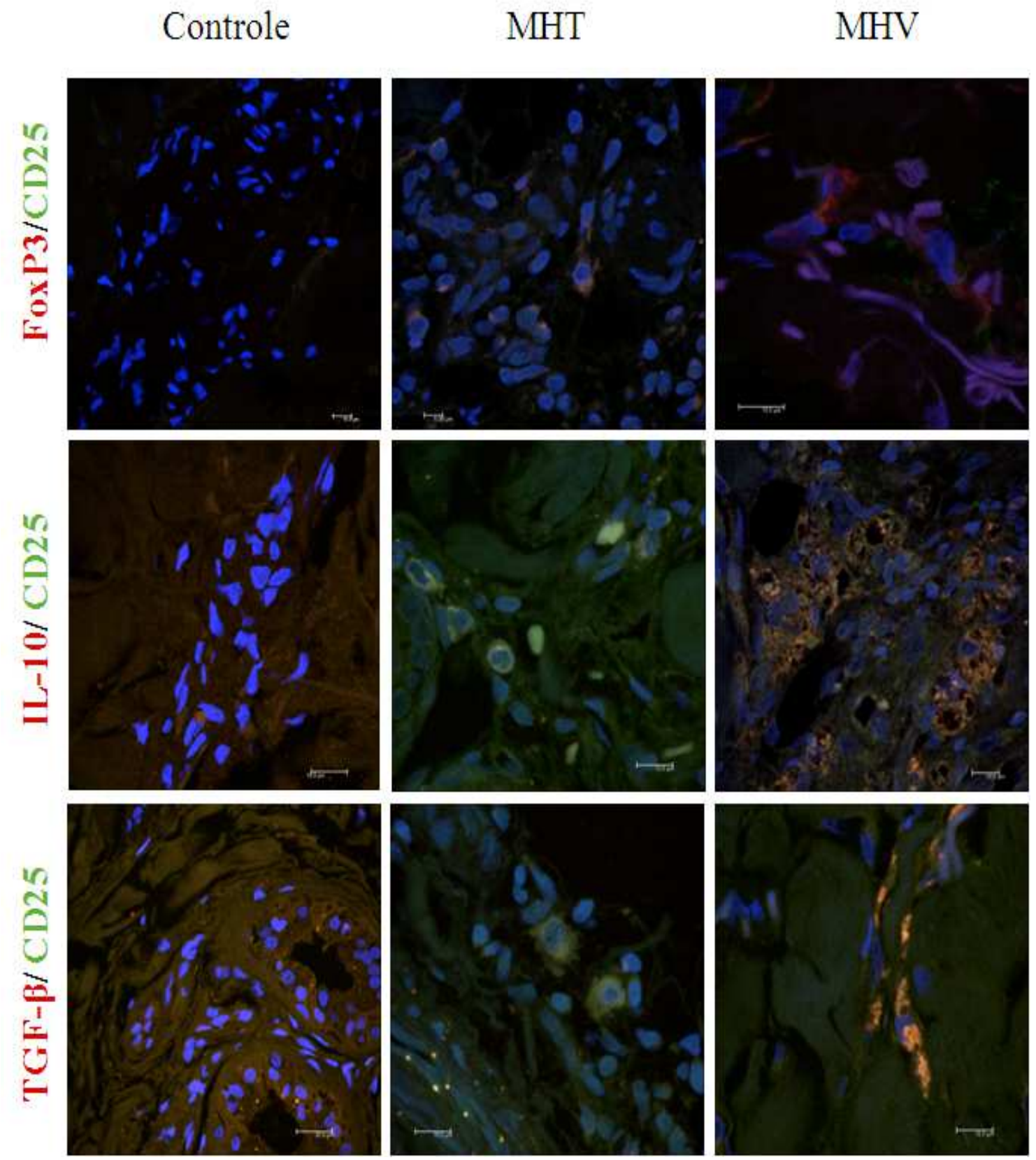

Figura 8. Fotomicrografias representativas das imunomarcações para CD25, FoxP3, IL10 e TGF- $\beta 1$ nas amostras de hanseníase e do grupo controle. Amostras de tecido de pacientes com hanseníase tuberculóide (MHT) e virchoviana (MHV) e de indivíduos saudáveis (controle) foram obtidas através de biópsias e, posteriormente, confeccionados cortes histológicos. A presença de células CD25 $5^{+}, \mathrm{IL}_{-} 10^{+}$, TGF- $\beta 1^{+}$, FoxP3 ${ }^{+}$foi determinada por imunofluorescência. Aumento de 630x para todas as figuras. 

Discussão 



\section{DISCUSSÃO}

A hanseníase é uma doença infecto-contagiosa causada por Mycobacterium leprae e apresenta diferentes formas clínicas, as quais são dependentes da resposta imune do hospedeiro (SCOLLARD et al., 2006). A maioria das pessoas exposta a M. leprae não desenvolverá hanseníase, no entanto, os indivíduos susceptíveis à doença apresentam polarização da resposta imune após a infecção com o bacilo, o que determina a forma clínica apresentada. De modo sucinto, os pacientes com hanseníase tuberculóide são resistentes à disseminação de $M$. leprae e persistência da doença por possuírem marcante resposta imune celular Th1. Nestes pacientes, os linfócitos $\mathrm{T} \mathrm{CD}^{+}$produzem principalmente IFN- $\gamma$, cuja participação na ativação de macrófagos é necessária a suas atividades efetoras através do aumento da produção de espécies reativas de oxigênio e nitrogênio (MOSSER; EDWARDS, 2008). Os linfócitos $\mathrm{T} \mathrm{CD}^{+}$do infiltrado inflamatório destes pacientes são também positivos para CD45RO, um marcador de linfócitos de memória (MODLIN et al., 1988), o que reitera a capacidade de ativação destas células. De fato, nós observamos no PBMC dos pacientes com hanseíase tuberculóide a produção de IFN- $\gamma$ e TNF- $\alpha$ e nesta forma da hanseníase também é comum o aumento no gradiente de citocinas inflamatórias, como IL-1 $\beta$, IL-2, IL-6 e IL-12, além de elevada expressão de MHC de classe 2 e moléculas de adesão, como ICAM-1 (FLAD et al., 1990; GARCIA et al., 1999; SULLIVAN et al., 1991).

Contrariamente, na forma virchoviana da doença há um predomínio de resposta imune humoral, com intensa produção de IL-5 e IL-4 pelos linfócitos desses pacientes, como observado em nossos resultados após a ativação policlonal dessas células. Estas citocinas atuam principalmente na diferenciação de linfócitos $\mathrm{B}$ em plasmócicos, favorecendo a produção de anticorpos, e no controle da diferenciação de linfócitos $\mathrm{CD}^{+}$, o que reduz capacidade citotóxica destas células (SIELING et al., 1993). A expressão de moléculas de ativação, como CD28, e de citocinas inflamatórias, como IFN- $\gamma$ e TNF- $\alpha$, também são negativamente modulada no PMBC de pacientes com hanseníase virchoviana após a exposição a antígenos de M. leprae (DAGUR et al., 2010; DUTHIE et al., 2008; KUMAR et al., 2011b; PALERMO et al., 2012). Além disto, importância da sinalização via IFN- $\gamma$ e IL-2 na resposta dos pacientes com hanseníase virchoviana foi demonstrada após a injeção intradérmica destas citocinas recombinates, o que modulou a migração de leucócitos para o 
local da infecção e a eliminação do bacilo (COHN; KAPLAN, 1991; KAPLAN, 1993; KAPLAN et al., 1991).

Dessa forma, a susceptibilidade de pacientes com haseníase virchoviana está relacionada à resposta imune predominantemente do tipo Th2 e alta produção de anticorpos. Tal padrão de resposta favorece a persistência do patógeno, uma vez que, por ser um microrganismo intracelular obrigatório, $M$. leprae se mantêm inacessível aos anticorpos e permanece viável no interior dos macrófagos (MODLIN, 1994; SCOLLARD et al., 2006). A despeito do intenso infiltrado inflamatório observado nas lesões desses pacientes com hanseníase virchoviana, dados indicam que a persistência do bacilo e manutenção da doença se deve à ausência ou prejuízo dos mecanismos efetores da resposta imune, ou à presença de uma população de linfócitos com atividade supressora (BLOOM; MODLIN; SALGAME, 1992; MODLIN et al., 1986; MUTIS et al., 1994; OTTENHOFF et al., 1986).

Os linfócitos $\mathrm{T}$ supressores ou reguladores são células cruciais para o controle da resposta imune, tanto aos antígenos próprios como aos não próprios, e também aos patógenos e comensais (CAMPBELL; KOCH, 2011; SAKAGUCHI et al., 1995). Dentre os mecanismos relacionados com a persistência dos patógenos a presença de uma população de linfócitos $\mathrm{CD} 4^{+} \mathrm{CD} 25^{+} \mathrm{FoxP}^{+}$com atividade supressora tem recebido especial atenção (BELKAID, 2007; VIGNALI; COLLISON; WORKMAN, 2008) Embora evidências consistentes, baseadas em infecções por M. leprae, sugiram que as células Treg possam ter papel relevante durante o desenvolvimento da hanseníase, os mecanismos pelos quais essas células atuam ainda não estão totalmente esclarecidos (ATTIA et al., 2010; KUMAR et al., 2011a; MASSONE et al., 2010). Além disso, a associação entre as células Treg e a infecção por $M$. leprae ainda é pouco entendida. Neste trabalho, foi estudada a relação entra células $\mathrm{T}$ reguladoras e as formas polares da hanseníase e, de acordo com os dados apresentados, há indícios de que ocorra a modulação da resposta imune por células $\mathrm{T}$ reguladoras em pacientes com a forma virchoviana da hanseníase.

Em nosso estudo, não observamos diferenças na freqüência de linfócitos $\mathrm{T} \mathrm{CD}^{+}, \mathrm{B}$ $\left(\mathrm{CD} 19^{+}\right)$ou monócitos no sangue periférico de pacientes com hanseníase. Contudo, foi observado aumento na população de linfócitos $\mathrm{T} \mathrm{CD}^{+} \mathrm{CD} 25^{+} \mathrm{FoxP} 3^{+}$no sangue periférico de pacientes com a forma virchoviana da doença. $\mathrm{O}$ aumento no número de células Treg pode modular a resposta imune do hospedeiro e, consequentemente, permitir a sobrevivência do 
parasita e sua multiplicação. Por outro lado, o aumento das células Treg poderia limitar a exacerbação da patologia durante a infecção, o que beneficiaria o hospedeiro, ao evitar danos aos órgãos devido ao controle da resposta inflamatória.

$\mathrm{O}$ estudo de células $\mathrm{T}$ reguladoras em humanos é complexo e apresenta algumas limitações, pois a identificação dessas células é difícil pelo fato da expressão de FoxP3 ser observada também em células T efetoras (ALLAN et al., 2007; KMIECIAK et al., 2009). Do mesmo modo, CD25 e outros marcadores de células Treg não podem ser usados para discriminar Treg naturais ou induzidas e células T ativadas. Além disso, nos tecidos linfóides de indivíduos infectados com HIV, por exemplo, a maioria das células $\mathrm{T} \mathrm{CD}^{+} \mathrm{CD} 25^{+}$são FoxP3 ${ }^{\text {low }}$ (APOIL et al., 2005). Grande parte dos estudos que avalia a função ou o número de células $\mathrm{T}$ reguladoras naturais em humanos foi realizada usando o sangue periférico, uma vez que esta é a forma mais acessível para a obtenção dessas células. Entretanto, o fenótipo e número destas células no sangue periférico não podem ser empregados para representar as células presentes nos tecidos. Em algumas infecções crônicas, as células Tregs naturais acumulam-se em tecidos infectados e são raramente detectáveis no sangue. Apesar destas dificuldades, alguns artigos evidenciam o papel de células $\mathrm{T}$ reguladoras naturais em controlar a resposta imune em diversas doenças infecciosas humanas (BELKAID, 2007; CAMPBELL; KOCH, 2011; VIGNALI; COLLISON; WORKMAN, 2008).

Uma variedade de moléculas foi descrita como marcadores de superfície para a identificação de células $\mathrm{T}$ reguladoras e como mediadores da atividade destas células, incluindo as moléculas co-inibitórias, como GITR , CTLA-4, ICOS e PD-1, fatores de transcrição como FoxP3, além de receptores de quimiocinas e citocinas (BELKAID, 2007; CAMPBELL; KOCH, 2011; COLLISON; VIGNALI, 2008; FEUERER et al., 2009; YAMAGUCHI et al., 2007).

GITR é expresso constitutivamente em células Treg naturais e é regulado pela pelo fator de transcrição FoxP3 (BELKAID; ROUSE, 2005; HORI; NOMURA; SAKAGUCHI, 2003). Inicialmente, a molécula GITR foi descrita por estar relacionada com a atividade supressora dessas células (SHEVACH; STEPHENS, 2006). Entretanto, estudos posteriores demonstraram que o aumento da expressão dessa molécula promove a proliferação das células reguladoras (KO et al., 2005; NISHIOKA et al., 2008; SCHAER; MURPHY; WOLCHOK, 2012; SHIMIZU et al., 2002), permitindo um aumento potencial de sua atividade supressora 
(SHEVACH; STEPHENS, 2006). As células T reguladoras de pacientes com hanseníase apresentaram elevada expressão GITR, e nos pacientes com hanseníase virchoviana a expressão de GITR foi também detectada em células T FoxP3- $\mathrm{O}$ aumento de células $\mathrm{T}$ $\mathrm{CD} 4^{+} \mathrm{CD} 25^{+} \mathrm{FoxP}^{+}$co-expressando GITR em pacientes com a forma virchoviana da doença pode refletir parcialmente a expansão das células Treg observada nesses indivíduos.

Semelhantemente a GITR, a expressão de ICOS foi positivamente regulada nos pacientes com hanseníase. ICOS é expresso em linfócitos após a ativação e a sinalização através deste receptor fosforila moléculas como MAPK, ERK e ativa PI3K modulando a proliferação e viabilidade celular (SIMPSON; QUEZADA; ALLISON, 2010). ICOS tem importante papel na manutenção e viabilidade das Tregs, como demonstrado através da redução no número de Tregs em animais $\operatorname{ICOS}^{-/-}$(BURMEISTER et al., 2008). Além disto, a produção de IL-10 e TGF- $\beta$ é diferentemente regulada entre as população de linfócitos T FoxP $3^{+} \mathrm{ICOS}^{\text {hi }}$, o que sugere que a expressão desta molécula pode distinguir subtipos de Tregs (ITO et al., 2008). Nos pacientes com hanseníase a expressão deste receptor pode refletir o estado de ativação dos linfócitos e não necessariamente a atividade supressora das células Tregs.

A molécula CTLA-4 também é expressa nas Treg e sua interação com CD80 ou CD86 resulta em indução de atividade supressora. Observou-se o aumento da expressão de CTLA-4 em linfócitos $\mathrm{T} \mathrm{CD}^{+} \mathrm{CD} 25^{+} \mathrm{FoxP} 3^{+}$de pacientes com hanseníase tuberculóide e virchoviana. A população de células $\mathrm{T} \mathrm{CD} 4^{+} \mathrm{CD} 25^{+} \mathrm{CTLA}-4^{+}$apresenta forte atividade reguladora in vitro e o bloqueio desta molécula leva a um aumento da resposta imune, estimulando a proliferação de linfócitos obtidos de pacientes com hanseníase virchoviana (SCHLIENGER et al., 1998). O efeito supressivo da CTLA-4 está associado à redução da produção de IL-2 e à manutenção das células na fase G1 do ciclo celular (GREENWALD et al., 2001; GREENWALD et al., 2002; SHEVACH, 2009). Com isso, a inabilidade de proliferar em resposta à estimulação policlonal poderia ser devido à expressão aumentada de CTLA-4, uma molécula que se liga também a CD80/CD86, promovendo anergia e influenciando negativamente a função efetora de células T, inibindo, assim, a progressão no ciclo celular. As células T reguladoras CTLA$4^{+}$inibem a maturação de células dendríticas e este processo é dependente de IDO. Os mecanismos pelos quais as células dendríticas se mantêm imaturas incluem a modulação da expressão de Foxo e redução da produção de citocinas inflamatórias, como IL-6 (MELLOR; MUNN, 2004; PUCCETTI; GROHMANN, 2007; QURESHI, O.S. et al., 2011; WALKER, 
L.S.; SANSOM, 2011). Embora não tenhamos analisado a expressão de IDO, a expressão desta molécula foi detectada em células dendríticas de pacientes com hanseníase virchoviana (DE SOUZA SALES et al., 2011; MOURA et al., 2012), o que sugere a participação deste mecanismo de controle da resposta imune pelas Tregs nesta forma da doença.

Dentre os mecanismos de supressão exercidos pelas Tregs, a expressão de PD-1 também está relacionada à produção de citocinas anti-inflamatórias e controle da proliferação de células efetoras e da maturação das células dendríticas, no entanto ainda não se sabe como tal receptor contribui para o potencial supressor das Tregs (FRANCISCO; SAGE; SHARPE, 2010; KEIR et al., 2008; SHARPE et al., 2007; FIFE; BLUESTONE, 2008). A sinalização via PD-1 está envolvida com a indução de anergia em linfócitos através da regulação da transdução do sinal intracelular após apresentação de antígeno ao TCR e ativação do receptor de IL-2 (SHARPE et al., 2007). Os nossos resultados evidenciaram elevada expressão de PD1 em linfócitos $\mathrm{T} \mathrm{CD}^{+} \mathrm{CD} 25^{+} \mathrm{FoxP}^{+}$de pacientes com hanseníase e semelhantemente às demais moléculas co-inibitórias analisadas, a população de células $\mathrm{T}$ CD4 ${ }^{+} \mathrm{CD} 25^{+} \mathrm{FoxP} 3^{-}$ apresentou elevada expressão de PD-1 nos pacientes com hanseníase virchoviana, o que sugere um estado anérgico desta população de células e as torna susceptíveis a conversão em Tregs pela expressão de FoxP3, na presença de citocinas anti-inflamatórias, como TGF- $\beta$ (FRANCISCO et al., 2009). De fato, PD-1 regula a atividade das células T reguladoras uma vez que as Treg obtidas de animais deficientes de PD-1 apresentam comprometimento da sua atividade supressora sobre células efetoras (POLANCZYK et al., 2007). Além disto, há uma relação direta entre a expressão de PD-1 por linfócitos efetores e o aumento no número de células T reguladoras (FRANCISCO; SAGE; SHARPE, 2010; FRANCISCO et al., 2009). Em doenças infecciosas crônicas como hepatite B, doença de chagas e malária, o bloqueio de PD-1 restabelece a resposta efetora do hospedeiro e reduz a gravidade da doença, o que demonstra o papel desta via de sinalização no controle da resposta imune (BLATTMAN; GREENBERG, 2006; BONI et al., 2007; GUTIERREZ et al., 2011; HAFALLA et al., 2012; PENG et al., 2008).

Uma questão importante a respeito das Treg é a regulação de sua migração para os tecidos periféricos. Embora tenham sido identificadas nos tecidos linfóides, elas também migram para a periferia, particularmente sob condições patológicas (HUEHN; HAMANN, 2005), possivelmente via receptores de quimiocinas CCR4, CCR5 e CCR8 (IELLEM et al., 2001; WYSOCKI et al., 2005). Na tolerância a aloenxerto, o recrutamento de células 
TCD $4^{+} \mathrm{CD} 25^{+} \mathrm{Foxp}^{+}$é dependente de CCR4 e seu ligante CCL22, assim como na infecção por $P$. brasiliensis na qual a presença de células $\mathrm{T}$ reguladoras nas lesões é dependente de CCR5 (MOREIRA et al., 2008). Os resultados do presente estudo evidenciaram alta freqüência de células $\mathrm{T}$ reguladoras de pacientes com hanseníase expressando os receptores de quimiocina CCR4 e CCR5, o que indica que estas células podem migrar para o sítio da inflamação. De fato, nas lesões de pele de pacientes com hanseníase tuberculóide e virchoviana há o acúmulo de células T reguladoras, possivelmente mediado pela produção de quimiocinas por diferentes populações celulares da pele em resposta à presença de M. leprae. Destaca-se o maior acúmulo de células $\mathrm{T}$ reguladoras em amostras de pacientes com hanseníase virchoviana, indivíduos mais susceptíveis a infecção e onde se observa a permanência do bacilo nos tecidos. De modo relevante, dados recentes evidenciam que os micro-organismos induzem a diferenciação e migração de células reguladoras para assegurar sua própria sobrevivência (CARAMALHO et al., 2003; NETEA et al., 2004; SUTMULLER et al., 2006; ZANIN-ZHOROV et al., 2006). Entretanto, sobreviver a uma infecção requer a geração de uma resposta imune que reconheça e controle a replicação do patógeno, enquanto limita/controla os danos aos tecidos do hospedeiro, que podem ser resultado de uma resposta imune exacerbada. Isto implica que a indução de células $\mathrm{T}$ reguladoras e a expressão de moléculas co-inibitórias são também uma conseqüência da resposta do hospedeiro ao processo infeccioso em um mecanismo para manter ou restaurar a homeostasia do organismo.

A retenção de células Tregs nos tecidos periféricos é modulada principalmente por integrinas como CD103 e CD62L e a expressão destas moléculas não foi diferente entre os linfócitos dos pacientes com hanseníase. A importância de CD103 foi demonstrada após infecção experimental por L. major, quando se observou que na ausência desta molécula, o número de Tregs nas lesões cutâneas foi reduzido, favorecendo a resposta do hospedeiro (SUFFIA et al., 2005). Embora CD62L seja crucial para o homing de linfócitos aos órgãos linfóides secundários, a expressão desta molécula também influencia a capacidade supressiva das Tregs, como constatado na encefalomielite auto-imune experimental (LANGE et al., 2011).

As condições criadas pelo processo infeccioso favorecem o recrutamento e/ou a permanência de células $T$ reguladoras no local da infecção. TGF- $\beta$ é freqüentemente produzido em altos níveis durante as infecções crônicas e é um importante fator para a sobrevivência e função das células T reguladoras (GARIDOU et al., 2012; LETTERIO; 
ROBERTS, 1998; LI; FLAVELL, 2008). Vários pátogenos podem induzir diretamente a produção de TGF- $\beta$, em adição, o término de um processo inflamatório também é caracterizado pela produção elevada de TGF- $\beta$. Cabe ressaltar, que as células T CD4 ${ }^{+}$ convencionais também podem se tornar supressoras na presença de altos níveis de TGF- $\beta$ o que contribuiria para os mecanismos de persistência do patógeno (BILATE; LAFAILLE, 2012; CAMPBELL; KOCH, 2011; VIGNALI; COLLISON; WORKMAN, 2008). Contudo, os mecanismos relacionados com a conversão de células $\mathrm{T}$ convencionais em reguladoras durante o processo infeccioso ainda precisam ser estabelecidos. TGF- $\beta 1$ e sua isoforma $\beta 2$ são frequentemente detectadas na derme de pacientes com hanseníase (KHANOLKARYOUNG; SNOWDON; LOCKWOOD, 1998; KISZEWSKI et al., 2003; PALERMO et al., 2012). Estes dados estão de acordo com os nossos achados, onde se detectou intensa produção de TGF- $\beta$ e co-expressão com células $\mathrm{CD}_{2} 5^{+}$em amostras de pacientes com hanseníase virchoviana. Assim, a produção de TGF- $\beta$ pelas células T reguladoras contribuiria para os mecanismos de persistência do patógeno observado em pacientes com hanseníase virchoviana.

Outra citocina importante nos mecanismos supressores mediado pelas Tregs é a IL-10. A presença desta citocina é comum no infiltrado inflamatório dos pacientes virchovianos (MOURA et al., 2012; PALERMO et al., 2012). No presente trabalho, detectou-se a presença de IL-10 em amostras de pacientes com hanseníase virchoviana em associação com células $\mathrm{CD}^{2} 5^{+}$. O papel de IL-10 no controle de uma resposta imune é evidenciado em animais IL-10/. os quais apresentam alta resistência à infecção por L. major, P. carinii e C. pneumoniae (PENTTILA et al., 2008; QURESHI, M.H.; HARMSEN; GARVY, 2003; SACKS; ANDERSON, 2004). IL-10 é produzida por uma variedade de células, como macrófagos, monócitos, células dendríticas e por diferentes populações de linfócitos, sendo que a sua produção pelas Tregs é um de seus relevantes mecanismos de supressão, principalmente para a indução de anergia e parada do ciclo celular em G1 (ADLER; STEINBRINK, 2008; SARAIVA; O'GARRA, 2010). Na presença de IL-10 a produção de IFN- $\gamma$, TNF- $\alpha$, IL-6 e IL2 é inibida, bem como a ativação de macrófagos e a produção de espécies reativas de oxigênio e nitrogênio (DUELL et al., 2012). M. leprae induz a produção de IL-10 por PBMC de pacientes com hanseníase e indivíduos saudáveis, e o bloqueio desta citocinas leva ao aumento da produção de IFN- $\gamma$ e TNF- $\alpha$ (MODLIN, 1994). IL-10, assim como TGF- $\beta$, está relacionada à indução de fenótipo regulador em linfócitos na periferia e controle da resposta no sítio da infecção (ADLER; STEINBRINK, 2008; BILATE; LAFAILLE, 2012). Nos 
pacientes com hanseníase tuberculóide não detectamos a presença de IL-10 no infiltrado inflamatório das lesões, o que estaria correlacionado com a menor atividade supressora das células $\mathrm{T} \mathrm{CD}^{+} \mathrm{CD} 25^{+}$destes pacientes. Enquanto que a produção de IL-10 por células T reguladoras em amostras de pacientes com hanseníase virchoviana correlacionaria-se com a persistência do patógeno.

Os linfócitos $\mathrm{T} C D 4^{+} \mathrm{CD} 25^{+}$de pacientes com hanseníase tuberculóide e virchoviana, embora não sejam completamente diferentes quanto à expressão de marcadores fenotípicos, apresentaram distinta capacidade supressora, como constatado no ensaio funcional. As células $\mathrm{T} \mathrm{CD} 4^{+} \mathrm{CD} 25^{+}$isoladas dos pacientes com hanseníase virchoviana inibiram a proliferação de PBMC alogênico, o que possivelmente pode ser influenciado pelo aumento da expressão de moléculas co-inibitórias PD-1, GITR e CTLA-4. As células T CD4 ${ }^{+} \mathrm{CD} 25^{-}$de pacientes com hanseníase virchoviana possuem menor capacidade de estimular a proliferação do PBMC alogênico, quando comparadas às dos pacientes tuberculóides. De acordo com nossos resultados, na paracoccidioidomicose também foi observado que o número de células $\mathrm{T}$ $\mathrm{CD} 4^{+} \mathrm{CD} 25^{+}$isoladas de pacientes não é diferente do grupo controle, mas as células $\mathrm{T}$ reguladoras dos pacientes apresentam maior atividade supressora (CAVASSANI et al., 2006).

Além de inibir a proliferação de PBMC alogênico, as células $\mathrm{T} \mathrm{CD} 4^{+} \mathrm{CD} 25^{+}$isoladas de pacientes com hanseníase virchoviana inibem a produção de IFN- $\gamma$ e TNF- $\alpha$, citocinas importantes para a ativação de macrófagos e conseqüente eliminação do bacilo (HAGGE et al., 2004). IFN- $\gamma$ atua em macrófagos ampliando sua atividade microbicida através da indução de intermediários reativos de oxigênio e nitrogênio (SCHRODER et al., 2004) e na presença de IFN- $\gamma$ macrófagos são capazes de eliminar mais facilmente $M$. leprae (ADAMS et al., 1991; HAGGE et al., 2004; RAMASESH et al., 1991). A sinalização via TNF- $\alpha$ também é necessária à atividade fagocítica dos macrófagos (MOSSER; EDWARDS, 2008; SOEHNLEIN; LINDBOM, 2010) e formação do granuloma, estando positivamente regulada após a infecção com M. leprae (HAGGE et al., 2009; KANG; CHAE, 2011; KRUTZIK et al., 2003), fato que poderia colaborar para a permanência do patógeno nas lesões de pacientes com hanseníase virchoviana.

Acredita-se que não apenas a presença de células $\mathrm{T}$ reguladoras no infiltrado inflamatório das lesões de pacientes com hanseníase, mas também, sua capacidade de inibir a proliferação e produção de citocinas, controlem a qualidade da resposta imune desenvolvida 
contra o bacilo, tornando os indivíduos mais susceptíveis à infecção, como observado nos pacientes com hanseníase virchoviana. Alguns questionamentos surgem sobre quais fatores influenciam a presença e manutenção das células T reguladoras na hanseníase, principalmente porque os antígenos de $M$. leprae modulam diversos aspectos da resposta imune inata e adaptativa, desde a expressão de receptores de reconhecimento padrão em células dendríticas e macrófagos, até a proliferação e ativação de linfócitos, comprometendo a resposta do hospedeiro nesta doença.

Algumas espécies de micobactérias apresentam potencial tolerogênico sobre células apresentadoras de antígenos, sendo Mycobacterium leprae capaz de alterar a maturação de células dendríticas através da ligação às moléculas de DC-SIGN, receptor de lecitina, e induzir a produção de citocinas anti-inflamatórias, como IL-10 (BALBOA et al., 2010; GEIJTENBEEK et al., 2003; GRINGHUIS et al., 2007). Os antígenos de M. leprae induzem a expressão de TLR2, molécula capaz de reconhecer lipoproteínas da parede celular bacteriana e modulam negativamente a produção de diversas citocinas inflamatórias, como IL-1 $\beta$, IL-6, IL-18, TNF- $\alpha$ e IL-18 (KRUTZIK et al., 2003; SINSIMER et al., 2010). M. leprae também altera a diferenciação de monócitos em células dendríticas, reduzindo a expressão de HLADR, de moléculas co-estimulatórias, como CD80 e CD86, e a produção de citocinas como IL12 e IL-6, necessárias à polarização da resposta imune em Th1 (LEE, D.J. et al., 2007; MAKINO et al., 2006; MURRAY et al., 2007). Dessa forma, os macrófagos e células dendríticas de pacientes sob constante estimulação por $M$. leprae são tolerogênicas (DE SOUZA SALES et al., 2011; MOURA et al., 2012; PINHEIRO et al., 2011), o que não apenas limita a redução da ativação de linfócitos efetores mas também favorece ao aumento do número de Tregs induzidas (BILATE; LAFAILLE, 2012; GROUX; FOURNIER; COTTREZ, 2004; STEINMAN; HAWIGER; NUSSENZWEIG, 2003).

Segundo a "teoria do perigo", de Polly Matzinger, o desencadeamento de uma resposta imune é dependente não apenas da presença de um antígeno estranho, mas principalmente do dano que este pode vir a causar ao organismo (MATZINGER, 2002). Neste sentido, o organismo é capaz de tolerar antígenos que não ativam mecanismos de vigilância/alarme do sistema imune (MATZINGER, 2002). Esta indução de tolerância é dependente da apresentação de antígenos em locais como as mucosas e da ausência de coestímulos ou de citocinas inflamatórias (APPLEMAN; BOUSSIOTIS, 2003; WEINER et al., 2011). Dessa forma, antígenos endógenos e exógenos podem induzir tolerância quando 
administrados por via oro-nasal (FRIEDMAN; WEINER, 1994; WEINER et al., 2011) e esse é um dos motivos pelos quais a microbiota residente, em condições de homeostasia, não estimula uma forte resposta imune no trato oral, respiratório e gástrico (FENG; ELSON, 2011; LEE, Y.K.; MAZMANIAN, 2010; TLASKALOVA-HOGENOVA et al., 2004). A presença desta microbiota residente e de baixa patogenicidade também está associada a presença de população de células $\mathrm{T} \mathrm{CD} 4^{+} \mathrm{CD} 25^{+}$com atividade supressora, característica que não é observada em animais germ free (ATARASHI et al., 2011; ISHIKAWA et al., 2008). Outro fator relevante associado à indução de tolerância e formação de Tregs é a estimulação por baixas doses do antígeno (LONG et al., 2011), o que também é capaz de induzir anergia em linfócitos efetores (STEINMAN; HAWIGER; NUSSENZWEIG, 2003).

Em relação à patogênese da hanseníase, desenvolverão a doença apenas indivíduos geneticamente susceptíveis que mantiverem contato íntimo e prolongado com indivíduos bacilíferos. Características peculiares ao M. leprae e à hanseníase, como baixa taxa de replicação do bacilo (cerda de 14 dias), densa camada lipídica externa, transmissão por via oro-nasal e amplo intervalo entre o contato com a bactéria e o desenvolvimento da doença, tornam M. leprae pouco imunogênico e favorecem a indução de tolerância a seus antígenos nas mucosas orais e nasais (CREE; SMITH, 1998; RAMAPRASAD et al., 1997). Dessa forma, é possível que neste microambiente da mucosa oro-nasal, a presença de citocinas antiinflamatórias, como TGF- $\beta$, e a ausência de co-estímulo favoreçam o desenvolvimento de células T reguladoras e limitem o desenvolvimento de uma efetiva resposta imune contra $M$. leprae.

A caracterização dos antígenos de $M$. leprae com propriedades imunogênicas tem sido realizada como parte dos esforços para a produção de uma vacina eficaz conta este bacilo. Proteínas do choque térmico (HSP) e também o PGL-1 são antígenos que possivelmente modulam o sistema imune, induzindo um estado de anergia ou tolerância de células imunes (MARENGO et al., 2008; SINSIMER et al., 2008). Além destas evidências mencionadas acima de que $M$. leprae pode modular a maturação das células apresentadoras de antígenos, antígenos de $M$. leprae também controlam a proliferação de PBMC e induzem aumento no número de linfócitos $\mathrm{T} \mathrm{CD}^{+} \mathrm{CD} 25^{+} \mathrm{FoxP}^{+}$produtores de IL-10 (KUMAR et al., 2011a; PALERMO et al., 2012). Um dos possível mecanismos relacionados à ativação das Tregs pelo bacilo pode ser através da ligação às moléculas de TLR2 e TLR4, como observado em antígenos de $C$. albicans e LPS de S. Typhymurium e E. coli (CARAMALHO et al., 2003; 
KABELITZ; WESCH; OBERG, 2006; SUTMULLER et al., 2006; VAN MAREN et al., 2008). Além disto, HSP obtidas de ovos do parasita Schistosoma japonicum são capazes de induzir a formação de uma população de células $\mathrm{T} C D 4^{+} \mathrm{CD} 25^{+}$através da ligação com TLR2. A caracterização desta proteína revelou que diversas seqüências peptídicas apresentam-se altamente conservadas em diversos organismos os quais apresentam epítopos correspondentes em linfócitos T de humanos e camundongos (SUTMULLER et al., 2006; WANG et al., 2009).

As proteínas do choque térmico, principalmente HSP60, desempenham importante papel na homeostase do organismo e estão relacionadas à formação de nTregs (COELHO; FARIA, 2012). HSP60 potencializa a atividade de Tregs, independentemente da presença de célula apresentadoras de antígenos, e a ativação de TLR2 nestas células limita a fosforilação de ERK e a ativação de NF-אB, além de aumentar a produção de IL-10 e TGF- $\beta$ (ZANINZHOROV et al., 2006). Semelhantemente, altas doses de HSPgp96 também favoreceram o aumento no número de células $\mathrm{T}$ reguladoras em animais com hepatite $\mathrm{B}$ contudo, a exposição a baixas doses desta proteína restabeleceu o número de células citotóxicas e limitou o crescimento de células de melanoma injetadas em animais (LIU et al., 2009). Dessa forma, o potencial imunomodulador das proteínas do choque térmico de $M$. leprae tem sido estudado, e em modelo experimental de alergia induzida por ovalbumina observou-se aumento do número de células $\mathrm{T}$ reguladoras e marcante resposta anti-inflamatória após a imunização com Hsp65 recombinante de M. leprae (FONSECA et al., 2012). No entanto, o efeito modulador desta proteínas ainda não é completamente compreendido e em alguns casos HSP não demonstrou efeitos imunomodulatórios (MARENGO et al., 2009; RODRIGUEZNARCISO et al., 2011), o qual foi restabelecido após mutações pontuais em HSP65 de $M$. leprae recombinante, capaz de controlar o lupus eritematoso sistêmico experimental (MARENGO et al., 2008; MARENGO et al., 2011). Dessa forma, é necessário que se estabeleça quais são as vias de sinalização intracelular e quais populações celulares estão envolvidas com a modulação do sistema imune exercida pelos antígenos de M. leprae, o que pode vir a ser uma das estratégias para controle da rejeição de transplantes e tratamento de doenças auto-imunes.

Nos pacientes com hanseníase, deseja-se que o tratamento seja capaz de reverter o estado de anergia apresentado pelos pacientes virchovianos. Pouco se conhece sobre a reversão do fenótipo regulador em linfócitos $\mathrm{T} \mathrm{CD}^{2} 5^{+} \mathrm{FoxP} 3^{+}$, e quais moléculas determinam 
esta mudança fenotípica, contudo a inibição de Eos, fator de transcrição da família Ikaros, reprime a expressão gênica de genes controlados por FoxP3 e restaura a atividade de linfócitos efetores (PAN et al., 2009). Nos pacientes com hanseníase, o monitoramento da imunossupressão modulada por Tregs pode ser um dos critérios de sucesso do tratamento, principalmente ao término do uso do poliquimioterapia. Há indícios biológicos e epidemiológicos que sugerem que apenas o tratamento poliquimioterápico não é capaz de controlar a doença, o que torna urgente a necessidade de novos métodos de acompanhamento da cura desses pacientes (NSAGHA et al., 2011).

Certamente, a hanseníase ainda será um problema de saúde pública por alguns tempo e sua eliminação parece ser uma meta inatingível (PATRO; MADHANRAJ; SINGH, 2011). Embora seja possível observar uma redução nas estatísticas relacionadas à prevalência e incidência desta doença, estes números são influenciados por medidas como o menor do tempo de tratamento e simplificação do diagnóstico (SMITH; RICHARDUS, 2008), as quais podem estar associadas ao tratamento insuficiente, aumento na resistência medicamentosa do bacilo e manutenção da cadeia de transmissão da doença (NAAFS, 2006). Embora a hanseníase seja tratável e curável, o número de novos casos ainda é elevado em regiões hiperendêmicas e as seqüelas físicas e sociais são recorrentes. A crença de que a hanseníase é uma doença sob controle e que acomete apenas uma pequena parcela da população em áreas hiperendêmicas são fatores que podem estar associados à negligência em seu diagnóstico. Dessa forma, a identificação e o tratamento precoces são medidas que poderiam auxiliar na redução das seqüelas neurais irreversíveis, que é a principal causa dos estigmas provocados pela doença.

As razões para a maior frequencia de Tregs na forma virchoviana da hanseníase não são completamente compreendidas, mas fatores genéticos do hospedeiro associados à características moleculares dos antígenos de M. leprae, via de transmissão do bacilo, estado imunológico do hospedeiro e modulação do microambiante inflamatório (SCOLLARD et al., 2006) possivelmente determinam a magnitude da participação destes linfócitos na resposta imune contra M. leprae. 
Conclusão 



\section{CONCLUSÃO}

Com base nos resultados apresentados, pode-se concluir que:

- A resposta imune de pacientes virchovianos contra M. leprae é modulada pela presença de linfócitos $\mathrm{T}$ reguladores com elevada atividade supressora.

- A alta frequência de células $\mathrm{T}$ reguladoras em pacientes com hanseníase virchoviana relaciona-se com a expressão de moléculas co-inibitórias, a inibição da produção de citocinas inflamatórias e controle local da resposta do hospedeiro através de citocinas anti-inflamatórias.

- Em pacientes com hanseníase tuberculóide ocorre um equilíbrio entre o número de células $\mathrm{T}$ efetoras e reguladoras o que permite o desenvolvimento de resposta imune protetora contra Mycobacterium leprae. 

Referências 



\section{REFERÊNCIAS}

Adams LB, Franzblau SG, Vavrin Z, Hibbs JB, Jr., Krahenbuhl JL. L-arginine-dependent macrophage effector functions inhibit metabolic activity of Mycobacterium leprae. J Immunol. 1991;147(5):1642-6.

Adler HS, Steinbrink K. MAP kinase p38 and its relation to T cell anergy and suppressor function of regulatory T cells. Cell Cycle. 2008;7(2):169-70.

Alberts CJ, Smith WC, Meima A, Wang L, Richardus JH. Potential effect of the World Health Organization's 2011-2015 global leprosy strategy on the prevalence of grade 2 disability: a trend analysis. Bull World Health Organ. 2011;89(7):487-95.

Allan SE, Crome SQ, Crellin NK, Passerini L, Steiner TS, Bacchetta R, et al. Activationinduced FOXP3 in human $\mathrm{T}$ effector cells does not suppress proliferation or cytokine production. Int Immunol. 2007;19(4):345-54.

Alter A, Alcais A, Abel L, Schurr E. Leprosy as a genetic model for susceptibility to common infectious diseases. Hum Genet. 2008;123(3):227-35.

Alter A, Grant A, Abel L, Alcais A, Schurr E. Leprosy as a genetic disease. Mamm Genome. 2011;22(1-2):19-31.

Apoil PA, Puissant B, Roubinet F, Abbal M, Massip P, Blancher A. FOXP3 mRNA levels are decreased in peripheral blood CD4+ lymphocytes from HIV-positive patients. J Acquir Immune Defic Syndr. 2005;39(4):381-5.

Appleman LJ, Boussiotis VA. T cell anergy and costimulation. Immunol Rev. 2003;192:16180 .

Atarashi K, Tanoue T, Shima T, Imaoka A, Kuwahara T, Momose Y, et al. Induction of colonic regulatory T cells by indigenous Clostridium species. Science. 2011;331(6015):33741.

Attia EA, Abdallah M, Saad AA, Afifi A, El Tabbakh A, El-Shennawy D, et al. Circulating CD4+ CD25 high FoxP3+ T cells vary in different clinical forms of leprosy. Int J Dermatol. 2010;49(10):1152-8.

Azuma T, Takahashi T, Kunisato A, Kitamura T, Hirai H. Human CD4+ CD25+ regulatory T cells suppress NKT cell functions. Cancer Res. 2003;63(15):4516-20. 
Bach MA, Launois P. Mechanisms of Mycobacterium leprae-specific T-cell deficiency in lepromatous leprosy. Biochimie. 1988;70(8):1013-8.

Balboa L, Romero MM, Yokobori N, Schierloh P, Geffner L, Basile JI, et al. Mycobacterium tuberculosis impairs dendritic cell response by altering CD1b, DC-SIGN and MR profile. Immunol Cell Biol. 2010;88(7):716-26.

Barreiro LB, Quach H, Krahenbuhl J, Khaliq S, Mohyuddin A, Mehdi SQ, et al. DC-SIGN interacts with Mycobacterium leprae but sequence variation in this lectin is not associated with leprosy in the Pakistani population. Hum Immunol. 2006;67(1-2):102-7.

Belkaid Y, Rouse BT. Natural regulatory $\mathrm{T}$ cells in infectious disease. Nat Immunol. 2005;6(4):353-60.

Belkaid Y. Regulatory $\mathrm{T}$ cells and infection: a dangerous necessity. Nat Rev Immunol. 2007;7(11):875-88.

Berretta F, St-Pierre J, Piccirillo CA, Stevenson MM. IL-2 contributes to maintaining a balance between CD4+Foxp3+ regulatory $\mathrm{T}$ cells and effector CD4+ $\mathrm{T}$ cells required for immune control of blood-stage malaria infection. J Immunol. 2011;186(8):4862-71.

Bilate AM, Lafaille JJ. Induced CD4+Foxp3+ regulatory T cells in immune tolerance. Annu Rev Immunol. 2012;30:733-58.

Blattman JN, Greenberg PD. PD-1 blockade: rescue from a near-death experience. Nat Immunol. 2006;7(3):227-8.

Bloom BR, Modlin RL, Salgame P. Stigma variations: observations on suppressor T cells and leprosy. Annu Rev Immunol. 1992;10:453-88.

Boni C, Fisicaro P, Valdatta C, Amadei B, Di Vincenzo P, Giuberti T, et al. Characterization of hepatitis B virus (HBV)-specific T-cell dysfunction in chronic HBV infection. J Virol. 2007;81(8):4215-25.

Brunkow ME, Jeffery EW, Hjerrild KA, Paeper B, Clark LB, Yasayko SA, et al. Disruption of a new forkhead/winged-helix protein, scurfin, results in the fatal lymphoproliferative disorder of the scurfy mouse. Nat Genet. 2001;27(1):68-73.

Burmeister Y, Lischke T, Dahler AC, Mages HW, Lam KP, Coyle AJ, et al. ICOS controls the pool size of effector-memory and regulatory T cells. J Immunol. 2008;180(2):774-82. 
Campanelli AP, Roselino AM, Cavassani KA, Pereira MS, Mortara RA, Brodskyn CI, et al. CD4+CD25+ $\mathrm{T}$ cells in skin lesions of patients with cutaneous leishmaniasis exhibit phenotypic and functional characteristics of natural regulatory $\mathrm{T}$ cells. $\mathrm{J}$ Infect Dis. 2006;193(9):1313-22.

Campbell DJ, Koch MA. Phenotypical and functional specialization of FOXP3+ regulatory T cells. Nat Rev Immunol. 2011;11(2):119-30.

Caramalho I, Lopes-Carvalho T, Ostler D, Zelenay S, Haury M, Demengeot J. Regulatory T cells selectively express toll-like receptors and are activated by lipopolysaccharide. J Exp Med. 2003;197(4):403-11.

Carpenter AC, Bosselut R. Decision checkpoints in the thymus. Nat Immunol. 2010;11(8):666-73.

Cavassani KA, Campanelli AP, Moreira AP, Vancim JO, Vitali LH, Mamede RC, et al. Systemic and local characterization of regulatory $\mathrm{T}$ cells in a chronic fungal infection in humans. J Immunol. 2006;177(9):5811-8.

Chattree V, Khanna N, Rao DN. Alterations in T cell signal transduction by M. leprae antigens is associated with downregulation of second messengers PKC, calcium, calcineurin, MAPK and various transcription factors in leprosy patients. Mol Immunol. 2007;44(8):206677.

Coelho V, Faria AM. HSP60: issues and insights on its therapeutic use as an immunoregulatory agent. Front Immunol. 2012;2:97.

Cohn ZA, Kaplan G. Hansen's disease, cell-mediated immunity, and recombinant lymphokines. J Infect Dis. 1991;163(6):1195-200.

Cole ST, Eiglmeier K, Parkhill J, James KD, Thomson NR, Wheeler PR, et al. Massive gene decay in the leprosy bacillus. Nature. 2001;409(6823):1007-11.

Collison LW, Murphy EJ, Jolly CA. Glycerol-3-phosphate acyltransferase-1 regulates murine T-lymphocyte proliferation and cytokine production. Am $\mathrm{J}$ Physiol Cell Physiol. 2008;295(6):C1543-9.

Collison LW, Vignali DA. Interleukin-35: odd one out or part of the family? Immunol Rev. 2008;226:248-62.

Cree IA, Smith WC. Leprosy transmission and mucosal immunity: towards eradication? Lepr Rev. 1998;69(2):112-21. 
Curotto de Lafaille MA, Lafaille JJ. Natural and adaptive foxp3+ regulatory T cells: more of the same or a division of labor? Immunity. 2009;30(5):626-35.

Dagur PK, Sharma B, Kumar G, Khan NA, Katoch VM, Sengupta U, et al. Mycobacterial antigen(s) induce anergy by altering TCR- and TCR/CD28-induced signalling events: insights into T-cell unresponsiveness in leprosy. Mol Immunol. 2010;47(5):943-52.

Darrasse-Jeze G, Deroubaix S, Mouquet H, Victora GD, Eisenreich T, Yao KH, et al. Feedback control of regulatory $\mathrm{T}$ cell homeostasis by dendritic cells in vivo. J Exp Med. 2009;206(9):1853-62.

de Souza Sales J, Lara FA, Amadeu TP, de Oliveira Fulco T, da Costa Nery JA, Sampaio EP, et al. The role of indoleamine 2, 3-dioxygenase in lepromatous leprosy immunosuppression. Clin Exp Immunol. 2011;165(2):251-63.

Deaglio S, Dwyer KM, Gao W, Friedman D, Usheva A, Erat A, et al. Adenosine generation catalyzed by CD39 and CD73 expressed on regulatory T cells mediates immune suppression. J Exp Med. 2007;204(6):1257-65.

Duell BL, Tan CK, Carey AJ, Wu F, Cripps AW, Ulett GC. Recent insights into microbial triggers of interleukin-10 production in the host and the impact on infectious disease pathogenesis. FEMS Immunol Med Microbiol. 2012;64(3):295-313.

Duthie MS, Goto W, Ireton GC, Reece ST, Sampaio LH, Grassi AB, et al. Antigen-specific T-cell responses of leprosy patients. Clin Vaccine Immunol. 2008;15(11):1659-65.

Dwyer KM, Deaglio S, Gao W, Friedman D, Strom TB, Robson SC. CD39 and control of cellular immune responses. Purinergic Signal. 2007;3(1-2):171-80.

Feng T, Elson CO. Adaptive immunity in the host-microbiota dialog. Mucosal Immunol. 2011;4(1):15-21.

Feuerer M, Hill JA, Mathis D, Benoist C. Foxp3+ regulatory T cells: differentiation, specification, subphenotypes. Nat Immunol. 2009;10(7):689-95.

Fife BT, Bluestone JA. Control of peripheral T-cell tolerance and autoimmunity via the CTLA-4 and PD-1 pathways. Immunol Rev. 2008;224:166-82.

Fitness J, Tosh K, Hill AV. Genetics of susceptibility to leprosy. Genes Immun. 2002;3(8):441-53. 
Flad HD, Arnoldi J, Ohlert A, Kazda J, Gerdes J. Cytokine production and proliferative capacity of infiltrating cells in various forms of leprosy. Trop Med Parasitol. 1990;41(3):3079.

Fonseca DM, Wowk PF, Paula MO, Campos LW, Gembre AF, Turato WM, et al. Recombinant DNA immunotherapy ameliorate established airway allergy in a IL-10 dependent pathway. Clin Exp Allergy. 2012;42(1):131-43.

Fontenot JD, Rasmussen JP, Gavin MA, Rudensky AY. A function for interleukin 2 in Foxp3-expressing regulatory T cells. Nat Immunol. 2005;6(11):1142-51.

Fontenot JD, Rudensky AY. Molecular aspects of regulatory T cell development. Semin Immunol. 2004;16(2):73-80.

Francisco LM, Sage PT, Sharpe AH. The PD-1 pathway in tolerance and autoimmunity. Immunol Rev. 2010;236:219-42.

Francisco LM, Salinas VH, Brown KE, Vanguri VK, Freeman GJ, Kuchroo VK, et al. PD-L1 regulates the development, maintenance, and function of induced regulatory $\mathrm{T}$ cells. $\mathrm{J}$ Exp Med. 2009;206(13):3015-29.

Friedman A, Weiner HL. Induction of anergy or active suppression following oral tolerance is determined by antigen dosage. Proc Natl Acad Sci U S A. 1994;91(14):6688-92.

Garcia VE, Uyemura K, Sieling PA, Ochoa MT, Morita CT, Okamura H, et al. IL-18 promotes type 1 cytokine production from NK cells and $\mathrm{T}$ cells in human intracellular infection. J Immunol. 1999;162(10):6114-21.

Garidou L, Heydari S, Gossa S, McGavern DB. Therapeutic blockade of transforming growth factor beta fails to promote clearance of a persistent viral infection. $J$ Virol. 2012;86(13):7060-71.

Geijtenbeek TB, Van Vliet SJ, Koppel EA, Sanchez-Hernandez M, Vandenbroucke-Grauls CM, Appelmelk B, et al. Mycobacteria target DC-SIGN to suppress dendritic cell function. J Exp Med. 2003;197(1):7-17.

Geluk A, Ottenhoff TH. HLA and leprosy in the pre and postgenomic eras. Hum Immunol. 2006;67(6):439-45.

Gottschalk RA, Corse E, Allison JP. TCR ligand density and affinity determine peripheral induction of Foxp3 in vivo. J Exp Med. 2010;207(8):1701-11. 
Grader-Beck T, van Puijenbroek AA, Nadler LM, Boussiotis VA. cAMP inhibits both Ras and Rap1 activation in primary human T lymphocytes, but only Ras inhibition correlates with blockade of cell cycle progression. Blood. 2003;101(3):998-1006.

Greenwald RJ, Boussiotis VA, Lorsbach RB, Abbas AK, Sharpe AH. CTLA-4 regulates induction of anergy in vivo. Immunity. 2001;14(2):145-55.

Greenwald RJ, Oosterwegel MA, van der Woude D, Kubal A, Mandelbrot DA, Boussiotis VA, et al. CTLA-4 regulates cell cycle progression during a primary immune response. Eur $\mathbf{J}$ Immunol. 2002;32(2):366-73.

Gringhuis SI, den Dunnen J, Litjens M, van Het Hof B, van Kooyk Y, Geijtenbeek TB. Ctype lectin DC-SIGN modulates Toll-like receptor signaling via Raf-1 kinase-dependent acetylation of transcription factor NF-kappaB. Immunity. 2007;26(5):605-16.

Groux H, Fournier N, Cottrez F. Role of dendritic cells in the generation of regulatory T cells. Semin Immunol. 2004;16(2):99-106.

Guckel E, Frey S, Zaiss MM, Schett G, Ghosh S, Voll RE. Cell-intrinsic NF-kappaB activation is critical for the development of natural regulatory $\mathrm{T}$ cells in mice. PLoS One. 2011;6(5):e20003.

Gutierrez FR, Mariano FS, Oliveira CJ, Pavanelli WR, Guedes PM, Silva GK, et al. Regulation of Trypanosoma cruzi-induced myocarditis by programmed death cell receptor 1 . Infect Immun. 2011;79(5):1873-81.

Hafalla JC, Claser C, Couper KN, Grau GE, Renia L, de Souza JB, et al. The CTLA-4 and PD-1/PD-L1 inhibitory pathways independently regulate host resistance to Plasmodiuminduced acute immune pathology. PLoS Pathog. 2012;8(2):e1002504.

Hagge DA, Ray NA, Krahenbuhl JL, Adams LB. An in vitro model for the lepromatous leprosy granuloma: fate of Mycobacterium leprae from target macrophages after interaction with normal and activated effector macrophages. J Immunol. 2004;172(12):7771-9.

Hagge DA, Saunders BM, Ebenezer GJ, Ray NA, Marks VT, Britton WJ, et al. Lymphotoxinalpha and TNF have essential but independent roles in the evolution of the granulomatous response in experimental leprosy. Am J Pathol. 2009;174(4):1379-89.

Han XY, Sizer KC, Thompson EJ, Kabanja J, Li J, Hu P, et al. Comparative sequence analysis of Mycobacterium leprae and the new leprosy-causing Mycobacterium lepromatosis. J Bacteriol. 2009;191(19):6067-74. 
Harada Y, Elly C, Ying G, Paik JH, DePinho RA, Liu YC. Transcription factors Foxo3a and Foxo1 couple the E3 ligase Cbl-b to the induction of Foxp3 expression in induced regulatory T cells. J Exp Med. 2010;207(7):1381-91.

Haribhai D, Williams JB, Jia S, Nickerson D, Schmitt EG, Edwards B, et al. A requisite role for induced regulatory $\mathrm{T}$ cells in tolerance based on expanding antigen receptor diversity. Immunity. 2011;35(1):109-22.

Hasko G, Linden J, Cronstein B, Pacher P. Adenosine receptors: therapeutic aspects for inflammatory and immune diseases. Nat Rev Drug Discov. 2008;7(9):759-70.

Hett EC, Rubin EJ. Bacterial growth and cell division: a mycobacterial perspective. Microbiol Mol Biol Rev. 2008;72(1):126-56, table of contents.

Hori S, Nomura T, Sakaguchi S. Control of regulatory T cell development by the transcription factor Foxp3. Science. 2003;299(5609):1057-61.

Hotez PJ, Aksoy S. An interfaith dialogue on the neglected tropical diseases. PLoS Negl Trop Dis. 2011;5(12):e1240.

Huehn J, Hamann A. Homing to suppress: address codes for Treg migration. Trends Immunol. 2005 Dec;26(12):632-6.

Iellem A, Mariani M, Lang R, Recalde H, Panina-Bordignon P, Sinigaglia F, et al. Unique chemotactic response profile and specific expression of chemokine receptors CCR4 and CCR8 by CD4 ${ }^{+} \mathrm{CD} 25^{+}$regulatory T cells. J. Exp. Med. 2001. 194: 847-853.

Ishikawa H, Tanaka K, Maeda Y, Aiba Y, Hata A, Tsuji NM, et al. Effect of intestinal microbiota on the induction of regulatory CD25+ CD4+ $\mathrm{T}$ cells. Clin Exp Immunol. 2008;153(1):127-35.

Ito T, Hanabuchi S, Wang YH, Park WR, Arima K, Bover L, et al. Two functional subsets of FOXP3+ regulatory T cells in human thymus and periphery. Immunity. 2008;28(6):870-80.

Jo EK. Mycobacterial interaction with innate receptors: TLRs, C-type lectins, and NLRs. Curr Opin Infect Dis. 2008;21(3):279-86.

Jonuleit $\mathrm{H}$, Schmitt E. The regulatory T cell family: distinct subsets and their interrelations. J Immunol. 2003;171(12):6323-7. 
Josefowicz SZ, Rudensky A. Control of regulatory $\mathrm{T}$ cell lineage commitment and maintenance. Immunity. 2009;30(5):616-25.

Kabelitz D, Wesch D, Oberg HH. Regulation of regulatory T cells: role of dendritic cells and toll-like receptors. Crit Rev Immunol. 2006;26(4):291-306.

Kang TJ, Chae GT. The Role of Intracellular Receptor NODs for Cytokine Production by Macrophages Infected with Mycobacterium leprae. Immune Netw. 2011;11(6):424-7.

Kang TJ, Yeum CE, Kim BC, You EY, Chae GT. Differential production of interleukin-10 and interleukin-12 in mononuclear cells from leprosy patients with a Toll-like receptor 2 mutation. Immunology. 2004;112(4):674-80.

Kaplan G, Britton WJ, Hancock GE, Theuvenet WJ, Smith KA, Job CK, et al. The systemic influence of recombinant interleukin 2 on the manifestations of lepromatous leprosy. J Exp Med. 1991;173(4):993-1006.

Kaplan G, Weinstein DE, Steinman RM, Levis WR, Elvers U, Patarroyo ME, et al. An analysis of in vitro $\mathrm{T}$ cell responsiveness in lepromatous leprosy. $\mathrm{J}$ Exp Med. 1985;162(3):917-29.

Kaplan G. Recent advances in cytokine therapy in leprosy. J Infect Dis. 1993;167 Suppl 1:S18-22.

Keir ME, Butte MJ, Freeman GJ, Sharpe AH. PD-1 and its ligands in tolerance and immunity. Annu Rev Immunol. 2008;26:677-704.

Khanolkar-Young S, Snowdon D, Lockwood DN. Immunocytochemical localization of inducible nitric oxide synthase and transforming growth factor-beta (TGF-beta) in leprosy lesions. Clin Exp Immunol. 1998;113(3):438-42.

Kiszewski CA, Becerril E, Baquera J, Aguilar LD, Hernandez-Pando R. Expression of transforming growth factor-beta isoforms and their receptors in lepromatous and tuberculoid leprosy. Scand J Immunol. 2003;57(3):279-85.

Kmieciak M, Gowda M, Graham L, Godder K, Bear HD, Marincola FM, et al. Human T cells express CD25 and Foxp3 upon activation and exhibit effector/memory phenotypes without any regulatory/suppressor function. J Transl Med. 2009;7:89.

Ko K, Yamazaki S, Nakamura K, Nishioka T, Hirota K, Yamaguchi T, et al. Treatment of advanced tumors with agonistic anti-GITR $\mathrm{mAb}$ and its effects on tumor-infiltrating Foxp3+CD25+CD4+ regulatory T cells. J Exp Med. 2005;202(7):885-91. 
Krutzik SR, Ochoa MT, Sieling PA, Uematsu S, Ng YW, Legaspi A, et al. Activation and regulation of Toll-like receptors 2 and 1 in human leprosy. Nat Med. 2003;9(5):525-32.

Kumar S, Naqvi RA, Khanna N, Pathak P, Rao DN. Th3 immune responses in the progression of leprosy via molecular cross-talks of TGF-beta, CTLA-4 and Cbl-b. Clin Immunol. 2011a;141(2):133-42.

Kumar S, Naqvi RA, Khanna N, Rao DN. Disruption of HLA-DR raft, deregulations of LckZAP-70-Cbl-b cross-talk and miR181a towards $\mathrm{T}$ cell hyporesponsiveness in leprosy. Mol Immunol. 2011b;48(9-10):1178-90.

Kupper TS, Fuhlbrigge RC. Immune surveillance in the skin: mechanisms and clinical consequences. Nat Rev Immunol. 2004;4(3):211-22.

Lal G, Bromberg JS. Epigenetic mechanisms of regulation of Foxp3 expression. Blood. 2009;114(18):3727-35.

Lange C, Scholl M, Melms A, Bischof F. CD62L(high) Treg cells with superior immunosuppressive properties accumulate within the CNS during remissions of EAE. Brain Behav Immun. 2011;25(1):120-6.

Lavania M, Katoch K, Katoch VM, Gupta AK, Chauhan DS, Sharma R, et al. Detection of viable Mycobacterium leprae in soil samples: insights into possible sources of transmission of leprosy. Infect Genet Evol. 2008;8(5):627-31.

Lee AJ, Wu X, Cheng H, Zhou X, Cheng X, Sun SC. CARMA1 regulation of regulatory T cell development involves modulation of interleukin-2 receptor signaling. J Biol Chem. 2010;285(21):15696-703.

Lee DJ, Sieling PA, Ochoa MT, Krutzik SR, Guo B, Hernandez M, et al. LILRA2 activation inhibits dendritic cell differentiation and antigen presentation to $\mathrm{T}$ cells. $\mathrm{J}$ Immunol. 2007;179(12):8128-36.

Lee YK, Mazmanian SK. Has the microbiota played a critical role in the evolution of the adaptive immune system? Science. 2010;330(6012):1768-73.

Letterio JJ, Roberts AB. Regulation of immune responses by TGF-beta. Annu Rev Immunol. 1998;16:137-61.

Li MO, Flavell RA. TGF-beta: a master of all T cell trades. Cell. 2008;134(3):392-404. 
Liang S, Alard P, Zhao Y, Parnell S, Clark SL, Kosiewicz MM. Conversion of CD4+ CD25cells into $\mathrm{CD} 4+\mathrm{CD} 25+$ regulatory $\mathrm{T}$ cells in vivo requires $\mathrm{B} 7$ costimulation, but not the thymus. J Exp Med. 2005;201(1):127-37.

Liu Z, Li X, Qiu L, Zhang X, Chen L, Cao S, et al. Treg suppress CTL responses upon immunization with HSP gp96. Eur J Immunol. 2009;39(11):3110-20.

Lockwood DN. Leprosy--a changing picture but a continuing challenge. Trop Doct. 2005;35(2):65-7.

Long SA, Rieck M, Tatum M, Bollyky PL, Wu RP, Muller I, et al. Low-dose antigen promotes induction of FOXP3 in human CD4+ T cells. J Immunol. 2011;187(7):3511-20.

Lu LF, Rudensky A. Molecular orchestration of differentiation and function of regulatory $\mathrm{T}$ cells. Genes Dev. 2009;23(11):1270-82.

Makino M, Maeda Y, Mukai T, Kaufmann SH. Impaired maturation and function of dendritic cells by mycobacteria through IL-1beta. Eur J Immunol. 2006;36(6):1443-52.

Marengo EB, Commodaro AG, Peron JP, de Moraes LV, Portaro FC, Belfort R, Jr., et al. Administration of Mycobacterium leprae rHsp65 aggravates experimental autoimmune uveitis in mice. PLoS One. 2009;4(11):e7912.

Marengo EB, de Moraes LV, Faria M, Fernandes BL, Carvalho LV, Tambourgi DV, et al. Administration of M. leprae Hsp65 interferes with the murine lupus progression. PLoS One. 2008;3(8):e3025.

Marengo EB, de Moraes LV, Melo RL, Balan A, Fernandes BL, Tambourgi DV, et al. A Mycobacterium leprae Hsp65 mutant as a candidate for mitigating lupus aggravation in mice. PLoS One. 2011;6(9):e24093.

Marson A, Kretschmer K, Frampton GM, Jacobsen ES, Polansky JK, MacIsaac KD, et al. Foxp3 occupancy and regulation of key target genes during T-cell stimulation. Nature. 2007;445(7130):931-5.

Massone C, Nunzi E, Ribeiro-Rodrigues R, Talhari C, Talhari S, Schettini AP, et al. T regulatory cells and plasmocytoid dentritic cells in hansen disease: a new insight into pathogenesis? Am J Dermatopathol. 2010;32(3):251-6.

Mattos KA, D'Avila H, Rodrigues LS, Oliveira VG, Sarno EN, Atella GC, et al. Lipid droplet formation in leprosy: Toll-like receptor-regulated organelles involved in eicosanoid formation and Mycobacterium leprae pathogenesis. J Leukoc Biol. 2010;87(3):371-84. 
Matzinger P. The danger model: a renewed sense of self. Science. 2002;296(5566):301-5.

Mellor AL, Munn DH. IDO expression by dendritic cells: tolerance and tryptophan catabolism. Nat Rev Immunol. 2004;4(10):762-74.

Ministério da Saúde B. Guia para o controle da Hanseníase. Brasília: Ministério da Saúde; 2002.

Miranda A, Amadeu TP, Schueler G, Alvarenga FB, Duppre N, Ferreira H, et al. Increased Langerhans cell accumulation after mycobacterial stimuli. Histopathology. 2007;51(5):64956.

Misch EA, Berrington WR, Vary JC, Jr., Hawn TR. Leprosy and the human genome. Microbiol Mol Biol Rev. 2010;74(4):589-620.

Miyao T, Floess S, Setoguchi R, Luche H, Fehling HJ, Waldmann H, et al. Plasticity of Foxp3(+) $\mathrm{T}$ cells reflects promiscuous Foxp3 expression in conventional $\mathrm{T}$ cells but not reprogramming of regulatory $\mathrm{T}$ cells. Immunity. 2012;36(2):262-75.

Modlin RL, Mehra V, Wong L, Fujimiya Y, Chang WC, Horwitz DA, et al. Suppressor T lymphocytes from lepromatous leprosy skin lesions. J Immunol. 1986;137(9):2831-4.

Modlin RL, Melancon-Kaplan J, Young SM, Pirmez C, Kino H, Convit J, et al. Learning from lesions: patterns of tissue inflammation in leprosy. Proc Natl Acad Sci U S A. 1988;85(4):1213-7.

Modlin RL. Th1-Th2 paradigm: insights from leprosy. J Invest Dermatol. 1994;102(6):82832.

Modlin RL. The innate immune response in leprosy. Curr Opin Immunol. 2010;22(1):48-54.

Monot M, Honore N, Garnier T, Araoz R, Coppee JY, Lacroix C, et al. On the origin of leprosy. Science. 2005;308(5724):1040-2.

Montoya D, Cruz D, Teles RM, Lee DJ, Ochoa MT, Krutzik SR, et al. Divergence of macrophage phagocytic and antimicrobial programs in leprosy. Cell Host Microbe. 2009;6(4):343-53.

Moorman JP, Wang JM, Zhang Y, Ji XJ, Ma CJ, Wu XY, et al. Tim-3 Pathway Controls Regulatory and Effector $\mathrm{T}$ Cell Balance during Hepatitis $\mathrm{C}$ Virus Infection. J Immunol. 2012;189(2):755-66. 
Moreira AP, Cavassani KA, Massafera Tristao FS, Campanelli AP, Martinez R, Rossi MA, et al. CCR5-dependent regulatory $\mathrm{T}$ cell migration mediates fungal survival and severe immunosuppression. J Immunol. 2008;180(5):3049-56.

Morelli AE, Thomson AW. Tolerogenic dendritic cells and the quest for transplant tolerance. Nat Rev Immunol. 2007;7(8):610-21.

Mosser DM, Edwards JP. Exploring the full spectrum of macrophage activation. Nat Rev Immunol. 2008;8(12):958-69.

Moura DF, Mattos KA, Amadeu TP, Andrade PR, Sales JS, Schmitz V, et al. CD163 favors Mycobacterium leprae survival and persistence by promoting anti - inflammatory pathways in lepromatous macrophages. Eur J Immunol. 2012.

Murray RA, Siddiqui MR, Mendillo M, Krahenbuhl J, Kaplan G. Mycobacterium leprae inhibits dendritic cell activation and maturation. J Immunol. 2007;178(1):338-44.

Mutis T, Cornelisse YE, Datema G, van den Elsen PJ, Ottenhoff TH, de Vries RR. Definition of a human suppressor T-cell epitope. Proc Natl Acad Sci U S A. 1994;91(20):9456-60.

Mutis T, Kraakman EM, Cornelisse YE, Haanen JB, Spits H, De Vries RR, et al. Analysis of cytokine production by Mycobacterium-reactive $\mathrm{T}$ cells. Failure to explain Mycobacterium leprae-specific nonresponsiveness of peripheral blood $\mathrm{T}$ cells from lepromatous leprosy patients. J Immunol. 1993;150(10):4641-51.

Naafs B. Treatment of leprosy: science or politics? Trop Med Int Health. 2006;11(3):268-78.

Nestle FO, Di Meglio P, Qin JZ, Nickoloff BJ. Skin immune sentinels in health and disease. Nat Rev Immunol. 2009;9(10):679-91.

Netea MG, Sutmuller R, Hermann C, Van der Graaf CA, Van der Meer JW, van Krieken JH, et al. Toll-like receptor 2 suppresses immunity against Candida albicans through induction of IL-10 and regulatory T cells. J Immunol. 2004;172(6):3712-8.

Nishioka T, Nishida E, Iida R, Morita A, Shimizu J. In vivo expansion of CD4+Foxp3+ regulatory T cells mediated by GITR molecules. Immunol Lett. 2008;121(2):97-104.

Nsagha DS, Bamgboye EA, Assob JC, Njunda AL, Kamga HL, Zoung-Kanyi Bissek AC, et al. Elimination of leprosy as a public health problem by 2000 AD: an epidemiological perspective. Pan Afr Med J. 2011;9:4. 
Ochoa MT, Loncaric A, Krutzik SR, Becker TC, Modlin RL. "Dermal dendritic cells" comprise two distinct populations: CD1+ dendritic cells and CD209+ macrophages. J Invest Dermatol. 2008;128(9):2225-31.

Oderup C, Cederbom L, Makowska A, Cilio CM, Ivars F. Cytotoxic T lymphocyte antigen-4dependent down-modulation of costimulatory molecules on dendritic cells in CD4+ CD25+ regulatory T-cell-mediated suppression. Immunology. 2006;118(2):240-9.

Ottenhoff TH, Elferink DG, Klatser PR, de Vries RR. Cloned suppressor T cells from a lepromatous leprosy patient suppress Mycobacterium leprae reactive helper T cells. Nature. 1986;322(6078):462-4.

Palermo ML, Pagliari C, Trindade MA, Yamashitafuji TM, Duarte AJ, Cacere CR, et al. Increased expression of regulatory $\mathrm{T}$ cells and down-regulatory molecules in lepromatous leprosy. Am J Trop Med Hyg. 2012;86(5):878-83.

Pan F, Yu H, Dang EV, Barbi J, Pan X, Grosso JF, et al. Eos mediates Foxp3-dependent gene silencing in CD4+ regulatory T cells. Science. 2009;325(5944):1142-6.

Patro BK, Madhanraj K, Singh A. Is leprosy 'elimination' a conceptual illusion? Indian J Dermatol Venereol Leprol. 2011;77(5):549-51.

Peng G, Li S, Wu W, Tan X, Chen Y, Chen Z. PD-1 upregulation is associated with HBVspecific T cell dysfunction in chronic hepatitis B patients. Mol Immunol. 2008;45(4):963-70.

Penttila T, Haveri A, Tammiruusu A, Vuola JM, Lahesmaa R, Puolakkainen M. Chlamydia pneumoniae infection in IL-10 knock out mice: accelerated clearance but severe pulmonary inflammatory response. Microb Pathog. 2008;45(1):25-9.

Pinheiro RO, de Souza Salles J, Sarno EN, Sampaio EP. Mycobacterium leprae-host-cell interactions and genetic determinants in leprosy: an overview. Future Microbiol. 2011;6(2):217-30.

Polanczyk MJ, Hopke C, Vandenbark AA, Offner H. Treg suppressive activity involves estrogen-dependent expression of programmed death-1 (PD-1). Int Immunol. 2007 Mar;19(3):337-43.

Prado Montes de Oca E. Human polymorphisms as clinical predictors in leprosy. J Trop Med. 2011;2011:923943.

Puccetti P, Grohmann U. IDO and regulatory T cells: a role for reverse signalling and noncanonical NF-kappaB activation. Nat Rev Immunol. 2007;7(10):817-23. 
Qureshi MH, Harmsen AG, Garvy BA. IL-10 modulates host responses and lung damage induced by Pneumocystis carinii infection. J Immunol. 2003;170(2):1002-9.

Qureshi OS, Zheng Y, Nakamura K, Attridge K, Manzotti C, Schmidt EM, et al. Transendocytosis of CD80 and CD86: a molecular basis for the cell-extrinsic function of CTLA-4. Science. 2011;332(6029):600-3.

Ramakrishnan L. Revisiting the role of the granuloma in tuberculosis. Nat Rev Immunol. 2012;12(5):352-66.

Ramaprasad P, Fernando A, Madhale S, Rao JR, Edward VK, Samson PD, et al. Transmission and protection in leprosy: indications of the role of mucosal immunity. Lepr Rev. 1997;68(4):301-15.

Ramasesh N, Adams LB, Franzblau SG, Krahenbuhl JL. Effects of activated macrophages on Mycobacterium leprae. Infect Immun. 1991;59(9):2864-9.

Rambukkana A. Molecular basis for the peripheral nerve predilection of Mycobacterium leprae. Curr Opin Microbiol. 2001;4(1):21-7.

Rea TH. Suppressor cell activity and phenotypes in the blood or tissues of patients with leprosy. Clin Exp Immunol. 1983;54(2):298-304.

Relland LM, Mishra MK, Haribhai D, Edwards B, Ziegelbauer J, Williams CB. Affinitybased selection of regulatory $\mathrm{T}$ cells occurs independent of agonist-mediated induction of Foxp3 expression. J Immunol. 2009;182(3):1341-50.

Ridley DS, Jopling WH. Classification of leprosy according to immunity. A five-group system. Int J Lepr Other Mycobact Dis. 1966;34(3):255-73.

Rodrigues LC, Lockwood D. Leprosy now: epidemiology, progress, challenges, and research gaps. Lancet Infect Dis. 2011;11(6):464-70.

Rodriguez-Narciso C, Perez-Tapia M, Rangel-Cano RM, Silva CL, Meckes-Fisher M, Salgado-Garciglia R, et al. Expression of Mycobacterium leprae HSP65 in tobacco and its effectiveness as an oral treatment in adjuvant-induced arthritis. Transgenic Res. 2011;20(2):221-9.

Rubtsov YP, Niec RE, Josefowicz S, Li L, Darce J, Mathis D, et al. Stability of the regulatory T cell lineage in vivo. Science. 2010;329(5999):1667-71. 
Sacks D, Anderson C. Re-examination of the immunosuppressive mechanisms mediating non-cure of Leishmania infection in mice. Immunol Rev. 2004;201:225-38.

Sakaguchi S, Sakaguchi N, Asano M, Itoh M, Toda M. Immunologic self-tolerance maintained by activated T cells expressing IL-2 receptor alpha-chains (CD25). Breakdown of a single mechanism of self-tolerance causes various autoimmune diseases. J Immunol. 1995;155(3):1151-64.

Saraiva M, O'Garra A. The regulation of IL-10 production by immune cells. Nat Rev Immunol. 2010;10(3):170-81.

Schaer DA, Murphy JT, Wolchok JD. Modulation of GITR for cancer immunotherapy. Curr Opin Immunol. 2012;24(2):217-24.

Schlienger K, Uyemura K, Jullien D, Sieling PA, Rea TH, Linsley PS, et al. B7-1, but not $\mathrm{CD} 28$, is crucial for the maintenance of the CD4+ $\mathrm{T}$ cell responses in human leprosy. $\mathrm{J}$ Immunol. 1998;161(5):2407-13.

Schroder K, Hertzog PJ, Ravasi T, Hume DA. Interferon-gamma: an overview of signals, mechanisms and functions. J Leukoc Biol. 2004;75(2):163-89.

Scollard DM, Adams LB, Gillis TP, Krahenbuhl JL, Truman RW, Williams DL. The continuing challenges of leprosy. Clin Microbiol Rev. 2006;19(2):338-81.

Sharpe AH, Wherry EJ, Ahmed R, Freeman GJ. The function of programmed cell death 1 and its ligands in regulating autoimmunity and infection. Nat Immunol. 2007;8(3):239-45.

Shevach EM, Stephens GL. The GITR-GITRL interaction: co-stimulation or contrasuppression of regulatory activity? Nat Rev Immunol. 2006;6(8):613-8.

Shevach EM. CD4+ CD25+ suppressor T cells: more questions than answers. Nat Rev Immunol. 2002;2(6):389-400.

Shevach EM. Mechanisms of foxp3+ T regulatory cell-mediated suppression. Immunity. 2009;30(5):636-45.

Shimizu J, Yamazaki S, Takahashi T, Ishida Y, Sakaguchi S. Stimulation of CD25(+)CD4(+) regulatory $\mathrm{T}$ cells through GITR breaks immunological self-tolerance. Nat Immunol. 2002;3(2):135-42. 
Shortman K, Naik SH. Steady-state and inflammatory dendritic-cell development. Nat Rev Immunol. 2007;7(1):19-30.

Sieling PA, Abrams JS, Yamamura M, Salgame P, Bloom BR, Rea TH, et al. Immunosuppressive roles for IL-10 and IL-4 in human infection. In vitro modulation of T cell responses in leprosy. J Immunol. 1993;150(12):5501-10.

Sieling PA, Jullien D, Dahlem M, Tedder TF, Rea TH, Modlin RL, et al. CD1 expression by dendritic cells in human leprosy lesions: correlation with effective host immunity. J Immunol. 1999;162(3):1851-8.

Sieling PA, Modlin RL. Regulation of cytokine patterns in leprosy. Ann N Y Acad Sci. 1994;730:42-52.

Simpson TR, Quezada SA, Allison JP. Regulation of CD4 T cell activation and effector function by inducible costimulator (ICOS). Curr Opin Immunol. 2010;22(3):326-32.

Sinsimer D, Fallows D, Peixoto B, Krahenbuhl J, Kaplan G, Manca C. Mycobacterium leprae actively modulates the cytokine response in naive human monocytes. Infect Immun. 2010;78(1):293-300.

Sinsimer D, Huet G, Manca C, Tsenova L, Koo MS, Kurepina N, et al. The phenolic glycolipid of Mycobacterium tuberculosis differentially modulates the early host cytokine response but does not in itself confer hypervirulence. Infect Immun. 2008;76(7):3027-36.

Smith C, Richardus JH. Leprosy strategy is about control, not eradication. Lancet. 2008;371(9617):969-70.

Soehnlein O, Lindbom L. Phagocyte partnership during the onset and resolution of inflammation. Nat Rev Immunol. 2010;10(6):427-39.

Sridevi K, Neena K, Chitralekha KT, Arif AK, Tomar D, Rao DN. Expression of costimulatory molecules (CD80, CD86, CD28, CD152), accessory molecules (TCR alphabeta, TCR gammadelta) and $\mathrm{T}$ cell lineage molecules (CD4+, CD8+) in PBMC of leprosy patients using Mycobacterium leprae antigen (MLCWA) with murabutide and T cell peptide of Trat protein. Int Immunopharmacol. 2004;4(1):1-14.

Steinman RM, Hawiger D, Nussenzweig MC. Tolerogenic dendritic cells. Annu Rev Immunol. 2003;21:685-711.

Suffia I, Reckling SK, Salay G, Belkaid Y. A role for CD103 in the retention of CD4+CD25+ Treg and control of Leishmania major infection. J Immunol. 2005;174(9):5444-55. 
Sullivan L, Sano S, Pirmez C, Salgame P, Mueller C, Hofman F, et al. Expression of adhesion molecules in leprosy lesions. Infect Immun. 1991;59(11):4154-60.

Sutmuller RP, den Brok MH, Kramer M, Bennink EJ, Toonen LW, Kullberg BJ, et al. Tolllike receptor 2 controls expansion and function of regulatory $\mathrm{T}$ cells. $\mathrm{J}$ Clin Invest. 2006;116(2):485-94.

Suzuki K, Akama T, Kawashima A, Yoshihara A, Yotsu RR, Ishii N. Current status of leprosy: epidemiology, basic science and clinical perspectives. J Dermatol. 2012;39(2):121-9.

Tabouret G, Astarie-Dequeker C, Demangel C, Malaga W, Constant P, Ray A, et al. Mycobacterium leprae phenolglycolipid-1 expressed by engineered M. bovis BCG modulates early interaction with human phagocytes. PLoS Pathog. 2010;6(10):e1001159.

Takahashi T, Kuniyasu Y, Toda M, Sakaguchi N, Itoh M, Iwata M, et al. Immunologic selftolerance maintained by CD25+CD4+ naturally anergic and suppressive T cells: induction of autoimmune disease by breaking their anergic/suppressive state. Int Immunol. 1998;10(12):1969-80.

Tang Q, Bluestone JA. The Foxp3+ regulatory $\mathrm{T}$ cell: a jack of all trades, master of regulation. Nat Immunol. 2008;9(3):239-44.

Tanigawa K, Suzuki K, Kimura H, Takeshita F, Wu H, Akama T, et al. Tryptophan aspartatecontaining coat protein (CORO1A) suppresses Toll-like receptor signalling in Mycobacterium leprae infection. Clin Exp Immunol. 2009;156(3):495-501.

Taylor MD, van der Werf N, Harris A, Graham AL, Bain O, Allen JE, et al. Early recruitment of natural CD4+ Foxp3+ Treg cells by infective larvae determines the outcome of filarial infection. Eur J Immunol. 2009;39(1):192-206.

Tlaskalova-Hogenova H, Stepankova R, Hudcovic T, Tuckova L, Cukrowska B, LodinovaZadnikova R, et al. Commensal bacteria (normal microflora), mucosal immunity and chronic inflammatory and autoimmune diseases. Immunol Lett. 2004;93(2-3):97-108.

Turankar RP, Lavania M, Singh M, Siva Sai KS, Jadhav RS. Dynamics of Mycobacterium leprae transmission in environmental context: deciphering the role of environment as a potential reservoir. Infect Genet Evol. 2012;12(1):121-6.

van der Wel N, Hava D, Houben D, Fluitsma D, van Zon M, Pierson J, et al. M. tuberculosis and M. leprae translocate from the phagolysosome to the cytosol in myeloid cells. Cell. 2007;129(7):1287-98. 
van Maren WW, Jacobs JF, de Vries IJ, Nierkens S, Adema GJ. Toll-like receptor signalling on Tregs: to suppress or not to suppress? Immunology. 2008;124(4):445-52.

Vignali DA, Collison LW, Workman CJ. How regulatory T cells work. Nat Rev Immunol. 2008;8(7):523-32.

von Boehmer H, Melchers F. Checkpoints in lymphocyte development and autoimmune disease. Nat Immunol. 2010;11(1):14-20.

Walker LS, Chodos A, Eggena M, Dooms H, Abbas AK. Antigen-dependent proliferation of CD4+ CD25+ regulatory T cells in vivo. J Exp Med. 2003;198(2):249-58.

Walker LS, Sansom DM. The emerging role of CTLA4 as a cell-extrinsic regulator of T cell responses. Nat Rev Immunol. 2011;11(12):852-63.

Walker SL, Lockwood DN. The clinical and immunological features of leprosy. Br Med Bull. 2006;77-78:103-21.

Wang X, Zhou S, Chi Y, Wen X, Hoellwarth J, He L, et al. CD4+CD25+ Treg induction by an HSP60-derived peptide SJMHE1 from Schistosoma japonicum is TLR2 dependent. Eur J Immunol. 2009;39(11):3052-65.

Weiner HL, da Cunha AP, Quintana F, Wu H. Oral tolerance. Immunol Rev. 2011;241(1):241-59.

White C. Leprosy and stigma in the context of international migration. Lepr Rev. 2011;82(2):147-54.

WHO WHO. Leprosy. 2012 [cited 2012 July, 30]; Available from: http://www.who.int/lep/en/

Wildin RS, Ramsdell F, Peake J, Faravelli F, Casanova JL, Buist N, et al. X-linked neonatal diabetes mellitus, enteropathy and endocrinopathy syndrome is the human equivalent of mouse scurfy. Nat Genet. 2001;27(1):18-20.

Wing K, Sakaguchi S. Regulatory T cells exert checks and balances on self tolerance and autoimmunity. Nat Immunol. 2010;11(1):7-13.

Worobec SM. Treatment of leprosy/Hansen's disease in the early 21 st century. Dermatol Ther. 2009;22(6):518-37. 
Wysocki CA, Jiang Q, Panoskaltsis-Mortari A, Taylor PA, McKinnon KP, Su L, et al. Critical role for CCR5 in the function of donor $\mathrm{CD} 4{ }^{+} \mathrm{CD} 25^{+}$regulatory $\mathrm{T}$ cells during acute graftversus-host disease. Blood. 2005 106: 3300

Yamaguchi T, Hirota K, Nagahama K, Ohkawa K, Takahashi T, Nomura T, et al. Control of immune responses by antigen-specific regulatory $\mathrm{T}$ cells expressing the folate receptor. Immunity. 2007;27(1):145-59.

Yamazaki S, Inaba K, Tarbell KV, Steinman RM. Dendritic cells expand antigen-specific Foxp3+ CD25+ CD4+ regulatory $\mathrm{T}$ cells including suppressors of alloreactivity. Immunol Rev. 2006;212:314-29.

Zanin-Zhorov A, Cahalon L, Tal G, Margalit R, Lider O, Cohen IR. Heat shock protein 60 enhances CD4+ CD25+ regulatory T cell function via innate TLR2 signaling. J Clin Invest. 2006;116(7):2022-32. 